\begin{abstract}
Title of dissertation: $\quad$ FACULTY AGENCY: DEPARTMENTAL CONTEXTS THAT MATTER IN FACULTY CAREERS

Corbin M. Campbell, Doctor of Philosophy, 2012

Dissertation directed by: Professor KerryAnn O'Meara

Department of Counseling, Higher Education, \& Special Education
\end{abstract}

The purpose of this study was to investigate the organizational factors that influence faculty sense of agency in their professional lives and whether the relationship between organizational factors and faculty agency manifests differently by gender. Past literature on faculty has largely taken an approach that was termed a "narrative of constraint," focusing on the challenges that faculty face in modern academe, such as increased academic capitalism, striving, and new technologies (O'Meara, Terosky, \& Neumann, 2008; Schuster \& Finkelstein, 2006). More recently, certain scholars sought to understand what keeps faculty satisfied and thriving in a higher education context with multiple challenges (Baez, 2000a; Neumann, Terosky, \& Schell, 2006; O’Meara, Terosky, \& Neumann, 2008). The construct of agency is a powerful perspective to uncover how faculty navigate academe and succeed in their own goals.

Guided by the O'Meara, Campbell, and Terosky (2011) framework on agency in faculty professional lives, this study used Structural Equation Modeling to investigate which organizational factors (perceptions of tenure and promotion process, work-life climate, transparency, person-department fit, professional development resources, and collegiality) influenced faculty agency perspective and agency behavior and whether 
agency was associated with important faculty outcomes, such as intent to stay, satisfaction, and productivity. Then, this studied investigated whether the resulting model differed by gender. Results showed that work-life climate and person-department fit had a positive direct influence on agency perspective and a positive indirect influence on agency behavior. Professional development resources had a positive influence on agency perspective, but a negligible influence on agency behavior. Results also showed a very large effect of agency perspective on agency behavior. The invariance test by gender demonstrated that the relationships between organizational factors and faculty sense of agency were the same for men and women. This study illustrated the importance of departmental contexts in faculty professional lives, regardless of gender. It has important implications for administrators regarding departmental role in faculty agency, and also contributes to the continued development of a theoretical framework on faculty agency. 


\title{
FACULTY AGENCY: DEPARTMENTAL CONTEXTS THAT MATTER IN FACULTY CAREERS
}

\author{
by
}

\author{
Corbin M. Campbell
}
Dissertation submitted to the Faculty of the Graduate School of the University of Maryland, College Park in partial fulfillment of the requirements for the degree of
Doctor of Philosophy
2012

Advisory Committee:

Professor KerryAnn O'Meara, Chair

Professor Alberto F. Cabrera

Professor Noah D. Drezner

Professor Susan R. Komives

Professor Nelly Stromquist

Dean Donna L. Wiseman, Dean's Representative 
CCopyright by

Corbin M. Campbell

2012 


\section{Dedication}

This dissertation is dedicated to my husband Jason Richard Campbell, my two sons, Brycen Philip Campbell and Owen Errington Campbell, and to women faculty who aspire to fulfill their most far-reaching career aspirations. 


\section{Acknowledgements}

I would like to acknowledge the village that kept me on this Ph.D. journey. A husband who never once questioned my aspirations and supported them emotionally, financially, and intellectually. Two sons who give me inspiration and reprieve every day. My parents and grandparents who gave me constant support and the belief that I can achieve my goals and dreams. The Advancement of Women in Education (AWE) group who gave me strategic feedback, support, and challenge to make the most of my doctorate and long term career. Other friends, particularly the Glasers, Burleys, Higgins, and Alexanders, who provided support, spiritual solace, and fun outside academe.

I would further like to acknowledge my remarkable career and scholarly mentors who have given me inspiration and marvelous examples of how to enact a full and meaningful scholarly life. Dr. Alberto Cabrera took me under his wing as a mentee even though I was not his official advisee. He showed me how to take calculated risks in research and how to be a thoughtful and tireless teacher and researcher. He also spent countless hours with me taking me step by step through advance statistical techniques. Dr. Susan Komives showed me the importance of collaborative research and how to run an effective research team. She also gave me hope in becoming a self-actualized woman in career and family — and how the worlds can blend. Sharon La Voy, my former supervisor at IRPA, showed me the importance of loyalty in career and the ultimate importance of collegiality in an office. IRPA (through Sharon and the Campus Assessment Working Group; CAWG) was also where I found my passion for evidence based decision-making. Dr. Ada Demb, who was my advisor for my master's degree, planted a seed seven years ago that I could be a good faculty member. 
I would like to acknowledge my dissertation committee, Dr. Alberto Cabrera, Dr. Noah Drezner, Dr. Susan Komives, Dr. Nelly Stromquist, and Dean Donna Wiseman for graciously serving on my committee. Your comments, discussion, and questions have led me to think critically about my research, conceptually, methodologically, and practically.

I also acknowledge the Higher Education Program faculty and students, the College of Education at the University of Maryland, and the University of Maryland more broadly. I have been intellectually challenged and awakened in this environment in ways that surpassed my wildest imagination. From this experience, I have learned what a scholarly community can be, and I am reminded of the meaning of higher learning.

Last, but certainly not least, I would like to acknowledge my dissertation Chair and Advisor, Dr. KerryAnn O’Meara, for caring so deeply about my doctoral career. She believed in my ability to succeed in my Ph.D. and in my potential for becoming a faculty member. She was forgiving when I fell short, but kept me to the very highest of standards. She taught me to think strategically in terms of what projects I should undertake, with whom I should connect, and how to think deeply about my scholarship. She recognized my work in visible an intentional ways that promoted my career advancement. She supported my family life and also role modeled a fulfilling scholarly work and home life. I am not sure that I will ever be fully able to thank Dr. O'Meara for the immense time, thought, and effort she took in our mentoring relationship, but I know that I am forever changed in the way I will teach, research, advise, and mentor my own students in my faculty career as a result of her mentorship. 


\section{Table of Contents}

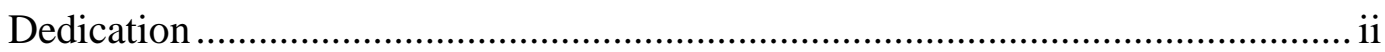

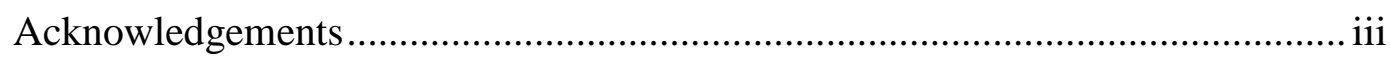

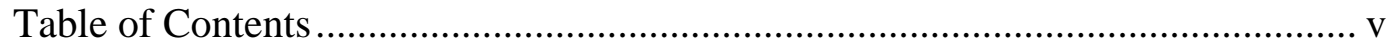

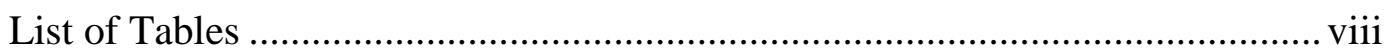

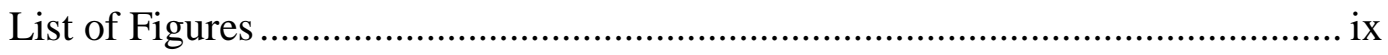

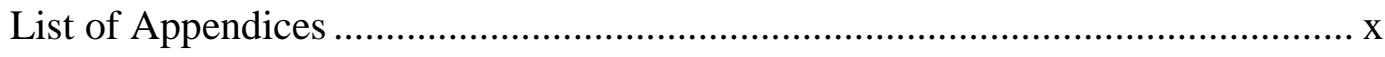

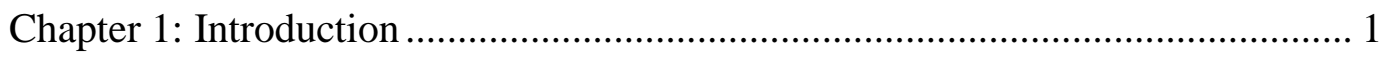

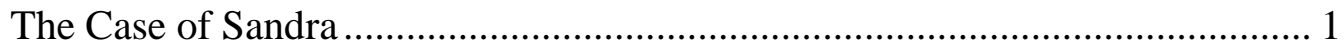

Agency as a Powerful Perspective for 21 st Century Faculty Life ...................... 2

Twenty-First Century Contexts that Shape Faculty Agency …………….......... 5

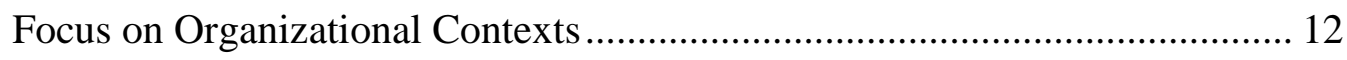

Focus on Women Tenure Track Faculty in Research Institutions..................... 13

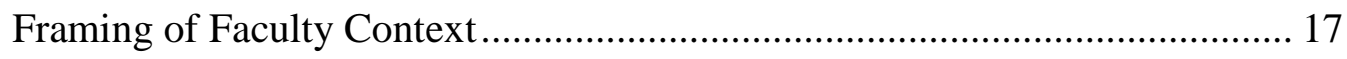

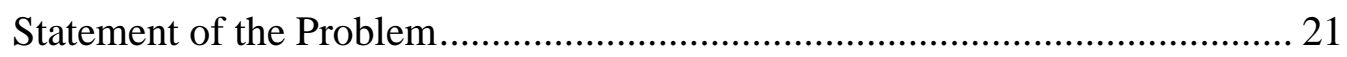

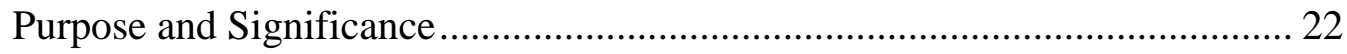

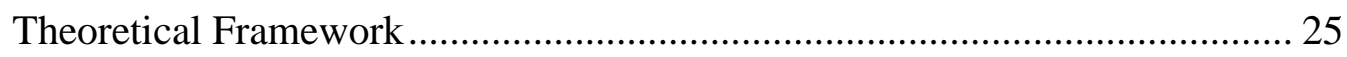

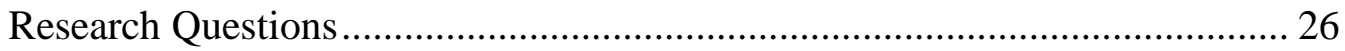

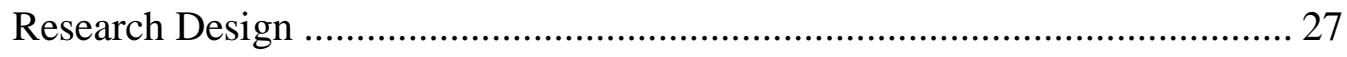

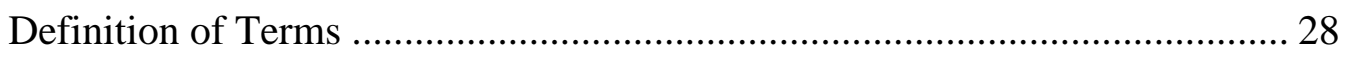

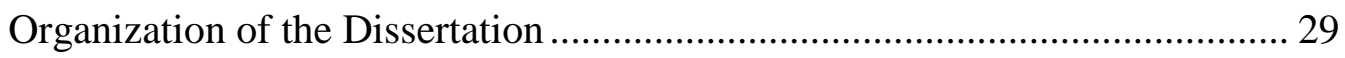

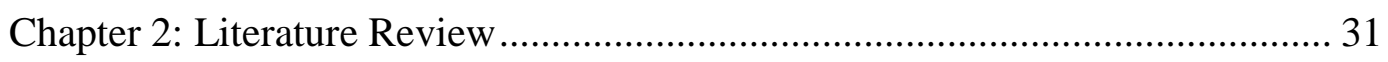

The Case of Dalinda—Early Career Faculty Member........................................ 31 


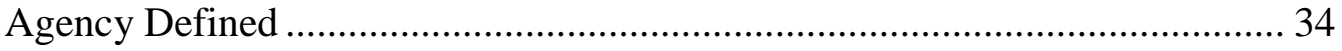

Theoretical Perspectives on Agency ................................................................. 44

Applications of the Concept of Agency to Higher Education ........................... 55

Applications of the Concept of Agency to Studies of Faculty ...........................56

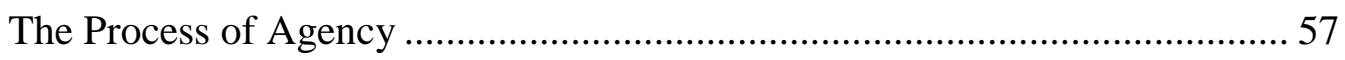

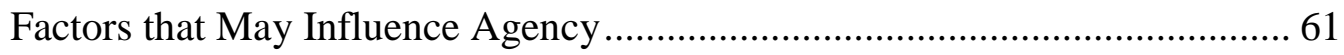

Potential Outcomes of Faculty Agency ........................................................... 70

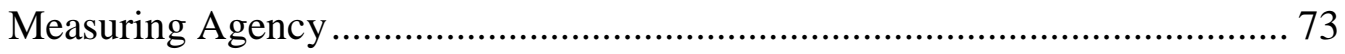

The Model: O'Meara, Campbell, and Terosky (2011)Framework of Agency in Faculty

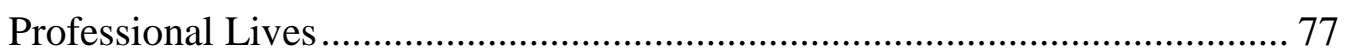

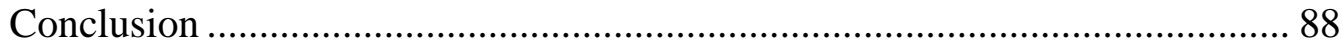

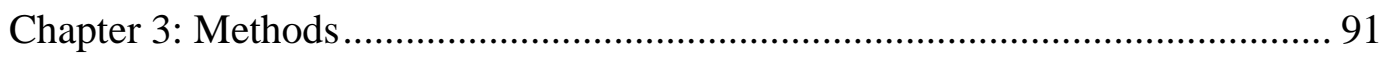

Purpose of the Study and Research Questions.................................................. 91

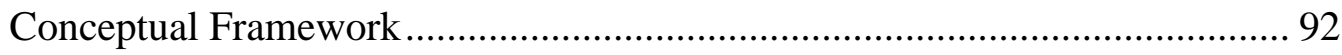

Use of Conceptual Framework in This Study.................................................... 94

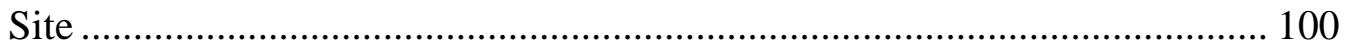

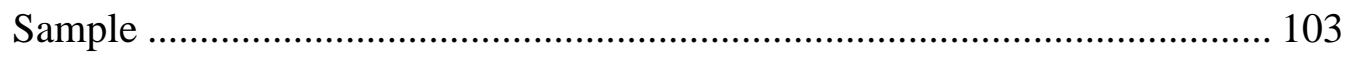

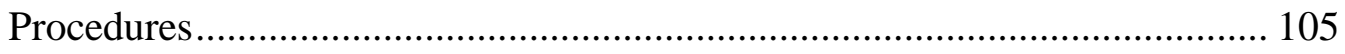

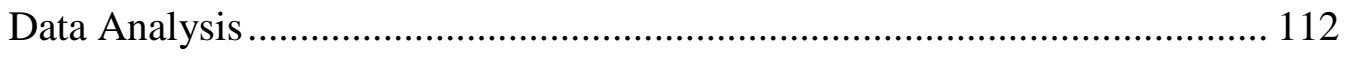

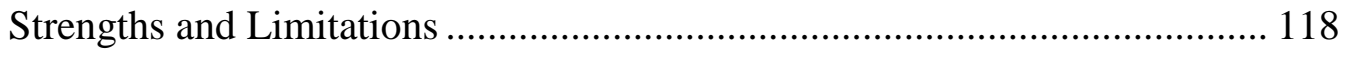

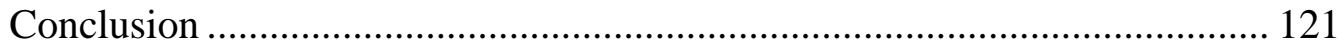

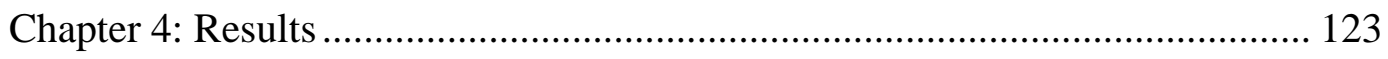

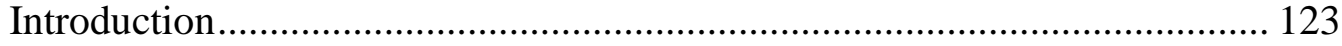




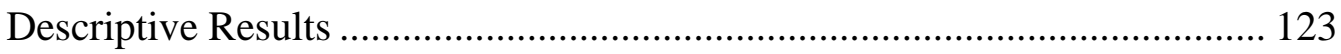

Analysis of Psychometric Properties-The Measurement Model................. 128

Results for Structural Models .............................................................. 135

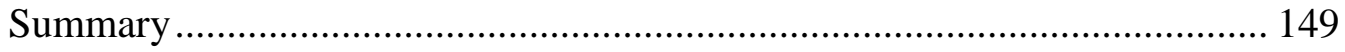

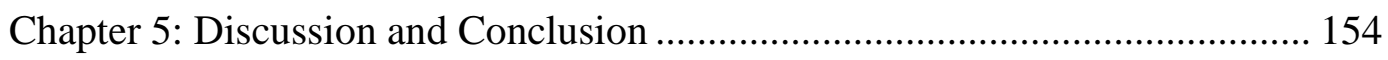

Discussion of Research Question 1 ..................................................... 154

Discussion of Research Question 2 ...................................................... 168

Discussion of Research Question 3 ................................................... 169

Implications for Practice ............................................................... 173

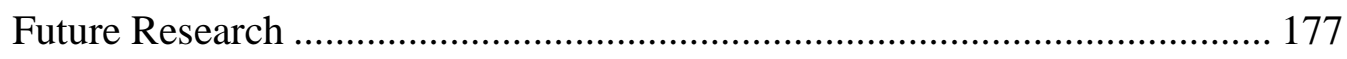

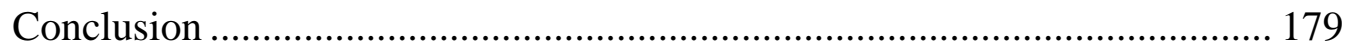

Appendix A. UM Faculty Work Environments Survey................................ 182

Appendix B. Revised Faculty Agency Framework.........................199

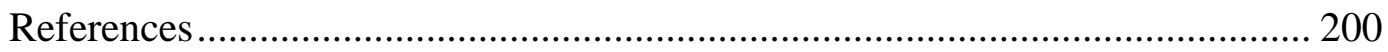




\section{List of Tables}

Table 1. Theoretical Perspectives on Agency..................................54

Table 2. Demographics of Tenure-Track faculty at the University of Maryland

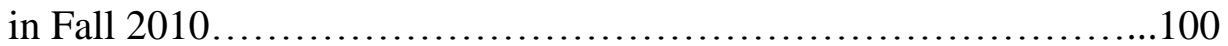

Table 3. Promotion Rates for Tenured/Tenure Track Faculty Hired between 1993 and 2003

Table 4. STEM Tenured/Tenure Track Faculty by Rank, Gender, and Unit....102

Table 5. Construct-Item Map.............................................. 108

Table 6. Means of Items within Constructs by Gender....................... 125

Table 7. 11 Factor Confirmatory Factor Analysis Intercorrelations............131

Table 8. Intercorrelations among 7 Constructs.............................133

Table 9. Item Loadings and Reliabilities for the Seven Factor CFA Model.....134

Table 10. Direct, Indirect, and Total Effects of Organizational Factors on Agency...................................................... 140 


\section{List of Figures}

Figure 1. Faculty and $\mathrm{PhD}$ recipients in the U.S. 1999.......................14

Figure 2. O’Meara, Campbell, and Terosky (2011) Framework of Agency in

Faculty Professional Lives......................................25

Figure 3. Operationalization of the O’Meara, Campbell, and Terosky (2011)

Faculty Agency Framework in the Current Study......................96

Figure 4. New model of departmental influences on faculty agency...........136

Figure 5. Revised model of departmental influence on faculty sense of agency....................................................

Figure 6. Final model for test of invariance by gender.................... 142

Figure 7. Model of organizational influence on faculty agency for men.......143

Figure 8. Model of organizational influence on faculty agency for women.....144

Figure 9. Model for test of configural invariance........................ 146

Figure 10. Model for test of full structural and psychometric invariance........149 


\section{List of Appendices}

Appendix A. UM Faculty Work Environments Survey....................207

Appendix B. Revised Faculty Agency Framework........................221 


\section{Chapter 1: Introduction}

\section{The Case of Sandra}

Sandra is an Associate Professor of Sociology at Striving University (SU), a mid-sized, private university in the North-East. Sandra was promoted to tenured Associate Professor last year, and is learning to navigate the new terrain of her post-tenure career. After seven grueling years of a 'publish or perish' mindset, she was looking forward to the security of being tenured. Sandra had stopped her tenure clock and took an unpaid leave when she and her partner adopted their daughter, but when she returned from maternity leave, she felt she had to make up for lost time.

Now that she is tenured, she has new goals for her career. She wants to focus her energy on one specific area of scholarship, to improve her teaching effectiveness, and to find more time to spend with her partner and her daughter. Sandra feels that she has hit her stride in her research agenda. She has identified an area of research about which she is deeply passionate, and she wants to make it her signature contribution to her field. By contrast, Sandra has felt less competent in her teaching abilities. She has focused so much on research over the past few years, teaching took a back seat. She had often felt like she couldn't relate to her students and she felt inadequate in using technology in the classroom. Now that she is tenured, she wants to focus more on giving back and understanding her students' needs. Additionally, after Sandra's maternity leave, she was focused on re-proving herself to her colleagues, sometimes at the expense of her family-life. She is determined to find a better balance that works for her needs at home.

Outside of Sandra's three post-tenure career goals, she has been thrown into additional career responsibilities. She has been asked to serve on two different university-wide committees, and has taken on certain administrative responsibilities in her program related to her institution's accreditation process. Simultaneously, her mentor has encouraged her to seek out grants, based on a university-wide imperative. She wonders whether she can meet her goals and find satisfaction and fulfillment from her new post-tenure work-life in the midst of this new context.

I created the above vignette, the case of Sandra, based on the literature on faculty

(Gappa, Austin, \& Trice, 2007; Schuster \& Finkelstein, 2006) to demonstrate how faculty

in the $21^{\text {st }}$ century are navigating new contexts that dramatically shape their work-lives and the agency they feel in their roles. In the modern higher education context, faculty 
encounter several factors that shape their agency, including a new emphasis on accountability, broad reaching academic capitalism, striking shifts in both faculty and student demographics, increased and more complex uses of technology, and a redefinition of the very nature of scholarship (Gappa, Austin, \& Trice, 2007; O’Meara, Kaufman, \& Kuntz 2003; O’Meara, Terosky, \& Neumann, 2008; Schuster \& Finkelstein, 2006). The combination of these significant shifts in the professoriate constitutes a perfect storm, where previous conceptions of faculty life and traditional frameworks for understanding faculty work are insufficient.

This introduction presents a description of why agency is a vital tool for facilitating faculty success, followed by a description of recent changes in faculty work contexts and how they shape faculty agency. Then, it discusses the narrative surrounding faculty in the $21^{\text {st }}$ century and the strengths and weaknesses of theoretical frameworks that have traditionally been used to inform studies of faculty. Next, it presents evidence for why these narratives and frameworks are inadequate for understanding faculty needs in the changing context of higher education. The chapter introduces faculty agency as a new framework that has recently emerged in the literature on faculty and how it may present an informative vantage point for illuminating faculty work in the $21^{\text {st }}$ century, with a particular focus on women faculty.

\section{Agency as a Powerful Perspective for 21st Century Faculty Life}

Agency is a powerful standpoint for understanding and enhancing faculty careers in the $21^{\text {st }}$ century. The concept of agency, developed from sociological and psychological theories, suggests that humans have a capacity for intentionality and there are internal resources that bring to bear strategic and intentional behavior or meaning- 
making (Marshall, 2005; Neumann, Terosky, \& Schell, 2006). Various definitions and theoretical perspectives that contribute to the construct of agency are discussed in great detail in Chapter 2. The present study defines agency as strategic or intentional actions or view towards goals that matter to oneself (Marshall, 2005; McAdams, de St. Aubin, \& Logan, 1993; Neumann, Terosky, \& Schell, 2006; O’Meara, Terosky, \& Neumann, 2008; Schutz, 1967; Sen, 1985).

Agency has important outcomes that are pertinent to faculty careers and work lives. For example, psychological and sociological studies have found a relationship between agency and educational/occupational attainment, life satisfaction, well-being, and personal development (Ackerman, Zuroff, \& Moskowitz, 2000; Alkire, 2005; Clausen, 1991). Also, O’Meara, Terosky, \& Neumann's (2008) professional growth framework states that the combined facets of faculty learning, agency, professional relationships, and commitments "all shape the degree to which faculty make contributions to students, colleagues, institutions, and society" (p. 32). There is also evidence that faculty learning is shaped by agency (Neumann, Terosky, \& Schell, 2006) and agency plays a role in creating a satisfactory work-life balance for faculty ( $\mathrm{O}^{\text {’Meara }}$ \& Campbell, 2011).

Individual agency can also produce collective or social outcomes. For example, according to theory on organizational culture, when an individual enters an organization there are two simultaneous processes that occur (Birnbaum, 1988; Bolman \& Deal, 1992). An individual assimilates into the organizational culture via mentoring, rituals, and norms. Simultaneously, a receptive and healthy organizational culture will also accommodate to the individual. In this way, faculty members who exhibit agency in any 
respect that is outside of conventional academic norms may push the boundaries of the organizational culture and the organization may partially change to meet that individual. However, rigid and unwelcoming environments may not make this shift, and instead, cast the individual as an outsider. In the case of Sandra, being the first person to stop the tenure clock at her institution may have paved the way towards a more family friendly departmental climate, or she might have been outcast by others if the climate was unreceptive to this change. Alkire (2005) notes that the acculturation process can also take place on a societal level: social change is possible when marginalized people take charge of their life course and enact self-direction or agency.

Agency can be facilitated by a number of individual, organizational and societal factors. For example, psychologists have found that individual resources, such as selfefficacy and personal histories, influence agency (Bandura, 1982; McAdams, de St. Aubin, \& Logan, 1993). Sociologists posit that social capital and societal standpoint have a direct bearing on human agency (Berger \& Luckman, 1966; Mayer \& Schoepflin, 1988; Meyer \& Jepperson, 2000). Organizational climate and structures can facilitate or restrict a faculty member's sense of agency (O’Meara \& Campbell, 2011; O’Meara, Terosky, \& Neumann, 2008). Scholars on the faculty experience have emphasized the importance of building a support structure that facilitates faculty agency. For example, Neumann, Terosky, and Schell (2006) state, "We deem it important that all tenured professors develop abilities to think and act, strategically, with agency. As we suggest later, we deem it important also that they have access to resources for doing so" (p. 94). The broad array of factors that influence agency and the outcomes of agency are discussed in Chapter 2. 
Very few studies to date have empirically examined the role of agency in faculty careers and which factors facilitate agency. Even fewer studies have investigated the different ways that agency manifests by gender or other demographic characteristics. The purpose of this study is to investigate the organizational factors that facilitate faculty sense of agency, the career outcomes of agency, and how agency acts differently for men and women faculty.

\section{Twenty-First Century Contexts that Shape Faculty Agency}

\section{Changes in faculty workload.}

Just prior to the turn of the century, pressures mounted to reconsider faculty work. In the 1980s and 1990s, calls for reform to the professoriate (especially the tenure system) were heard at all levels: among faculty, administrators, and legislators (Gappa, Austin, \& Trice, 2007; O’Meara, Kaufman, \& Kuntz, 2003; O’Meara, Terosky, \& Neumann 2008; Schuster, \& Finkelstein, 2006). Faculty were perceived as the root of problems in higher education. The public and legislators perceived faculty as uninterested in undergraduate students or the practical needs of higher education institutions, lazy, over indulgent, and narrowly interested in their own research agenda. Tenure was seen as a main contributor to these problems. The perception was that once a faculty member received tenure, she/he had little or no interest in remaining productive and institutions had little recourse to keep faculty accountable.

In reaction to these calls for accountability—and partially to protect the tenure system, academic freedom, and the peer review processes - institutions responded by placing pressure on faculty, demanding higher productivity in both research and teaching (O’Meara et al., 2003; Schuster, \& Finkelstein, 2006). Studies on the new faculty 
experience found that faculty feel higher demands on their time, higher stress, increased accountability, and pressure to fulfill more diverse roles (Schuster, \& Finkelstein, 2006).

The higher demands on faculty are particularly poignant at research institutions and institutions who are striving to increase their national standing. In these 'striving' institutions, faculty feel increased pressure to focus on research and other prestigious outputs, such as publications in top tier journals, grants, and awards (O’Meara, 2007; O’Meara \& Bloomgarden, 2010). Massy and Zemsky (1994) term this change in emphasis the "academic ratchet," whereby faculty members increase their discretionary time, loosen ties to the institution, and focus on research productivity, often to the detriment of undergraduate teaching. Faculty often feel pressure to "publish or perish" in the modern faculty experience.

Simultaneously, scholars and administrators were grappling with how to define scholarship in the context of faculty reward structures. Boyer's (1990) landmark work on defining scholarship suggested that there were four forms of scholarship that should be recognized and emphasized: the scholarship of discovery (basic research), the scholarship of integration (interdisciplinarity, meaning-making), the scholarship of application (applying knowledge), and the scholarship of teaching. Due to the effects of 'striving' and the 'academic ratchet,' faculty reward structures (particularly, but not exclusively, in research institutions) have mainly emphasized the scholarship of discovery (O’Meara, 2005; O’Meara, 2002). While faculty have begun to engage in several forms of scholarship, and there has been a particular growth in interdisciplinary, collaborative, and engaged work, institutions have lagged behind in terms of finding good ways to reward this work within the tenure process. Some institutions have reformed reward structures to 
be more inclusive of multiple forms of scholarship, but the effect has often been to increase expectations around the other three forms of scholarship without decreasing expectations on discovery (O’Meara, 2005).

The combined pressure of the calls for accountability, the 'academic ratchet,' and the pressure to perform in all scholarship arenas has led faculty to feel over-worked, often leading to a decrease in job satisfaction (Hagedorn, 2000; Rice \& Sorcinelli, 2002;

Schuster \& Finkelstein, 2006). In the case of Sandra who works at a striving institution, the multiple demands she experienced to publish, serve on committees, partake in the reaccreditation process, and to prove herself after her maternity leave cause her to question whether she can make her goals actionable. In this way, the increased and diversified workload might attenuate faculty sense of agency.

\section{Changes in resources.}

At the same time that faculty were asked to increase their workload, better document their productivity, and differentiate their work, resources became more constrained and institutions took on a mentality of academic capitalism. Academic capitalism is a term that is associated with Academy-Industry Relations (AIRs), meaning "institutional and professorial market or market-like efforts to secure external funds" (Slaughter \& Leslie, 1997, p. 209). The most consistently cited cause for the increase in AIRs and academic capitalism is the decline of government (especially state) funding (Anderson, 2001; Bonewits \& Soley, 2004; Lee \& Rhoades, 2004). Slaughter and Rhoades (2004) illuminate that it is not only the lack of governmental funding that drives academic capitalism, but a rise in institutional competition that has driven institutions for “excellence," which requires additional spending instead of reducing costs. 
The shift from government to external funds has three critical impacts on the professoriate. First, it causes tensions with regard to faculty research agenda: between basic and applied research; between keeping results of research secret (corporate interests) and the traditional academic value of making knowledge publicly available (Ylijoki, 2003). Faculty feel a constant pull between the institutional desires to work with applied industry and their own search for knowledge, and many hold a fear that industry will take over academe. Ylijoki (2003) sums this up nicely when he states, "it is not easy to serve two masters simultaneously" (p. 332). Secondly, academic capitalism may affect which departments and fields are better funded by the institution, creating a hierarchy within institutions that affects faculty functioning (Mendoza, 2007; Ylijoki 2003).

Lastly, there is some evidence that academic capitalism in the form of competition for state funds (i.e. educational entrepreneurialism) has shifted the educational emphasis from quality of teaching to quantity of students served (Bonewits \& Soley, 2004; Slaughter \& Rhoades, 2004). This change in emphasis has had a dramatic impact on the faculty landscape, giving rise to an extensive increase in adjunct faculty and graduate teaching assistants to teach courses (Gappa, Austin, \& Trice, 2007; Rhoades \& Slaughter, 2004; Schuster \& Finkelstein, 2006). The dramatic changes in higher education due to academic capitalism also caused fears in the public and increased the public's distrust of faculty — that the ideals of the academy for the pursuit of truth and unbiased knowledge have become tainted by the desire for higher education institutions to generate revenue, and that this revenue generation will direct what is being researched and the type of faculty that conduct that research. In the case of Sandra, academic 
capitalism (in the form of an institutional imperative to seek out grant funding) might limit her freedom to focus on her specific scholarship interests, and thereby her sense of agency to create a satisfying career context. On the other hand, if Sandra is able to secure grant funding, she might garner additional professional capital that could enhance her sense of agency in her role.

\section{New technology.}

Institutions of higher education have used technology as a means to stay relevant in an informational society (Austin, 2002). Technology became integral to the everyday tasks of faculty life (Schuster \& Finkelstein, 2006). Technology has been integrated in every classroom via online courses, online institutions, and technological tools to advance everyday classroom techniques. The new role of technology in teaching has caused faculty to need new and different skills, adapt to a new form of communication, and consider the implications for student learning. Further, technology has transformed the nature of research. Consider the technological advances in data collection and analysis, and implications for the scope, topic, delivery, timeline, and cost of research. In the case of Sandra, she felt disconnected from her students and less adequate as a teacher because she was not fluent in the newest classroom technologies.

\section{Changing student demographics.}

Over the past few decades, there have been substantial changes in the student demography of U.S. higher education institutions. Institutions continue to become heterogeneous, and faculty are called to respond to the needs of a diverse group of students with new and varied needs. For example, women students outnumber men. Racial and religious minorities, LGBT students, lower income students, first generation 
students, students with disabilities, and students of all ages have increased their representation and visibility on college campuses across the nation (Austin, 2002; Rendon, 1994; Schuster \& Finkelstein, 2006).

With this new diversity comes varying and different motivations that the new students bring to the classroom - for attending college, goals and desires after graduation, and perspectives on classroom materials (Austin, 2002; Rendon, 1994). For example, students may have significant commitments outside of college, such as family or work that change the nature of the collegiate experience. Students might grapple with various issues related to identity development, which likely intersect with the classroom experience. Students may have varying levels of knowledge of and support for college, which would impact their ability to take advantage of resources and experiences. Faculty need new and different skills to meet the needs and expectations of the new student population and to facilitate their success. In the case of Sandra, her own identity as a lesbian, woman, mother might give her agency to relate to student's struggles with their own identities. Yet, understanding different learners takes time, and Sandra felt less adequate as a teacher when she focused so much on research, causing her to feel disconnected from her students.

\section{A more diverse faculty.}

In addition to a diversified student body, the demographics of the American Professoriate were changing. Women and people of color became larger proportions of the faculty, with new and diverse needs (O’Meara, Terosky, \& Neumann, 2008; Schuster \& Finkelstein, 2006). These major shifts should be contextualized by larger trends in higher education and U.S. society: more institutions, increased diversity of institutions 
(especially notable rise in two year institutions), more women in the workforce, and growing racial diversity in the U.S. According to Schuster and Finkelstein (2006), faculty of color have slowly increased representation in the professoriate, but dramatically increased representation among doctoral recipients (64\% increase in a ten year period). Additionally, the proportion of new faculty who were women grew from $20 \%$ in 1969 to $44 \%$ in 2003. A greater diversity in the demographic of the professoriate means new expectations, needs, goals, and perspectives.

For Sandra, she was the first faculty member in her department to use the stop the clock policy. She benefitted by the earlier women's movement in the 1970s and 1980s that put these family friendly policies into place in academe (Astin \& Leland, 1991). Yet, since she was the first faculty member to use the policy within her department, she wondered what the response of her colleagues would be and caused her to feel that she needed to re-prove herself, limiting the agency she felt to create a satisfying work-life balance. On the other hand, it is the rise in women faculty and faculty parents that have made the stop-the-clock policies more prevalent, and simply having the policy in place allowed Sandra to exercise her agency to take leave and still achieve tenure.

\section{Changes in appointment type.}

Coinciding with increased demands on productivity, workload, and efficiency, the landscape of the professoriate was changing (O'Meara, Terosky, \& Neumann, 2008). Over the past four decades, the proportion of adjunct, part-time, or contingent faculty in American higher education has increased dramatically. In 1975, full-time tenured or tenure track faculty made up $57 \%$ of U.S. faculty (AAUP, 2007). This percentage dropped to $31 \%$ of faculty by 2007 . Reasons for this striking shift include cost, 
flexibility for institutions, flexible schedule for faculty, and a perceived higher level of accountability (Baldwin \& Chronister, 2001; Schuster \& Finkelstein, 2006).

In the case of Sandra, the demise of the tenure system and rise of the adjunct faculty might have added pressure on Sandra to achieve tenure, having been hired into the coveted tenure-track role. As a result of the adjunct faculty hiring trend, there are fewer openings for tenure-track positions, and having fewer options might limit the agency she would feel to take risks in her position.

\section{Focus on Organizational Contexts}

Countless studies have demonstrated the importance of organizational contexts in faculty professional lives (Hagedorn, 1994; Kezar, 2005; Lindholm, 2003; Rosser, 2005; Schuster \& Finkelstein, 2006). Organizational contexts can be constituted by structural facets of an organization (such as policies, hierarchy) or culture (such as norms, climate; Bess \& Dee, 2012). Hagedorn (1994) found that satisfaction with administration, satisfaction with salary, and support of colleagues all influenced important aspects of faculty professional lives, such as stress and satisfaction with academe. Rosser (2005) found that administrative support, professional development, and technical support all contributed to satisfaction among faculty.

Furthermore, organizational contexts appear to be particularly important to agency with respect to faculty. According to O’Meara, Terosky, and Neumann (2008): "Although much faculty motivation is intrinsic, faculty reward systems can facilitate faculty learning and growth, or they can frustrate and damage faculty members' senses of agency to shape their own learning and distinct intellectual and professional careers and work lives" (p. 93). Similarly, Baez (2000a) demonstrated how service is perceived 
organizationally as a burden, but for certain faculty of color, it can be an agencyenhancing activity. Lastly, in a study on faculty agency in making work-family decisions, O'Meara and Campbell (2011) found that department norms and policies (such as flexibility and parental leave/stop the clock) influenced agency for faculty parents.

This study focuses on six dimensions of organizational contexts: perceptions of the tenure and promotion process, transparency of decision-making, work-life climate, person-department fit, professional development resources, and collegial climate. These contexts seem to be highly relevant to faculty agency considering they have each been linked to important faculty outcomes, such as satisfaction, retention, and productivity (Birnbaum, 1988; Bolin, 2000; Bolman \& Deal, 2003; Bowen and Schuster, 1986; Johnsrud \& Rosser, 2002; Lindholm, 2004; Lindholm, 2008; Mason \& Eckman, 2007; Mason \& Goulden, 2004; Neumann, Terosky, \& Schell, 2006; O’Meara \& Campbell, 2011). Each of the six organizational contexts is described in depth in chapters 2 and 3.

\section{Focus on Women Tenure Track Faculty in Research Institutions}

While the representation of women faculty among all faculty has grown over time, it is still not equal to men nor is it consistent with their representation among doctoral programs, where they outnumber men (Schmidt, 2010; Schuster \& Finkelstein, 2006). Additionally, women in academe tend to be found in the less prestigious and lower compensated fields, institutions, and positions. For example, women are more likely to be adjunct, part-time faculty members (NCES, 2002). The representation of women decreases as rank increases (Figure 1). Women are more likely to teach in 2 year colleges, whereas men are more likely to teach in 4 year research institutions (NCES, 2002). Women receive lower base salaries (Schuster \&Finkelstein, 2006). As these 
examples demonstrate, women tend to be found among the most vulnerable across many career settings. By contrast, women tend to be least represented and face the most barriers in more powerful and prestigious career settings in academe, such as tenure-track positions in research institutions (Glazer-Raymo, 2008). There are also gender disparities across disciplines, with women least represented in the highest paying fields, such as the Science, Technology, Engineering, and Mathematics (STEM) fields (NCES, 2002).

Figure 1, below shows the representation of faculty by gender, race, and rank from the 1999 NSOPF survey.

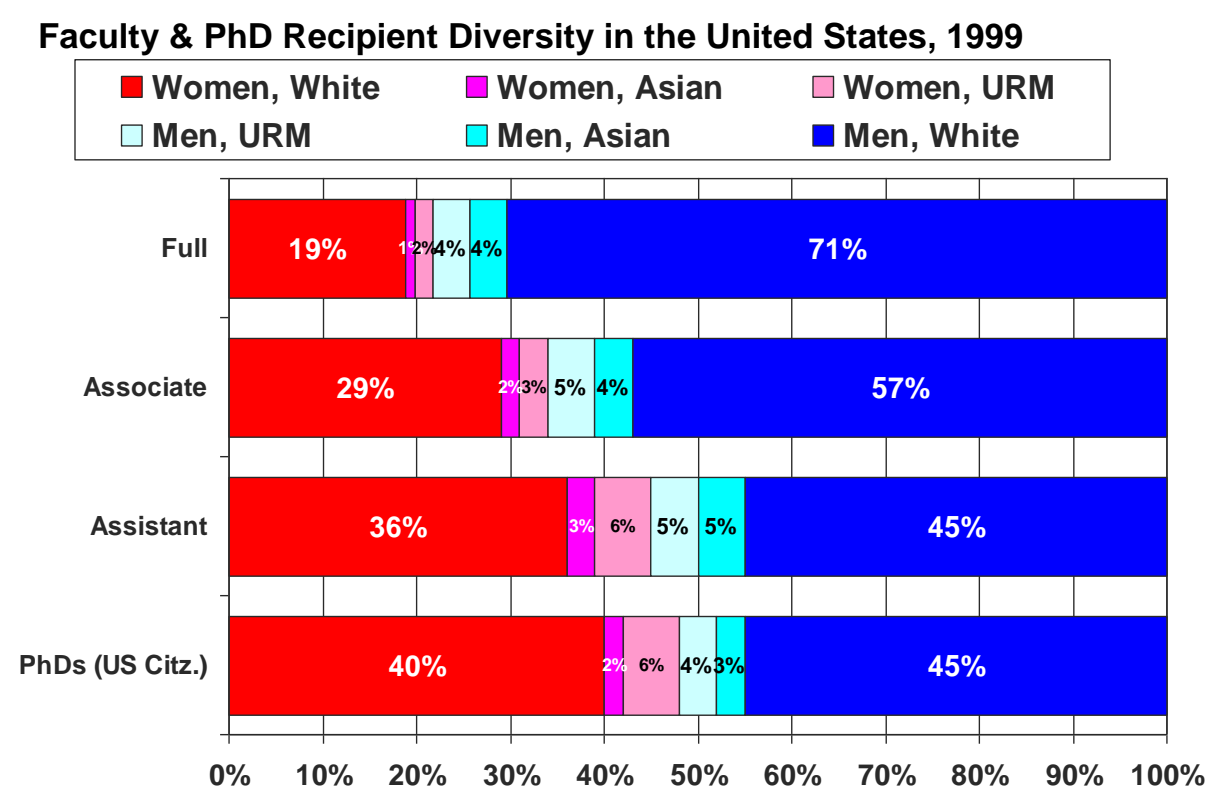

\footnotetext{
*Under Rep. Min. includes African Americans, Hispanic Americans, and Native Americans.
Sources: NCES, National Study of Post-Secondary Faculty, 1999 (for faculty) and NSF, Survey of Earned Doctorates, 1999 (for PhD recipients).
}

Figure 1. Faculty and $\mathrm{PhD}$ recipients in the U.S. 1999 (Thomas, 2005).

The largest growth in representation among female faculty has taken place over the last couple of decades (Glazer-Raymo, 2008). As more women enter the professoriate, institutions must have a better understanding of their experiences, needs, and aspirations. For example, many women make career decisions according to a holistic 
view of their needs including both work and family life. Tenure clocks tick at the same time as women's biological clock (Wolf-Wendel \& Ward, 2003), causing the academy to be potentially unique in its need to focus on the interplay between work and family. Women faculty who have children spent 101 hours per week on professional, housework and caregiving, compared with 88 hours per week for men with children and approximately 79 hours per week for both men and women without children (Mason \& Ekman, 2007). Additionally, women are more likely to teach more hours and less likely to focus their work hours on research activity than men, which has implications for tenure and promotion decisions (Bellas \& Toutkoushian, 1999).

Women faculty also face, what has been described as a "chilly climate," and are often left out of networking and advancement opportunities (Caplan, 1993; Sandler, 1986; Winkler, 2000). Some contributing factors include: sexist language, a masculine reward system, exclusion of women and women's values, and the devaluing of women's work. Specifically, the "un-written rules" of academia serve to "maintain the traditional power balance" and "this includes keeping women down" (Caplan, 1993, p.45).

While there are numerous similarities in the experiences of women faculty, it is critical to note that there are also important differences among women across all facets of identity —race, religion, sexual orientation, socio-economic status, etc. One of the most well-studied differences is regarding the experiences of women faculty of color. The concerns over representation, work-life needs, and climate are compounded when women faculty of color are concerned. Women faculty of color face discrimination based on both their gender and their race in both overt and subtle forms, which leaves them in a position of "multiple marginality" (Turner, 2002). A number of scholars have described 
the systematic isolation and invisibleness that women faculty of color experience in their roles (e.g., Gregory 2001; Turner, 2002; Winkler, 2000).

One of the manifestations of the racist sexist discrimination is that the lived experiences of women faculty of color are hidden under the guise of individual identities: women OR faculty of color (Turner, 2002). For example, many substantive reports by the U.S. government display information by race or gender, but not the intersection of the two (see, for example, NCES, 2002). Reconciling these contradictions may cause women faculty of color to live "biculturalism" whereby they must live between the culture of the academy and their own cultural heritages (Johnsrud \& Sadao, 2002). As a result of these contradictions and multiple roles, women faculty of color often feel "psychologically divided" (Turner, 2008, p. 237).

Additionally, Ladson-Billings (1997) describes extreme psychological discomfort associated with intellectual discrimination: feminist and critical race pieces are often not considered an acceptable form of scholarly pursuit in the academy. In Thomas and Hollingshead's (2001) study, they found that $77 \%$ of women faculty of color agree that they have to work very hard to be perceived as a legitimate scholar, where as $58 \%$ of White women, $58 \%$ of men faculty of color, and $46 \%$ of White male faculty agree.

With the increasing representation of women faculty, many institutions have created policies to make colleges and universities more supportive of women and families (Ehrenberg, 2006). Most of these policies support women with children, such as providing quality and affordable child care options, providing assistance with relocation issues for spouses and dependents, creating delayed or re-entry tenure-track opportunities 
for women who have taken time off to manage family responsibilities, and providing flexibility in the probationary period for tenure (Mason \& Eckman, 2007; Perna, 2005). Sandra's experience as a woman, tenure-track, associate professor at a research institution defies many of the statistics about women faculty. She is located in a prestigious position, in a prestigious institution, and now has job security as a tenured faculty member. It is likely that she had to exert a great deal of agency, often running against the tide of academia, to get to her current position. This leads to the question, what kinds of factors might have supported her agency to this point? What organizational climate allowed her to exert her own agency to be the first person to take the stop-the-clock policy? Even with all of these securities and her accumulated professional capital, she still felt torn about her decisions related to her work-family life and whether she would be able to meet her desired goals. If her desired goals (teaching, singular research focus, and more family time) run contrary to organizational needs (committee work, administrative work, and grant procurement), what organizational environment would give her the agency she needs to meet both demands?

\section{Framing of Faculty Context}

For decades, the literature explored the professoriate's change in environments, resources, and public opinion (Gappa, Austin, \& Trice, 2007; O’Meara, Terosky, \& Neumann, 2008; Schuster, \& Finkelstein, 2006). Until recently, scholars investigating the faculty experience viewed the changes in the professoriate as burdensome and constraining. Scholars focused on what faculty cannot do, how they are overburdened/overworked, the decrease in job satisfaction, the difficulty balancing workfamily commitments, the negative impact of fewer fiscal resources/academic capitalism, 
problems with the tenure system/reward structures, issues with campus climates, among others (August \& Waltman, 2004; Daly \& Dee, 2006; Gappa, Austin, \& Trice, 2007; O’Meara, Kaufmann, \& Kuntz, 2003; Rosser, 2005; Schuster \& Finkelstein, 2006; Slaughter \& Rhoades, 2004; Stack, 2004; Turner, 2002).

Highlighting the barriers and constraints in the faculty experience was useful in drawing attention to areas for improvement. Yet, there are limitations to what O'Meara, Terosky, and Neumann (2008) called the "narrative of constraint." For example, would a theoretical perspective that focuses on barriers adequately assist faculty in meeting the demands of the $21^{\text {st }}$ century? In a time of rising accountability, broadening demographics, and increased and more diverse workload in the professoriate, faculty have continued to find new ways to make meaning of their experiences and foster a sense of career satisfaction. The narrative of constraint may be limited in its understanding of how faculty continue to persevere, survive, and even blossom in contemporary academe (O’Meara, Terosky, \& Neumann, 2008).

Additionally, highlighting barriers and uncovering areas for improvement is only part of the way towards change. Creating a new plan and a new vision for an improved professoriate necessitates an understanding of what facilitates success. This would require a theoretical standpoint that that is rich with understanding how to support faculty rather than focusing on barriers. It appears that a new theoretical tool is necessary for understanding these problems that allows for facilitating, supporting, and enabling faculty success in meeting the $21^{\text {st }}$ century contexts.

Certain scholars have recognized the need for new theory to guide our understanding of the faculty experience (e.g., Baez, 2000a; O’Meara, Terosky, \& 
Neumann, 2008; Rhoades, McCormick, \& Kiyama, 2007). Recognizing that a majority of faculty are still satisfied in their careers despite these constraints (Rosser, 2005), scholars are beginning to ask questions about how faculty are negotiating these new roles, managing demands, and finding fulfillment in professional growth. These scholars move beyond the recognition that the demands of the faculty career are substantial to view the motivations that fuel faculty trajectories, meaning making, and success.

For example, O’Meara, Terosky, and Neumann (2008), observe that the narrative of constraint has dominated the scholarship of faculty to the exclusion of other theories, views and disciplinary perspectives. The concept of agency is one of the missing vantage points that could prove useful and instructive in shaping faculty development and the future of the professoriate. According to O’Meara, Terosky, and Neumann, "We know more about how reward systems inhibit faculty involvement in scholarly activities they deem important than how some faculty assume agency ... to reshape reward systems so as to value what they personally believe is important." (p. 148).

Choosing to frame the faculty experience through a new lens has already begun to shed light on new and important understandings of the faculty experience. For example, Neumann (2006) and Lattuca and Creamer (2005) found that successful faculty engage in a career long learning process that allows them to make meaning of their careers. This learning can be about one's discipline, effective teaching practices, and new administrative roles, among others. In addition, the Neumann (2006) study found that faculty who engage in this continual learning process are more satisfied and productive in their academic career. Moreover, while the professoriate is often portrayed as stoic and 
objective, Neumann (2006) found that faculty across all disciplines are motivated by a sense of passion in their research.

The agency perspective has allowed research on the faculty experience to be turned on its head. For example, past authors would highlight the negative role of service-work for minority faculty, discussing how minority faculty would be pulled away from their research agenda by service responsibilities (Tierney \& Bensimon, 1996). By contrast, Baez (2000a) demonstrated how certain faculty of color perceive service as an agency-enhancing activity that positively influences their job satisfaction and overall well-being in faculty roles. Likewise, previous research had discussed the burdens of multiple demands in early post-tenure faculty career (Neumann \& Terosky, 2003). By comparison, Neumann, Terosky, and Schell (2006) used a framework of agency and learning to uncover the various strategies and experiences of post-tenure faculty, finding that they were able to mold their post-tenure lives as scholars in intentional and reflective ways.

In the case of Sandra, a framework of constraint might highlight the pressure she felt in her role at a striving institution, the concern she had about returning from her leave, the complications of being a new mother and a faculty member, the fear she has about meeting her goals in light of unexpected post-tenure responsibilities, and the discrimination she faces as a woman. By contrast, a framework of agency allows different types of questions: What organizational factors facilitated Sandra taking advantage of stop-the-clock? What strategies can Sandra use to be successful in her posttenure goals while also meeting the needs of the institution? How can her department help her to find a satisfactory work-life balance? How does being a new mother enhance 
Sandra's professional competence? What aspects of her post-tenure goals are symbiotic with the institution's demands? How could Sandra's identity, as a woman, lesbian, mother, help her to shape her department in desired ways?

\section{Statement of the Problem}

Faculty must succeed in a new context in the twenty-first century (O’Meara, Terosky, \& Neumann, 2008; Schuster \& Finkelstein, 2006). Additionally, faculty demographics are changing, including more diversity in gender, race, religion, and other identities. Recent scholarship on faculty suggests that agency is a powerful lens for understanding how faculty can be successful within the new context (Baez, 2000a; Neumann, Terosky, \& Schell, 2006; O’Meara, Terosky, \& Neumann, 2008). Agency has been linked to (or theorized to be linked to) well-being, occupational/educational attainment, personal development, and life satisfaction. Among research on faculty, agency has been found to influence (or theorized to influence) professional growth, learning, and work-life balance (Neumann, Terosky, \& Schell, 2006; O’Meara \& Campbell, 2011; O’Meara, Terosky, \& Neumann, 2008).

Additionally, there is evidence that agency may be particularly important for underrepresented faculty. Scholars have often discussed agency in the context of overcoming boundaries, rising to challenges, and creating new pathways. Baez (2000a) used agency as a theoretical tool to uncover how faculty of color feel empowered by their service work despite navigating a reward structure that does not value service. Gregory (2001) demonstrated that Black women faculty create outside support systems to enable their personal agency. Both the Combahee River Collective (1985) and Lorde and Clark (2007) demonstrate how multiple oppressive structures for Black lesbian feminists give 
rise to their agency and control. Neumann, Terosky, and Schell (2006) use agency as a framework to understand the experiences of faculty who are facing a challenging turning point in their careers - moving from faculty to administrative roles. Some sociologists suggest that agency can only be exhibited when behavior is against or contrary to the typical social order (Elder, 1994; Heinz, 1996; Marshall, 2005). For underrepresented faculty, a framework of agency might contribute to our understanding of how faculty make meaning of and act in/navigate through an academic system with values and norms that may run contrary to their own.

While some scholars have begun to view and use agency as a tool to understand and assist faculty in the twenty-first century, few studies have investigated what factors facilitate agency, the outcomes of agency in faculty careers, and how agency manifests differently by gender and other individual and social contexts. In order to facilitate faculty success, retention, satisfaction, and realizing the full career potential of all faculty in the twenty-first century, new research must investigate the importance of agency in faculty careers, and what factors shape an individual's sense of agency.

\section{Purpose and Significance}

The purpose of this study was to contribute to our understanding of agency in faculty careers and work-lives and how agency manifests differently by gender. Using the O'Meara, Campbell, and Terosky (2011) framework on faculty agency, this study examined the organizational (perceptions of the tenure and promotion process, transparency, work-life climate, person-department fit, professional development resources, and collegiality) influences on faculty agency and the outcomes of faculty agency (intent to stay, job satisfaction, and productivity). By investigating the 
organizational factors that influence faculty sense of agency, this study provided insight into how colleges or universities might enhance the agency of individuals. Additionally, this study sought to provide a greater understanding of whether agency matters in important faculty career outcomes.

Navigating difficult terrain requires a strong will, strategic mindset, and action. Thriving in the midst of the transitioning landscape of the professoriate depends upon faculty agency. For example, Neumann, Terosky, and Schell (2006) state, "How faculty respond to such shifts in professional contexts and the extent to which they exert agency... appear[s] to frame professors' future identities as learners and possibly their scholarly learning" (p. 131).

In a context of constrained resources and high demands, institutions must learn what environments enable faculty to blossom, achieve, and be satisfied in their roles. Investigating the organizational factors that influence faculty agency is particularly informative for institutions. According to O'Meara, Terosky, and Neumann (2008), organizational context can either facilitate or frustrate faculty members' senses of agency in their careers and work lives. If certain organizational conditions facilitate individual faculty agency, institutions could emulate these best practices, thereby providing scaffolding for faculty success, and possibly their retention and institutional commitment. For example, with a diversified faculty comes tension between an older, mainly White, masculine, hegemonic culture and a new, more inclusive one. What differentiates a culture that encourages healthy challenge from new insiders verses one that forces accommodation to the hegemony and has a high backlash for faculty who oppose it? Are their particular environments that elicit agency in faculty who are more marginalized, 
such as women? Which environments will give faculty the sense that they can and will achieve their goals, and then give them strategic tools to realize those goals? Does having a sense of control over one's career path garner important institutional outcomes, such as institutional commitment, retention, and satisfaction?

Moreover, agency may be a particularly powerful tool for women. Women face a chilly climate in academia and must overcome resistance in order to succeed (Caplan, 1993; Dean, Bracken, \& Allen, 2009; Glazer-Raymo, 2008; Sandler, 1986). Elder (1994) and Heinz (1996) describe agentic behavior as overcoming resistance or resisting norms. Having a sense of agency may assist women faculty in negotiating an academic environment that is less supportive or welcoming. In fact, due to restrictive norms, success may require some form of agency for women faculty and particularly women faculty of color. For example, due to dual forms of suppression, Black feminist intellectuals must find the critical agency among themselves to reject institutionalized racism and sexism in order to succeed in their roles (Collins, 2000). Yet, agency is sometimes defined in ways that mirror masculine stereotypes. For example, two separate studies in different disciplines define agency as a masculine concept or trait-aggressive, ambitious, adventurous, assertive, autonomous, daring, dominant, enterprising, and forceful, among others (Ackerman et al., 2000; McAdams, de St. Aubin, \& Logan, 1993). In each of these studies, the "masculine" trait of agency is contrasted with a "feminine" trait of communality. Thus, while agency might be particularly important for the career success of women faculty, the notion of agency may run contrary to stereotypical roles for women. As a result, understanding how agency acts for women and men faculty 
could shed light on how to best support an ever-diversifying professoriate in the twenty first century.

\section{Theoretical Framework}

This study was guided by the O’Meara, Campbell, and Terosky (2011) framework of Agency in Faculty Professional Lives (Figure 2). The O’Meara, Campbell, and Terosky framework, represents findings from a comprehensive review of sociological, psychological, and organizational literature on agency (see, for example, Alkire, 2005; Bandura, 1982; Clausen, 1991; Elder, 1994; Emirbayer \& Mische, 1998; Marshall, 2005). The framework posits that agency is either strategic/intentional behavior or meaningmaking. This agentic behavior can either be about overcoming resistance or it can be self-direction more broadly.

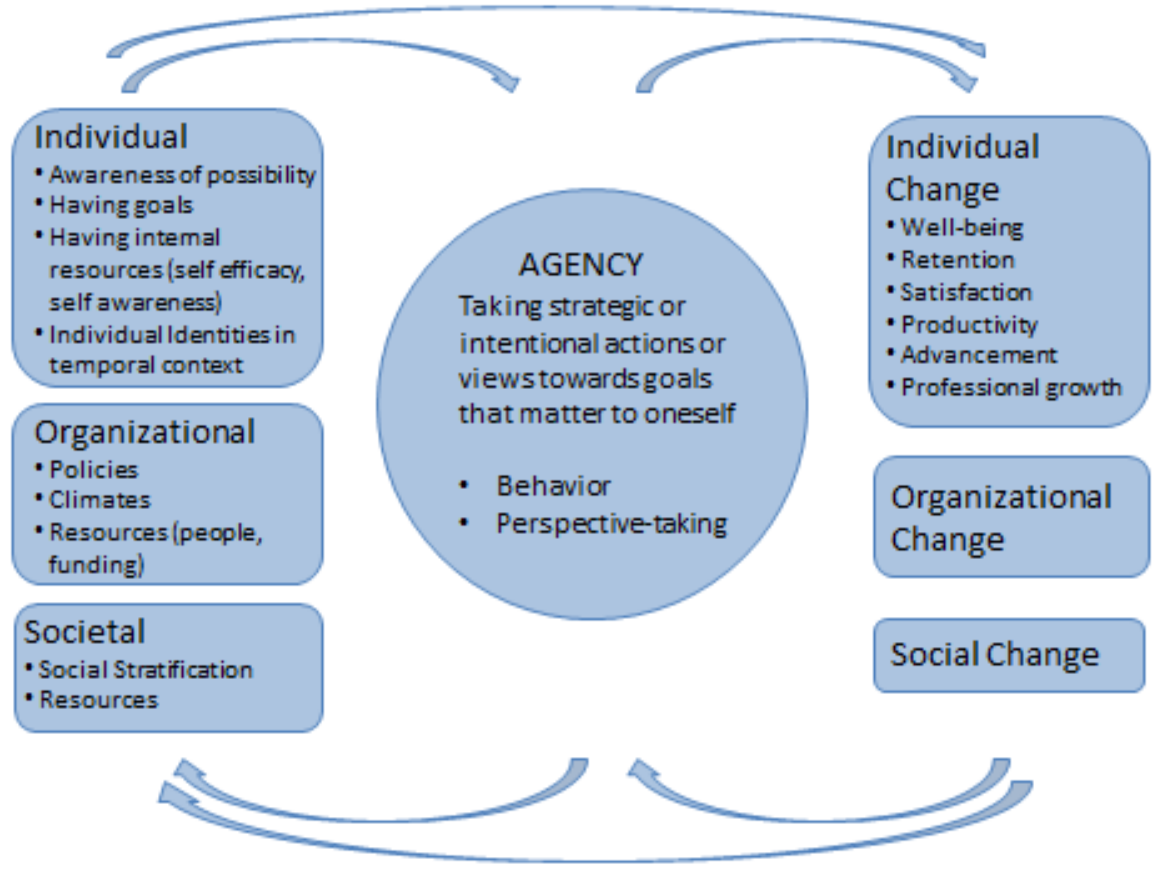

Figure 2. O’Meara, Campbell, and Terosky (2011) Faculty Agency Framework ${ }^{1}$

\footnotetext{
${ }^{1}$ The Faculty Agency Framework was revised by O’Meara, Campbell, and Terosky in 2012. See Appendix $\mathrm{B}$ for a visual of the updated model.
} 
According to the framework, there are factors that influence agency and also professional outcomes of faculty agency. Individual, organizational, and societal factors influence faculty agency. Individuals must have desired goals and self-efficacy in order to exert agency. Individual identities and temporal context (ex. gender, race, sexual orientation, religion, professional capital, family ties, etc.) also influence agency behavior. Agency is also influenced by the environmental context: both organizational and societal factors. According to the framework, there are personal (e.g., well-being; generativity), career (e.g., retention, organizational commitment, satisfaction, productivity and advancement; professional growth), organizational (e.g., organizational learning, innovation), and societal (social change) outcomes of agency perspective and behavior.

By using the O’Meara, Campbell, and Terosky (2011) framework for faculty agency, this study sought to investigate the influence that organizational factors had on faculty agency, whether agency behavior influenced faculty career outcomes, and how the framework of faculty agency manifested differently by gender.

\section{Research Questions}

Research Question 1: What organizational factors influence faculty agency?

Research Question 2: What faculty career outcomes are related to agency?

Research Question 3: How do the influences on and outcomes of agency differ for men and women faculty? 


\section{Research Design}

\section{Methodology.}

This study utilized a quantitative, cross-sectional, survey methodology (Groves, et al, 2004). Data were collected as a part of a Faculty Work Environment Survey (O’Meara \& Campbell, 2011), administered by the University of Maryland NSF ADVANCE grant research team in the Spring of 2011.

\section{Sample.}

The site of the research was the University of Maryland, a large, public research institution in the Mid-Atlantic. The target population for the overall UM Faculty Work Environment Survey was the population of full-time faculty at the University of Maryland, College Park (UM). The target population for this study was all full-time, tenure track faculty at the University of Maryland in fall of $2010(\mathrm{~N}=1549)$. The sample for this study was all full time, tenure track faculty at the University of Maryland who participated in the 2011 UMD ADVANCE Grant Faculty Work Environment Survey $(\mathrm{n}=488)$, yielding a $32 \%$ response rate.

\section{Analytic technique.}

Data were analyzed using Structural Equation Modeling (SEM; Byrne, 2006; Hancock \& Mueller, 2006; Mueller \& Hancock, 2008). SEM was appropriate to answer the research questions for four reasons. First, SEM is a confirmatory method that allows for the testing of a posited model, such as the relationships between the influencing factors, agentic process, and outcomes in the O’Meara, Campbell, and Terosky (2011) framework. Second, SEM allows for the study of multiple exogenous or dependent variables, which was the case in this study. Third, SEM can compare how models hold 
for different groups, which was necessary to compare how the different factors in the O'Meara, Campbell, and Terosky framework acted for men and women. Fourth, SEM accounts for measurement error, which was crucial in a survey of perceptions. Other common statistical techniques, such as OLS Regression or Hierarchical Linear Modeling (HLM) cannot account for measurement error.

This study relied on five measures of fit to judge the CFA model and the SEM models. These indices included: a) the Satorra-Bentler Scaled estimate of chi-square ( $\left.S-B \chi^{2}\right)$, b) the Yuan-Bentler Residual-based F-Statistic c) the Comparative Fit Index (CFI), d) the Non-Normed Fit Index (NNFI), and e) the Root Mean Square Error of Approximation (RMSEA).

\section{Definition of Terms}

Agency was defined as strategic and intentional behavior or perspective on behalf of goals that matter to oneself (Marshall, 2005; McAdams, de St. Aubin, \& Logan, 1993; Neumann, Terosky, \& Schell, 2006; O’Meara, Terosky, \& Neumann, 2008; Schutz, 1967; Sen, 1985). For the purposes of this study, agency was not defined by particular goals (such a research productivity, teaching ability). Instead, this study assumes that each faculty member will have different and likely very personal, career goals; some of which may even go against institutional priorities. Agency, then, was the intentional and strategic navigation of the faculty career in a way that was satisfying to each individual faculty member.

Faculty was defined as full-time tenured or tenure-track faculty at the University of Maryland who completed the UM Faculty Work Environment Survey administered by the NSF ADVANCE grant research team during the spring semester of 2011. This 
included tenured/tenure track faculty at assistant, associate, and full professor ranks in all disciplines across the campus.

Factors were defined as the organizational influences on faculty sense of agency. Organizational factors include perceptions of the tenure and promotion process, transparency, work-life climate, person-environment fit, professional development resources, and collegiality (O’Meara \& Campbell, 2011; O’Meara, Campbell, \& Terosky, 2011; O’Meara, Terosky, \& Neumann, 2008). The operationalization of each factor with specific survey items is included in Chapter 3.

Outcomes were defined by career outcomes, including intent to stay, job satisfaction, and productivity (Alkire, 2005; Clausen, 1991; Emirbayer \& Mische, 1998; Marshall, 2005). Men and Women were defined by faculty gender from institutional data.

\section{Organization of the Dissertation}

The professoriate has seen several changes in the past few decades including increasing workload, decreasing resources, new technology, a diversified student body, and a diversified faculty landscape. Thriving in the midst of the challenging landscape of the professoriate depends upon faculty agency. Institutions must know which types of environments will solicit faculty agency to successfully navigate their careers. The O’Meara, Campbell, and Terosky (2011) framework of faculty agency offers a potential tool to assist institutions and faculty in meeting faculty needs, but this framework has not yet been validated. The influences on and outcomes of agency have not yet been empirically tested.

Further, agency may be a particularly powerful tool for women or other underrepresented faculty. Institutions that seek to recruit and retain underrepresented 
faculty will need to understand which organizational factors act as facilitators of agency for specific groups of faculty. Yet, the way that agency manifests by gender, rank, race, and discipline has not yet been explored. This study sought to inform our understanding of faculty agency by investigating the organizational influences on agency and the career outcomes of agency for men and women faculty. The following chapters will describe in greater detail the literature on agency (Chapter 2) the quantitative, cross-sectional survey methodology using Structural Equation Modeling statistical technique (Chapter 3), the results of the research questions (Chapter 4), and discussion of the findings and implications for theory and practice (Chapter 5). 


\section{Chapter 2: Literature Review}

\section{The Case of Dalinda-Early Career Faculty Member}

Dalinda started one year ago as a tenure track assistant professor in biology at Southern U., a large, public, research extensive institution. She is one of only a handful of women in her department, one of only two women of color and the only Latina in the entire college of Life Sciences. She and her husband relocated to the south to be closer to her family before starting a family of their own. She had been in a prestigious post-doc before applying for this position, so she had her choice of working for an Ivy League institution or Southern U., close to her family. Since she started in her position, she has discovered that her department chair is very supportive of wanting her to succeed and also has two children. On the other hand, the rest of her department has been less welcoming and seems to view her as competition. She had hoped to be in a highly collegial department.

She and her husband want to have kids soon, but they are trying to time it during the summer. The university has a paid parental leave policy, but she has been told by colleagues that taking official leave is frowned upon during tenure review. Additionally, she wonders how she would continue to be involved with her lab from afar, and lab time is critical to the success of her research agenda. While she knows it will not always be easy, she has a strong sense of wanting to figure out a way to feel good about how she navigates her career and her family. Some days, she can picture how good she will feel when she gets tenure and is running around after her little one at the same time. Other times, especially when talking to her colleagues, the fear sneaks in: 'Can I really do this?' She thinks about how she needs this job, wants to stay at this institution and be close to family. Then, she remembers that she is competent, and brought a large grant from her research fellowship, so she believes that the department needs her too.

I created this vignette, the case of Dalinda, based on the literature on agency from educational, sociological, psychological, and organizational disciplines in order to demonstrate a powerful example of the factors that influence agency and how Dalinda's sense of agency shapes her experience at Southern U. Dalinda's identity and internal resources and the organizational climate and structure all impact her agency or the degree to which she is able to act on or make meaning of her strategic/intentional goals.

Dalinda's identity as a Latina shapes the agency that she feels in this situation.

She has chosen to be at this particular institution to be close to family, which limits her 
career options. As is often the case for women, this makes her more of a "local" scholar (who is limited to finding jobs in a specific area) rather than a "cosmopolitan" scholar (who could move around to whichever opportunity was best for career; Gouldner, 1957; Rhoades, McCormick, Kiyama, \& Quiroz, 2007). Additionally, being the only Latina in the college limits her ability to see herself in role models who have succeeded and may also make her feel isolated. As a result, her demographic identity may limit the agency that she feels to create the career and family that she craves. By contrast, it is possible that her marginality may drive her to want to succeed even more, using the isolation and resistance she feels as an agency instigator.

Dalinda's agency is facilitated by the professional capital she achieved via her previous experience in a prestigious fellowship where she brought in a major grant. She contextualizes how she thinks about her goals (being a successful tenure track faculty member and a mother) in her past experiences and future goals. Furthermore, she has several internal resources that enable her agency. She describes herself as competent and also pictures herself succeeding in her goals (i.e. self-efficacy in career). Simply the fact that she has goals/intentions (e.g., getting tenure and creating a satisfying work-family balance) is a step towards agentic process.

While Dalinda's identity, professional capital, temporal context, and internal resources impact her agency, there are also external factors that are seemingly as potent or more so. Her environmental context in a research institution within a science discipline situates her in a climate that has historically been less welcoming to women and academic parents (Glazer-Raymo, 2008; Dean, Bracken, \& Allen, 2009). Research institutions tend to have less transparency with tenure processes and higher demands, 
which can be difficult for academic parents of young children. In Dalinda's case, she experiences a chilly climate from her colleagues. Her sense of this climate directly impacts how she pictures her success. Departmental norms can impact agency for faculty parents (O’Meara \& Campbell, 2011). Disciplinary expectations also can impact one's agentic experience. For example, Dalinda must consider the impact of time away from her lab during parental leave on her research agenda and career goals.

There are two aspects of Dalinda's environment that act as facilitators of her agency. First, she has a strong ally in her department chair, and positive role models act as facilitators of agentic process (O’Meara \& Campbell, 2011). Second, her institution appears to have structural support for academic parents in the form of a paid parental leave policy. Unfortunately, Dalinda's colleagues said that she would experience a backlash in her tenure process if she took advantage of the policy. It appears that the negative departmental norms negate the positive impact of this policy. While there is evidence that structural policies can be facilitators of agency for academic parents (O’Meara \& Campbell, 2011), there is also evidence that few faculty take advantage of parental policies due to informal, negative norms (Williams, Alon, \& Bornstein, 2006).

The example of Dalinda is powerful and exemplified many of the influencing factors of agentic process. The rest of this chapter will provide a literature review on the concept of agency and how it works in faculty professional lives. First, various definitions of agency are explored and categorized, and the specific definition used in the present study is explained. Second the chapter explores the four main social science theoretical perspectives that contribute to agency in this study: psychological, sociological, life span, and organizational. Third, I describe applications of the concept 
of agency to higher education and to studies of faculty. Fourth, the chapter details all of the relevant factors that shape agency, the process of agency itself, and the potential outcomes of faculty agency. Finally, the chapter provides a review of how the construct of agency has been measured and fully describes the conceptual model for this study.

\section{Agency Defined}

The construct of agency may be of great value to understanding faculty professional growth and success (O’Meara, Terosky, \& Neumann, 2008). Yet, agency is often ambiguously defined, if defined at all, in many of the studies that examine this construct. According to Emirbayer and Mische (1998), "The term agency itself has maintained an elusive, albeit, resonant vagueness" (p. 962). Additionally, several disciplines including psychology, sociology, education, and life span theories contribute theoretical perspectives to the construct of agency, each bearing a specific and often distinct definition. These theoretical distinctions are discussed in detail later in this chapter.

Marshall (2005) demonstrates the varied perspectives and definitions of agency. According to his literature review, agency has been defined in the following ways:

- As a producer of development (Lerner and Busch-Rossnagel, 1981): A trait that spawns individual growth and development.

- As a determinant of environment (Lawton, 1989): A person shapes her/his own environment.

- As a masculine trait (Ackerman et al., 2000; McAdams, de St. Aubin, \& Logan, 1993): Agency is a characteristic that is associated with stereotypically male traits, such as assertiveness, strength, and power. 
- As a trait that assists choice-making within constraints (Elder, 1994): Individuals are constrained by social contexts, if they exhibit behavior outside of the socially determined behavior, it must be agency (i.e. the left over variance in a statistical model/behavior that can't be accounted for).

- As overcoming resistance (Elder, 1994; Heinz, 1996): Only those who resist norms are agentic.

- As assisting life transitions (Elder, 1994): Adapting to new life stages is a form of agency.

- As responsibility (Myer \& Jepperson, 2000): Agents of a cause act on behalf of an institution, person, culture, values, or self.

Recognizing the varied nature of these definitions, Marshall (2005) sought to provide a framework for the definitions of agency. Marshall argues that four distinctions among agency definitions should be made: "(1) the human capacity to make a choice, that is, to be intentional; (2) the resources within the individual or at the command of the individual that can be brought to bear in intentional or agentic behavior; (3) behavior of individuals that reflects intention; and (4) the social and physical structuring of choices" (p. 11). Each of these four categories is discussed in greater detail, below, along with examples of studies that utilize definitions that fit into the four categories.

\section{Agency as the human capacity to make choices or to be intentional.}

The first category of definitions of agency insists that agency is part of human nature. Each person has the capacity for agency. Agency is linked to the idea of free will, that humans are not entirely programmed, but rather make conscious and intentional choices that shape their life trajectories (Marshall, 2005). Neumann, Terosky, and Schell 
(2006) define agency in this manner: "We define agency as 'the human capacity ... to act intentionally, planfully and reflexively and in a temporal or a biographical mode,' and as reflecting the presumption that 'all human beings have free will (Marshall, 2000)" (p. 11). In psychology and some life span perspectives, this same conceptualization of agency is understood as "proactive adaptation" (Kahana \& Kahana; 1996).

This definition implies that, like other human traits, some people have more agency than others. For example, Clausen (1991), viewing agency as "planful competence" states that "some individuals ... are more effective than others in making positive events happen in the course of their development" (p. 810).

While this definition of agency operates mainly in the micro (i.e. focus on individual faculty), it also has the capacity to view an interaction between individual intentionality and environment. As Marshall (2005) describes, it relies on the "coconstitution of self and society" (p. 12). According to O'Meara, Terosky, and Neumann (2008): "Some social-organizational theories operate between the micro and macro, for example, considering how macroforces shape the life experiences of individuals in institutions, organizations, and society (Bronfenbrenner, 1979) and conversely how individuals exert agency to adjust their own and others' experiences of the multiple contexts in which lives are cast (Pallas, 2007)” (p. 129).

When related to faculty agency and the present study, a key element of Marshall's first category is 'intentionality', which invokes having strategic goals as necessary condition for agentic process. This definition contributes an individual's ability to navigate their life circumstances in the face of, or even despite challenging circumstances and environments. It also suggests that faculty have the ability to shape their career 
trajectory—but that this ability naturally varies by individual. For example, some individuals lack agency even in the most supportive of circumstances or could possess agency even in the most challenging environments. While others, might have more or less agency depending on the environmental factors. In the context of the present study, this suggests that institutions might be able to influence the agency of many faculty, but that some faculty will have agency regardless of organizational factors and others will never feel agentic. This definition suggests that while agency may be influenced by time or environment, there will always be a range of agentic process for each individual. This understanding is crucial to the measurement of faculty agency in this study.

\section{Agency as resources that bring to bear intentional behavior.}

The second definition, like the first, operates mainly within the micro, focusing on individual characteristics that enhance choicemaking. Rather than focusing on the innate human characteristic of free will, this definition focuses on the resources that might enhance or generate intentional behavior. The resources can be either within an individual (such as character traits and personal histories) or available to that individual (such as funding, policies, and support systems). In the context of faculty agency, O’Meara, Terosky, and Neumann (2008) state: "agency exceeds both autonomy and academic freedom: It originates from within the faculty member herself or himself and is nurtured in a professional community that provides resources to develop and sustain it" (p. 28). Neumann, Terosky, and Schell (2006) also view agency in this manner: "Effectiveness in activating agency in desirable ways may relate to the resources available to individuals (Marshall, 2000)" (p. 93). This study viewed the resources that 
support agency behavior as influences on agency behavior rather than defining agency itself. This study investigated organizational contexts as influences on faculty agency.

\section{Agency as intentional behavior.}

What distinguishes the third definition of agency from the first is that the focus is less on the human capacity for intentionality, and more on the tangible action or behavior of choicemaking. In this case, it would not be enough for a faculty member to consider different options in their career, to form intentions for what and how they will shape their career trajectory, or to feel empowered. Until the faculty member made the decision and acted on it, they would not be exhibiting agency. In this case, there could be many people with the capacity to make choices, but until those choices are made or acted upon, they are not engaged in an agentic process. According to Neumann, Terosky, and Schell (2006), "Despite the unique and varied circumstances into which they are born, and within which they subsequently live, individuals can and do influence their own life trajectories in intentional ways (Clausen, 1991; Elder, 1994; Lerner \& Busch-Rossnagel, 1981; Marshall, 2000)." In this quotation, it is the statement that individuals "can and do" change their paths that represents agency in the sense of intentional behavior.

Additionally, some scholars who subscribe to this definition seem to view agency as any behavior that cannot be explained by societal and external forces (Elder, 1994, Clausen, 1991). In essence, agentic behavior is that which operates outside the system. For example O'Meara, Terosky, and Neumann (2008) see one form of agency as navigating organizational or institutional constraints:

"We need theoretical frameworks and research designs that reveal faculty who pave their own distinct paths, often against the grain of longentrenched reward systems so that these navigation skills, these sets of confidences in oneself and the importance of self-defined work are more 
visible. One example of faculty who enact such agency, to choose and do from their own sense of direction and desire, are the scores of faculty currently involved in community engagement despite institutional reward systems that do not acknowledge or support this work (Boyte, 2008; O’Meara, 2008)" (p. 118).

The behavioral distinction informed the present study as one potential form of agentic process. The second form of agentic process for this study was perspective, which I describe later in this chapter. For measurement of the construct of faculty agency, the behavioral definition asks three questions: 1) Did the faculty member achieve their desired goals? 2) Did she/he take actions/steps toward achieving the goals? 3) Did she/he make choices that facilitated success of the goals? Additionally, agency behavior has implications for the outcomes of agency. Will there be a difference in the outcomes of faculty who took intentional and strategic actions towards their goals versus those who reflected on their goals/intentions, but took no action?

\section{Agency as society's structuring of choices.}

The fourth and final definition highlighted by Marshall (2005) relates to the opportunity structures (e.g., social, life place) that catalyze action. Here, agency is viewed in the macro sense, in terms of environmental influences. Individuals only make choices in the context of external forces. For decades, many sociological scholars have studied agency from this perspective. For example, Berger and Luckman (1966) posit that institutions define an individual's reality, behavior, and, consequently, agency. Berger and Luckman state "Institutionalization occurs whenever there is a reciprocal typification of habitualized actions by types of actors...The institution posits that actions of type $\mathrm{x}$ will be performed by actors of type x" (p. 43). In other words, people of a certain type (e.g., faculty) do the same things in a routine (e.g., jump through hoops for 
promotion). They lack control over these processes, and behavior is entirely determined by institutionalization.

While few studies of faculty take the perspective that agency behavior is entirely controlled by environment, many acknowledge that agency takes place within a context of multiple environments: society, institutions, and disciplines. Neumann, Terosky, and Schell. (2006) state: "We also acknowledge that individual actions, and hence lives, are significantly regulated by external influences and institutions (e.g., Buchmann, 1990; Mayer \& Schoepflin, 1989; Neugarten et al. 1965; O’Rand, 1996; 2000; Sorenson, 1986), and indeed, that agency is entwined with social structure, as acting freely takes place in the context of a structure that presents various opportunities and constraints (Elder, 1994)" (p. 4).

Another important external force that has been used to situate agency for faculty is the temporal context (O’Meara \& Campbell, 2011; O’Meara, Terosky, \& Neumann, 2008). Emirbayer and Mische (1998) first conceptualized agency in temporal context. They defined agency as "the temporally constructed engagement by actors of different structural environments - the temporal-relational contexts of action-which, through the interplay of habit, imagination, and judgment, both reproduces and transforms those structures in interactive response to the problems posed by changing historical situations" (p. 970). In the present study, faculty may have differing degrees of agency based on the specific life circumstances, professional capital (e.g., prestigious publications, grant funding), and social capital (e.g., reputation, scholarly network) that they experience at that specific point in time, tempered by the circumstances they remember from the past and foresee in the future. For example, a faculty member who is expecting a baby who 
has just begun a tenure track position, has few support systems, and has not yet accumulated professional capital (e.g. grants, publications) may have less agency in family choice making than a faculty member expecting a baby who has already received tenure and has made a name for her/himself in the field (Armenti, 2004; Mason \& Eckman, 2007; O’Meara \& Campbell, 2011).

For the purpose of this study, the fourth of Marshall's categories contributes an understanding of the temporal, social, and organizational forces that drive agency. Faculty do not consider their intentions, goals, and actions in a vacuum. They are situated in institutional, disciplinary, and societal contexts related to their demographic identities, career goals, and family goals, among others. While agentic process is primarily an act of the individual, it is always contextualized by external environmental forces. This defining aspect of agency was important to the significance of this study. According to the environmental definition of agency, policy-makers and administrators can have a significant impact on the agency of individual faculty members.

\section{Agency as perspective.}

Agency perspective emerged in the literature as a fifth category of agency definitions, outside of Marshall's (2005) framework (McAdams, de St. Aubin, \& Logan, 1993; Neumann, Terosky, \& Schell, 2006; Schutz, 1967). This definition emphasizes reflection rather than intentionality or choicemaking behavior. Agency is the ability to make meaning of human experiences, to reflect upon them, and to re-construct them internally. For example, McAdams, de St. Aubin, and Logan (1993) contend that we make meaning of our lives through personal stories or myths. Characters in our stories (formed mainly by our own experiences) include both agentic (masculine traits) and 
communal (female traits) characters. It is noteworthy that McAdams, de St. Aubin, and

Logan, view the agentic perspective as a masculine lens. Agentic characters:

"seek to conquer, master, control, overcome, create, produce, explore, persuade, advocate, analyze, understand, win. They are described by such adjectives as aggressive, ambitious, adventurous, assertive, autonomous, courageous, clever, courageous, daring, dominant, enterprising, forceful, independent, resourceful, restless, sophisticated, stubborn, and wise, among many others. Such characters may be considered 'masculine' in the sense that they personify some characteristics that are stereotypically associated with the male sex role" (p. 134).

In the present study, the understanding of agency as perspective was a second form of agentic process (with intentional behavior as the first). This understanding sheds light on how faculty members may alter their work lives by transforming them through reflection. For example, a woman of color assistant professor might feel marginalized and victimized when her research is undervalued by her peers or when she takes on numerous service opportunities and is pulled away from her research agenda. By contrast, as Baez (2000a) demonstrated, some women of color find enormous meaning in their service work, which flows into all aspects of their careers.

This study recognized that varying definitions of agency make important contributions to understanding the construct of agency. However, this study used the following operational definition: agency is strategic and intentional behavior or perspective on behalf of goals that matter to oneself (Marshall, 2005; McAdams, de St. Aubin, \& Logan, 1993; Neumann, Terosky, \& Schell, 2006; O’Meara, Terosky, \& Neumann, 2008; Schutz, 1967; Sen, 1985). This definition focuses specifically on agency as the human capacity for intentional behavior (Marshall's (2005) categories 1 and 3) and the new conceptualization of agency as perspective (Neumann, Terosky, \& 
Schell, 2006). The individual and environmental influences on agency in the present study mirror Marshall's (2005) categories 2 and 4.

Within the operational definition for this study, individuals might have an inherent range of agency. Each individual's range might be different. For example, if human agency were measured on a scale from 1 to 100 , faculty member $\mathrm{X}$ might have a range of 50-70 in any given moment (higher range), while faculty member Y might have a lower range (30-50) and faculty member $\mathrm{Z}$ might have a larger range (30-70). The faculty agency framework would posit that based on goals, internal resources, temporal context, organizational, and societal factors, faculty members $\mathrm{X}, \mathrm{Y}$, and $\mathrm{Z}$ might be operating in the higher or lower portions of their inherent agentic ranges. In essence, the present study presumed that agency comes from within, but is not completely fixed: rather, it operates and varies according to external factors within the constraints of that individual faculty member's inherent agentic capacity. In contrast with Marshall's fourth category of agency definitions which presumes that the external forces are a part of agency, this study presumed that external forces can impact an individual's level of agency.

The present study investigated certain organizational contexts that enhance the human capacity for intentional behavior and strategic perspective (agency), but viewed those contexts as outside of the construct of agency, itself. Viewing agency from this perspective allowed me to ask several important questions. Acknowledging that individual faculty members possess varying levels of capacity to construct their own realities and career trajectories, what conditions make it possible to maximize an individual's capacity to do so? What organizational resources bring to bear the 
maximum amount of agency in each individual faculty member? And further, does this agency have a real bearing on important faculty outcomes, such as faculty growth, tenure/promotion, and job satisfaction? In essence, can colleges or universities enhance the agency of individuals, and does agency matter in faculty career outcomes?

\section{Theoretical Perspectives on Agency}

As previously mentioned, there are four main theoretical perspectives that contributed to the understanding of agency of this study: sociology, psychology, life span, and organizational theory. These perspectives are presented in detail below and in sum in Table 1.

\section{Sociological perspectives on agency.}

The sociological conception of agency focuses on the impact that society has on individual or collective action. According to this framework, it is critical to understand the social structures that surround faculty members in order to understand how and why they motivate and act as individuals. In fact, the sociological perspective has consistently moved further away from identifying individuals as the central seat of agency and towards emphasizing the external and societal influences that govern behavior (Pickering 1993). In sociology, according to Emirbayer and Mische (1998), some of the most prominent early sociological theorists, such as Pierre Bordieu and Anthony Giddens, often considered the interplay between human action, institutions, and routine. Sociological scholars have been examining the construct of agency more specifically in the last half century, beginning with significant contributions in the 1960s and 1970s. Many of these contributions focus on the nexus between person and environment or society. For example, Schutz (1967) stated that interactions between people or person- 
environment interactions require simultaneous meaning-making. Actors construct a reality based on their own experience, while imagining the other person's (environment's) reality. Actors also have the capacity to motivate collective action and to galvanize larger, societal level agency (Alkire, 2005).

Interestingly, certain definitions of agency in sociology seem to posit that individual action is heavily constituted by external societal factors (Berger \& Luckman, 1966; Meyer and Jepperson, 2000). In 1966, Berger and Luckman posit that "institutions further imply historicity and control” (p. 386). Pickering (1993) deconstructs the contexts of science and technology, and postulates a semiotic relationship between human agency (individual action) and material agency (environmental influences). Pickering describes a process that begins with human agency and intentions. Then, the individual encounters resistance in the form of material agency, accommodates, and then finalizes action. More recently, Meyer and Jepperson (2000) state that modern Western society sees agency in individuals rather than in the realm of the spirit or culture, allowing individuals to exhibit agency on themselves and their own life course, on other agents, on other non-agents (e.g., whales, environment), or on principles. In essence a cultural shift allowing individuals to perceive they have agency has caused them to enact agency in a way that is structured within society—agency, although attributed to the individual, is socially constructed.

While many sociological perspectives provide room for both an agentic actor and the broader societal influences that impact sense of agency, the more extreme sociological perspectives are at a strong contrast to certain psychological perspectives on agency. There appears to be some irony in the most extreme forms of the sociological 
perspective on agency when it is viewed according to the psychological perspective on agency: the sociological perspective itself lacks agency. To state that intentions are at the whim of society and individuals have little to no role in them, that individual goals and will are a misperception and instead are a cog in a larger machine (such as is the case for Meyer and Jepperson, 2000) — that would be the opposite of agentic mindset according to the psychological perspective, which states that humans have the ability to transform, overcome, an manipulate their own course and even their environments.

The main strength of the sociological perspective is that it takes a collective view of agency, allowing for a complex conceptualization of the external factors that influence human agency. For example, the agency of women faculty must be considered in light of gender dynamics in broader society. The sociological lens provides the context and setting to understand how intentional choices are made. Intentionality may be defined by broader social pressures and power dynamics that may be unrelated to the individual, even if that individual feels as if she/he is exerting will. This perspective also facilitates an understanding of power dynamics in the structuring of choices. However, an overemphasis on the social structuring of agency may not give the full picture of the internal aspects of agency, such as perspective, which are more pronounced in other theoretical lenses (such as psychological and life span).

\section{Psychological perspectives on agency.}

By contrast to sociological perspectives on agency, the field of psychology has contributed to the understanding of agency as a human trait. According to Bandura (1982), "Psychological theories postulate intervening mechanisms through which external factors affect behavior" (p. 123). Psychologists tend to measure agency as both 
as a psychological trait and a characterization of behavior (Ackerman et al., 2000;

Kahana \& Kahana, 1996; Lawton, 1989). These studies concern how individual agency and the ability to intentionally shape one's life path relate to life outcomes (ex. generativity) and behavior.

Bandura (1989), in his landmark paper, described how social-cognitive theory, a theoretical framework of psychology, can be used to better understand the concept of human agency. According to Bandura (1989), there are three views of agency: autonomous agency—where individuals act on their own accord independently of outside influences; mechanical agency — where individuals only have agency in the context of their environment and have no individual or internal agency; and, lastly, emergent interactive agency.

Social Cognitive Theory (SCT) subscribes to emergent interactive agency, which posits that the actor and the environment have reciprocal influences (Bandura, 1989). Under this theory, individual actors are able to have some control over the way they think, feel, and act. At the same time, their environments are constantly influencing the way they think about their thoughts, feelings, and actions. Thus, it is the interplay of internal and external sources that causes motivation and action. According to SCT, the outcome of action then results from the cognitive and behavioral skills of the individual.

Particularly significant to our understanding of the concept of agency is the contribution of Bandura's (1982) study of self-efficacy. Bandura's study found that individuals' self-referent thought mediated knowledge and action. Bandura (1982) coined the term self-efficacy to describe an individual's perception of their ability to exercise control over their actions and lives in specific domains. Self-efficacy has a 
direct relationship with an individual's degree of agency. In essence, it is not enough to know how to do something-one must believe that she/he can do it in order to accomplish a goal. This study brought to light the concept of internal resources and selfperception. Self-efficacy and agency are also both domain specific, meaning that a person could have self-efficacy and agency toward career, but not in family life. Bandura (1982) also found that one's level of self-efficacy was alterable. Self-efficacy has been linked to many other factors related to agency (Bandura, 1989). High self-efficacy is associated with lower levels of stress during difficult situations and higher motivation. Additionally, individuals are more likely to select environments where they believe they can succeed.

Self-efficacy can be applied to faculty populations to better understand the role of self-perception in agency as a component of faculty growth. For example, Bandura (1989) described how scientists go through a process of rejection before their work is heralded. In order to overcome this rejection, one must have extremely high self-efficacy in his/her work. Faculty self-efficacy has been studied numerous times through the psychological lens. Kelly (2007) studied how self-efficacy in career, exercise, and social support contribute to faculty strain and burn out, finding that low self-efficacy contributed to faculty burn out. Self-efficacy in teaching is also a predictor for motivation, optimism, and more positive classroom management (Shechtman, Levy, \& Leichtentritt, 2005).

Another landmark psychological theory that relates to agency is locus of control, a part of social learning theory (Rutter, 1966). Under Rutter's theory, people act based on reinforcement and whether or not they feel that the outcome is under their control 
(internal locus of control) or the control of an external factor such as society (external locus of control). The construct of agency assumes that an individual believes that she/he has a role in achieving personal goals - that taking strategic steps will open doors and make their goals actionable. In this way, one aspect of agency is internal locus of control.

There are two main strengths of the psychological perspective to agency. The first is that it allows for an understanding of what influences individual agency, how it manifests in behavior, and how agency influences life outcomes. The second strength is that the psychological perspective contributes the ability to see the internal resources that motivate agency. Perceptions matter, and how faculty think about their experiences, their competence, and their goals will have a direct bearing on their agentic process. The weakness of this perspective is that it often focuses heavily on the perceptual nature of agency to the exclusion of an understanding of collective action.

\section{Life span perspectives on agency.}

The discipline of life span integrates both sociological and psychological perspectives to investigate the long-term patterns and trajectories of humans throughout their life course. Life span theories help us understand agency as a motivating force throughout the life course. Human agency is a central theme for life span studies (Clausen, 1991; Elder, 1994). According to Marshall (2005), "Every social theory has two components: energy and direction. In terms of life span theory, agency could be considered energy." Studies that investigate agency from the life span perspective tend to recognize the interplay of individuals and environments, and focus on how agency (in the form of intentional choicemaking) influences life trajectories. Elder (1994) states that 
there is an interplay between "the interlocking nature of human lives and generations" and "interlocking nature of individuals as choicemakers and agents of their own lives" (p.4) and that there is a "reciprocal influence between social and developmental trajectories" (p. 5).

Life span research on agency seems to vary with respect to whether agency is attributed to individual characteristics or societal pressures. With respect to human agency in the context of the life course, Clausen (1991) states "within the constraints of their world, people are planful and make choices among options that construct their life course" (p. 6). Additionally, life span theories on agency focus on the individual differences in agency (planful behavior) and outcomes (life trajectories). According to Clausen (1991), "Individual differences clearly matter in [life span] research, particularly as they interact with changing environments to produce behavioral outcomes" (p. 6). By contrast, Mayer and Schoepflin (1988) establish the relationship between the state (meaning government, society, broader environment) and agency in the life course. They posit that previous life span theory had ignored the role of the state, but that this perspective is evolving.

In relation to the present study, the life span perspective contributed the ability to see agency as changeable both on an individual and collective level. Life span theorists also shed light on how individuals can shape life trajectories, which contributed to our understanding of agency in career. This study viewed agency in a snapshot of time for faculty. Life span theorists might contend that agency is a part of a long-term process; that capturing a snapshot of time will need to be contextualized in a broader understanding of the life span, particularly the long term career trajectory. 
A weakness of life span theory is that it often takes such a broad, long-term perspective on agentic process that snapshots of agentic behavior might be ignored. For instance, the perspective might not shed light on the experience of a faculty member who typically feels victimized in a system or does not typically make intentional and strategic choices, but asserts her/his voice in a meeting one day. What is it about this particular moment that was different for this faculty member? What influenced her/his agency in that particular situation and how will it influence her/his future decisions?

\section{Organizational perspectives on agency.}

Organizational perspectives focus on how an organization can influence one's sense of agency, rather than perceiving the organizational structure as a part of agency itself. Organizational contexts that influence agency can be constituted by structural facets of an organization (such as policies) or culture (such as climate or norms). Yet, there are few studies of organizational influences on agency. O'Meara, Terosky, and Neumann (2008) state that organizational context can either facilitate or frustrate faculty members' senses of agency in their careers and work lives. Baez (2000a) demonstrated how service is perceived organizationally as a burden, but for certain faculty of color, it can be an agency-enhancing activity. O'Meara and Campbell (2011) found that department norms and policies (such as flexibility and parental leave/stop the clock) influenced agency for faculty parents. Rusch and Wilbur (2007) found that human agency can facilitate institutional transformation. Garnes (2005) found faculty selfefficacy (related to agency) can be helpful to an organizational strategic plan. In Garnes' study, a faculty member's self-efficacy in technology and hope contributed to technology implementation as a part of a strategic plan. 
Some managerial literature views agency as a helpful characteristic for a research manager. Sahay and Walsham (1997) investigated the mutuality of social structures and managerial agency in scientists who are project leaders in India. This article found that individual managers developed agency through manipulating their multiple roles and allegiances to societal structures such as national, communal, religious, domestic, and intellectual systems. Additionally, through this agency, managers make changes in the social structures, although over a longer period of time. In this study, the mutuality of individual and environment is present: the societal structures influence human agency and vice versa. This can be seen as helpful to the organizational culture and the success of the scientist managers.

Another line of research on organizations and agency views agency as problematic to an organization rather than helpful to an individual. According to GomezMejia and Balkin (1992), “An agency relationship is in effect whenever one party, a principal, hires another person — an agent—who possesses specialized knowledge and skills." Under this framework, each individual acts in their own self-interest, which often conflicts with organizational interests. Gomez-Mejia and Balkin studied business faculty members through the organizational lens of agency theory. This study found that the characteristics of higher education organizations are ripe for the "agency problem" because faculty have an autonomous and independent work environment and they hold specialized expertise that administrators do not possess. As a result, the study contends, managing faculty is very difficult, and administrators rely on incentives, such as salary, to motivate faculty-organizational unity. 
While few studies use the organizational lens to illuminate the construct of agency, organizational literature has focused on related concepts, particularly with regard to motivating workers. For example, one of the landmark managerial theories is Vroom's (1964) expectancy theory of work and motivation. According to Vroom's theory, there are three aspects that determine worker motivation: expectancy, instrumentality, and valence. Expectancy is the degree to which effort will result in performance (i.e. is the performance attainable?). For faculty, high expectancy might be the expectation that if a faculty member put in a significant amount of effort, she could be published in one of the top journals in her field. Expectancy is shaped by a number of factors including selfefficacy, support of supervisors, and fairness of process. Instrumentality is the extent to which there is a direct relationship between performance and a reward. For example, a faculty member might be motivated to perform if she knew for certain that she would attain tenure based on her performance. Lastly, valence describes the appeal of the award for each individual (positive or negative). Greater valence would mean greater motivation to perform.

The expectancy aspect of Vroom's (1964) theory seems to resonate most with agency perspective: a "can-do" mindset prime's an individual for action. Yet, the theory does not discuss intentionality or a strategic mindset in the same way that agency theory does. In expectancy theory, individuals are largely motivated by the systems within organizations (such as reward structures); it is the job of the organization to create meaningful reward structures that are directly linked to behavior. By contrast, the construct of agency allows the faculty member to set their own goals and make meaning of their performance and rewards. Additionally, the faculty agency framework considers 
individual identities, societal influences, and multiple levels of outcomes. Vroom's theory places primary emphasis on the motivation of workers within an organizational setting.

The organizational framework is crucial for understanding institutional, departmental, and disciplinary contexts to faculty agency. This perspective is informative for administrators and policy makers, underscoring that there are concrete actions that can be taken to shape faculty agency, such as creating supportive policies, mentoring opportunities, welcoming climates, and effective reward structures. A weakness of this perspective is that it does not consider the internal resources of individuals and the ability to make meaning of experiences outside of organizational structures.

Table 1

Theoretical Perspectives on Agency

\begin{tabular}{|c|c|c|c|}
\hline $\begin{array}{l}\text { Theoretical } \\
\text { Perspective }\end{array}$ & Focus & Strengths & Weaknesses \\
\hline Sociological & $\begin{array}{l}\text { The impact that society } \\
\text { has on individual or } \\
\text { collective action }\end{array}$ & $\begin{array}{l}\text { Decomposes power } \\
\text { dynamics; } \\
\text { Understands agentic } \\
\text { contexts and } \\
\text { environments }\end{array}$ & $\begin{array}{l}\text { Focuses less on the role } \\
\text { of individual agents-the } \\
\text { 'agent' may be society } \\
\text { itself }\end{array}$ \\
\hline Psychological & $\begin{array}{l}\text { Agency as a human trait; } \\
\text { Internal resources that } \\
\text { manifest agency }\end{array}$ & $\begin{array}{l}\text { Contributes an } \\
\text { understanding of self- } \\
\text { perceptions; } \\
\text { Individual action }\end{array}$ & $\begin{array}{l}\text { Does not focus on } \\
\text { collective action- } \\
\text { focuses less on broader } \\
\text { forces and more on } \\
\text { internal resources }\end{array}$ \\
\hline Life Span & $\begin{array}{l}\text { Agency as a motivating } \\
\text { force throughout the life } \\
\text { course }\end{array}$ & $\begin{array}{l}\text { Investigates the long- } \\
\text { term patterns and } \\
\text { trajectories of } \\
\text { humans throughout } \\
\text { their life course }\end{array}$ & $\begin{array}{l}\text { Does not see the agentic } \\
\text { process in snapshots of } \\
\text { time, only broader trends }\end{array}$ \\
\hline Organizational & $\begin{array}{l}\text { How an organization can } \\
\text { influence one's sense of } \\
\text { agency via structural } \\
\text { facets of an organization } \\
\text { (such as policies) or } \\
\text { culture (such as norms }\end{array}$ & $\begin{array}{l}\text { Reveals practical } \\
\text { issues for } \\
\text { administrators and } \\
\text { policy makers (e.g., } \\
\text { organizational } \\
\text { barriers to and } \\
\text { facilitators of agency) }\end{array}$ & $\begin{array}{l}\text { Does not consider the } \\
\text { internal resources of } \\
\text { individuals and the ability } \\
\text { to make meaning of } \\
\text { experiences outside of } \\
\text { organizational structures }\end{array}$ \\
\hline
\end{tabular}




\section{Applications of the Concept of Agency to Higher Education}

Studies of agency in the higher education setting have mainly investigated college student agency, particularly for underrepresented students or students from low socioeconomic status (SES) backgrounds. For example, Deil-Amen and Tevis (2010) conducted a qualitative investigation of the experiences of minority students from low SES backgrounds with regard to college entrance examinations and admissions processes. They used a self-efficacy framework to uncover the individual agency they were or were not able to exert within the college application process. Martinez Aleman (2010) conducted a qualitative longitudinal cohort study of the friendships among college women, finding that female friendships have a positive impact on both the social and intellectual agency of participants. It also appears that diversity experiences have an impact on agency for students more broadly. Nelson Laird (2005) found that college students' experiences with diversity had an impact on the social agency they exhibited.

The related construct of self-efficacy consistently emerged in the literature on college student agency. Several studies link self-efficacy to a number of college student outcomes. DeWitz, Woolsey, and Walsh (2009) found that students' self-efficacy was a significant predictor in life purpose, which contributes to college student retention. Vuong, Brown-Welty, and Tracz (2010) found that academic self-efficacy predicted GPA and persistence among sophomore students. Dugan and Komives (2010) found that leadership self-efficacy was a significant mediator in the relationship between college experiences and leadership outcomes. 


\section{Applications of the Concept of Agency to Studies of Faculty}

While studies on college students and students more broadly have utilized agency as a framework for decades, it has only been recently that agency has emerged in the literature on faculty. It has been used by Baez (2000a) to unpack the implications of service responsibilities on minority faculty. Neumann, Terosky, and Schell (2006) used agency as a framework for understanding how recently tenured faculty moving into administrative roles navigated their new career terrains. O’Meara, Terosky, and Neumann (2008) described faculty agency as a facet of professional growth. Dean, Bracken and Allen (2009) used agency as a means for understanding the experiences of senior academic women leaders (such as CAOs). O’Meara and Campbell (2011) uncovered the individual and institutional practices that facilitated or stunted the agency of faculty in their decisions about work and family. Baez (2000b) demonstrated that in order to fully understand racism for faculty of color, individual agency and social structures must be taken into account simultaneously and without duality.

In each of these studies, the framework of agency has been used to turn the rhetoric of faculty constraint upside down in topics where there is a great paradox. For example, past studies on faculty work-life balance have focused on the vast challenges and difficulties that befall academic parents (see, for example, Armenti, 2004; Bracken, Allen, \& Dean, 2006). The O'Meara and Campbell (2011) piece focused, instead, on the factors that facilitated academic parents' sense of agency: getting what they want out of faculty life and parenthood. Similarly, several past articles have bemoaned the burdens of both faculty service-work and differentiated post-tenure demands (Neumann \& Terosky, 2003; Tierney \& Bensimon, 1996). By contrast, Baez (2000a) focused on the 
empowering outcomes of service for minority faculty and Neumann, Terosky, and Schell (2006) found the characteristics of early post-tenure faculty that facilitated career learning.

While studies on faculty have begun to venture into a new narrative on agency and professional growth, there are a few critical problems with this line of research. First, the studies lack a clear, consistent definition of agency. Baez (2000a) necessitates that agency must be over-coming resistance. O’Meara and Campbell (2011) place agency in a temporal context. Neumann, Terosky, and Schell (2006) posit that agency is intentional meaning-making and behavior, without requiring over-coming resistance in the definition. A second concern with the research to date is that no studies to date investigate the outcomes of faculty agency. Faculty sense of agency within their careers and institutions is posited to be related to their retention, satisfaction, productivity and other forms of professional growth, such as learning (O’Meara, Terosky, \& Neumann, 2008). Yet, the studies on faculty agency mainly investigate the inputs to agency rather than outcomes. Third, to date, there are few, if any, quantitative studies of faculty agency. In order to have a full understanding of the agentic process for faculty, both quantitative and qualitative methods must be utilized.

\section{The Process of Agency}

The process of agency can take the form of intentional and strategic behavior or intentional/strategic meaning-making. Take the case of Dalinda (see introduction to Chapter 2). Dalinda has plans to become a mother and pursue tenure. She has stated, intentional, and strategic goals. There are several factors that influence her sense that her goals are possible: her department chair acts as a role model for her, she has the support 
of her spouse, and she has a proven record of success. She perceives herself as competent. Unfortunately, her departmental climate is unwelcoming and even hostile to perspectives that run outside the standard. What will it mean for her to partake in an agentic process?

First, let us consider agentic behavior: Dalinda could exert agency by taking concrete steps towards realizing her goals. These could be any number of actions, and might look different for each individual. Some examples might include engaging with a support network of academic parents, having open conversations with her department chair about her plans, gaining a concrete understanding of the strengths and weaknesses of her tenure case, researching child care and parental policies, 'banking' professional capital, or reading about academic parents. There are two important facets of each of these behaviors: they are intentional and strategic. They are intentional because in each of these possible examples, Dalinda would exert her will using her own resources to empower herself. The examples are strategic because she exerts her will in a specific direction: towards facilitating her stated goal of becoming a tenured faculty member who is also a mother.

There are several examples of agentic behavior in the literature on faculty, particularly with regard to marginalized groups of faculty. For example, while there were consistent challenges that women faculty of color reported in their daily interactions, they also reported great agency to rise above the resistance (Thomas \& Hollenshead, 2001). In fact, the women faculty of color in Thomas and Hollenshead's study found agency to address lack of respect from colleagues, unwritten rules in the academy, and lack of mentoring. In another example, Gregory (2001) calls on Black scholars to be more 
strategic: “learn to say 'no' to a request when saying 'yes' would detract from one's research and offering sound reasons for one's decision" (p. 134). Lastly, hooks (2000), Collins (2000), and the Combahee River Collective (1985) described how women faculty of color banded together, created strategic partnerships, and were empowered by their common experiences.

Not all agentic process is in the form of behavior. As Neumann, Terosky, and Schell (2006) describe, agency can also be in the form of strategic and intentional perspective - the ability to make meaning of human experiences, to reflect upon them, and to re-construct them internally. Agentic perspective is a paradigm change that leads to distinct outcomes in and of itself. For example, without agency, Dalinda could feel victimized by the hostile peers in her department. She might feel trapped or isolated. Winkler (2000) describes this experience, when she details the multiple barriers for women faculty of color. By contrast, Dalinda could be in the same situation with the same incredible challenges and hostile peers, but change her way of thinking. She might recognize the challenges in her environment, acknowledge that they are unfair, and yet feel empowered to navigate this difficult terrain. She might see several options in front of her, where she could see none before. For example, she might have felt powerless to stop the negative influence of her colleagues, but when she is in an agentic, meaningmaking mindset, she might consider working strategically around her peers, creating particular partnerships to cultivate powerful relationships. Or she could decide to negate the influence of her peers by forming powerful alternative networks. Or she could decide to transform the culture of her department by trying to change the negative norms themselves. 
A few examples of agentic process as perspective appear in the literature on faculty. O’Meara and Campbell (2011) found that having a flexible set of expectations facilitated agency in creating a satisfactory work-life experience for academic parents. According to this finding, faculty made meaning of their new life circumstances (as new parents) and transformed their own expectations around work and parenthood. By contrast, keeping rigid expectations of both their parental and work lives had a stunting effect on faculty agency. Another example of these shifting expectations might be understanding and feeling empowered by options and choices. For example, a faculty member might feel stuck in one particular position or institution if she/he needed to stay in one geographic area for family. On the other hand, if a faculty member felt she could easily change her job or change her family life to meet other needs, she might be empowered. In this case, the simple process of realizing that options exist (whether or not one acts on those options) is agentic process.

Neumann, Terosky, and Schell (2006) described a meaning-making process for recently tenured faculty, which they termed 'strategic response.' They found that faculty constructed their post-tenure lives as scholars in intentional ways, often through an intentional, reflective process. For example, some faculty decided to take one focal point that matters deeply to them, and organize all of their work-life activities around this central focus. With all of the demands on faculty life post-tenure (service responsibilities, administrative roles, etc.), faculty made meaning of their experiences and internally, intentionally molded their own work-lives to foster a sense of well-being.

In a last example, Baez (2000a) brought to light the ways that faculty of color make meaning of their service obligations in ways that are personally satisfying. Baez 
found that, although faculty of color felt obligation to do service, they could also extract great joy from these experiences. In fact, participants experienced critical agency and empowerment instead of feeling burdened by service. Again, there is no action in this agentic process; it is one's perspective on service that is agentic.

Agentic process has no particular content or outcomes. The content and outcomes will entirely depend on the individual's distinct goals. Certain studies have posited that the content of agentic process must be about resisting norms (Baez, 2000a; Elder, 1994; Heinz, 1996). In these cases, individuals can only be agentic when they act outside the system, challenge the status quo, or take the road less traveled. For example, Baez (2000a) described faculty of color who were fulfilled by their service responsibilities despite service being less rewarded in the tenure system. In this respect, the agency of certain faculty members may be instigated by the resistance/barriers to success.

By contrast, other scholars who study agency state that agentic process could be any act of will that is intentional or strategic, regardless of the position in or outside of the system (Emirbayer \& Mische’s, 1998; Lerner \& Busch-Rossnagel, 1981; Neumann, Terosky, \& Schell, 2006; Sen, 1985). In this context, agentic process could be a faculty of color deciding to avoid service-work since it is under-rewarded. Here, the faculty member might have a goal of obtaining tenure and make a strategic decision to only focus on the work that is rewarded the most in academe.

\section{Factors that May Influence Agency}

In the past few decades, sociological, psychological, life span, and educational scholars have examined what factors influence human agency. These influences can be separated into societal, organizational, and individual influences. Several sociological 
and life span theorists have posited the influences of society/the state on agency (Mayer \& Schoepflin, 1988; Meyer \& Jepperson, 2000; Berger \& Luckman, 1966). While the broader societal influences are not the focus of the present study, it is critical to mention that each individual may have a different experience with or perception of society, which may have a bearing on the agency that she/he feels and exhibits.

\section{Organizational influences on agency.}

Beyond the impact of society, organizational context has been found to influence human agency. Organizational contexts can be constituted by structural facets of an organization (such as policies) or culture (such as norms). Furthermore, organizational contexts appear to be particularly important to agency with respect to faculty. According to O’Meara, Terosky, and Neumann (2008): “Although much faculty motivation is intrinsic, faculty reward systems can facilitate faculty learning and growth, or they can frustrate and damage faculty members' senses of agency to shape their own learning and distinct intellectual and professional careers and work lives” (p. 93). Similarly, Baez (2000a) demonstrated how service is perceived organizationally as a burden, but for certain faculty of color, it can be an agency-enhancing activity. Lastly, in a study on faculty agency in making work-family decisions, O’Meara and Campbell (2011) found that department norms and policies (such as flexibility and parental leave/stop the clock) influenced agency for faculty parents.

Considering that organizational norms and structures seem to matter in agentic process, it is likely that differences may exist across institutional types. Understanding faculty agency may be particularly poignant at research institutions due to the high demands, pressures on publishing, and notoriously difficult tenure processes (Schuster \& 
Finkelstein, 2006). There is also evidence that the work-life experiences of faculty, particularly faculty parents, are extremely different by institutional type (Ward, WolfWendell, \& Twombley, 2007). Additionally, the niche quality to academic departments in research institutions makes departmental norms potent in the faculty experience (Clark, 1987).

Some studies investigate how environmental factors can influence self-efficacy, thereby indirectly influencing agency and action. Heppner (1994) uses self-efficacy through a psychological lens to describe the agency of psychology graduate teaching assistants. Using Bandura's four categories of self-efficacy, Heppner (1994) found that verbal persuasion, especially from peers, was the most positively associated factor with increasing self-efficacy beliefs about teaching. Secondarily, performance attainment was positively associated with self-efficacy beliefs. The most negative impact on selfefficacy was also in the performance attainment category: students' self-perceptions of their abilities in the classroom often caused negative beliefs about their teaching abilities. Here, we can see that the external environment of both performance experiences and peer feedback can have a significant influence on the internal self-efficacy. Shechtman, Levy, and Leichtentritt (2005) also investigated environmental factors that affect self-efficacy. This study used self-efficacy and psycho-social theory to understand teacher training for a life skills course. Although this was not a study of higher education faculty, the roles of the life skills teachers are similar to faculty roles, including teacher, role model, evaluator, motivator, and protector. According to Shechtman, Levy, and Leichtentritt (2005), certain environmental characteristics, such as autonomy and challenge, promoted self-efficacy. 


\section{Organizational influences on the faculty career that may influence faculty} agency.

While few studies focused on the influence of organizational contexts on faculty sense of agency, the literature on faculty has demonstrated the importance of institutional and departmental contexts on faculty careers, more broadly (Ambrose, Hudson, \& Norman, 2005; Bode, 1999; Lindholm, 2003; Olsen, Maple, \& Stage, 1995). These studies mainly investigated the influence of organizational contexts on specific career outcomes, such as faculty satisfaction (Johnsrud, 2002), intent to leave (Johnsrud \& Rosser, 2002), and productivity (Smeby \& Try, 2005). For example, Johnsrud and Rosser (2002) surveyed all faculty in a ten campus system of higher education in a western state, using a multi-level structural model for analysis and found that the individual perceptions of faculty work-life, faculty professional priorities and rewards, administrative relations and support, and the quality of benefits and services had a substantial effect on faculty morale and intent to stay.

While I could not include all organizational contexts in this study, I focused on six specific organizational contexts: work-life climate, person-department fit, professional development resources, perceptions of the tenure process, transparency, and collegiality. Each of these contexts has been linked to important faculty outcomes, and as a result, may also be likely to influence faculty agency in career. A positive work-life climate has been found to facilitate success for faculty, especially women faculty and faculty parents (Mason \& Eckman, 2007; Mason \& Goulden, 2004; O’Meara \& Campbell, 2011). Mason and Goulden (2004) found that tenured women faculty were less likely than men to be married with children and more likely to agree that they had 
fewer children than they had wanted. Additionally, tenured women with children do more work (housework and scholarly work) than men with children, single men, or single women. Studies like Mason and Goulden's demonstrate the importance of a positive work-life climate (such as flexibility, parental leave policies, supportive climates) for the careers of women faculty and faculty parents.

Person-department fit is another organizational context that has been highlighted in the literature on faculty. Lindholm (2003) defines person-organization fit as the "congruency between the values, interests, needs, and abilities of an individual and corresponding characteristics of the organization within which he or she works" (p. 128). This kind of congruency also represents an environment where there is a mutual sense of valuing - for example, a faculty member feeling that the department values his or her scholarship, teaching, and service commitments. In interviews of faculty, Lindholm (2004) found that faculty were attracted to academic careers, in part, because of the fit they felt with the academic environment. Lindholm (2008) also found that organizational fit was related to faculty vitality. Hagedorn (1994) found perceived support of colleagues related to stress and job satisfaction. Olsen, Maple, and Stage (1995) also found that feeling recognized by colleagues was related to job satisfaction.

Professional development resources (e.g. administrative support for research, grant support, and funds for travel) have been linked to important faculty outcomes. Hagedorn (1994) found that administrative support was related to stress level and job satisfaction for faculty. Similarly, Rosser (2004) found that administrative support and professional development resources were influential in faculty satisfaction. Lindholm (2003) reported that institutional resources were linked to a feeling of fit in a department. 
Career advancement is an important aspect of faculty life, and as such, faculty perceptions of the promotion and tenure process seem to play a role in faculty success. Scholars who study tenure have recommended an overhaul of the tenure process, by recognizing multiple forms of scholarship, greater flexibility in time to earn tenure, and increased clarity and fairness of the tenure and promotion processes (O’Meara \& Rice, 2005; Rice \& Sorcinelli, 2002). Additionally, Cipriano (2011) describes the importance of transparent leadership regarding the tenure process for faculty.

While clarity and transparency is important in the tenure process, transparency of decision-making also seems to play a role in faculty satisfaction and success. Cipriano (2011) describes the importance of transparent decision-making for faculty satisfaction and collegiality. Daly and Dee (2003) found that communication openness, a construct related to transparency, was positively associated with intent to stay. Additionally, recent research from an NSF ADVANCE grant at the University of Michigan demonstrates the importance of transparency (i.e. making information available and easy to find) in faculty retention and enabling faculty to thrive in their careers (Waltman \& Hollenshead, 2005).

The final organizational context in this study is collegiality. Collegiality has been documented as an important facet of academic environments for faculty by several prominent organizational theorists in higher education (Berquist, 1992; Birnbaum, 1988). In a study of universities as organizations, Birnbaum (1988) stated that collegial organizations treat employees as people rather than job descriptions, offer a more equal power structure among staff, and utilize consensus-building decision making, which leads to employees feeling valued and more likely to be retained and committed to the institution. Junior faculty and women faculty indicate a particular desire for collegial 
environments in academe (Ambrose, Huston, \& Norman, 2005, Bode, 1999; Boice, 1992; Neumann, 2009; Trower \& Chait, 2002). Cipriano (2011) underscores the importance of collegial leadership styles for successful departments in higher education. Collegiality and networks have also been linked to scholarly legitimacy and productivity (Creamer, 1998). Likewise, Lindholm (2008) found that collegiality, value congruence, and available resources all contributed to a perceived organizational fit for faculty at one research institution.

\section{Individual influences on agency.}

While this study focuses on organizational influences, the O’Meara, Campbell, and Terosky (2011) framework acknowledges that certain there are certain influences on agency that reside within the individual — internal resources, such as self-efficacy and personal histories. According to Bandura (1982), "Perceived self-efficacy is concerned with judgments of how well one can execute courses of action required to deal with prospective situations" (p. 122). Bandura posits that agency is a mediator of self-efficacy and action: "people often do not behave optimally, even though they know full well what to do. This is because self-referent thought also mediates the relationship between knowledge and action.” (p. 122). Bandura conducted an experimental study where he asked participants to assess their self-efficacy and then measured their performance on various tasks. In another facet of the Bandura study, he assigned a self-efficacy perspective to participants (by telling them or making them feel more or less adept at a task) then measured their performance on tasks. He found that participants increased self-efficacy when they gained new skills or had an experience that disconfirmed misbeliefs about an inability to complete a task or to master a fear. By contrast, if, while 
completing a task, a participant was confronted with information that would suggest a personal limitation in their ability to complete, their self-efficacy would decline even if they succeeded in the task.

Some scholars have found that aspects of personal histories, or stories, impact one's sense of agency. It appears that influential people in one's life have a particular influence on agency. McAdams, de St. Aubin, and Logan (1993) describe how an internal conceptualization of important life characters could exhibit agentic (masculine) or communal (feminine) traits. These internalized characters assist in the meaningmaking of one's life story. Additionally, personal champions, such as role models, seem to impact one's sense of agency. With respect to faculty agency, O’Meara and Campbell (2011) found that faculty parents who had positive role models of other faculty parents exhibited more agency in achieving their own work-family goals.

Lastly it appears that agency is constructed within a temporal context (Emirbayer \& Mische, 1998; O’Meara \& Campbell, 2011). Related to faculty agency, O’Meara and Campbell (2011) found that the past, current, and future perceptions of professional capital affected agency in taking parental leave. For the purposes of the present study, faculty agency, and consequently, faculty outcomes (satisfaction, professional growth, promotion) may depend on the self-perception of a faculty member's past, current, and future professional capital.

\section{Agency and gender.}

Gender seems to play a role in both the definitions and outcomes of agency. Interestingly, two separate studies in different disciplines define agency as a masculine concept or trait (Ackerman et al., 2000; McAdams, de St. Aubin, \& Logan, 1993). In 
each of these studies, the "masculine" trait of agency is contrasted with a "feminine" trait of communality. For example, according to McAdams, de St. Aubin, and Logan, masculine agentic characters:

seek to conquer, master, control, overcome, create, produce, explore, persuade, advocate, analyze, understand, win. They are described by such adjectives as aggressive, ambitious, adventurous, assertive, autonomous, courageous, clever, courageous, daring, dominant, enterprising, forceful, independent, resourceful, restless, sophisticated, stubborn, and wise, among many others. Such characters may be considered 'masculine' in the sense that they personify some characteristics that are stereotypically associated with the male sex role (p.134).

By contrast communal characters in McAdams and Associates' study are:

oriented towards love and intimacy, these are characters who seek to unite with others in passionate embrace, who love and care for others, who nurture, cooperate, encourage, communicate and share with others... They are described by adjectives such as affectionate, charming, altruistic, enticing, gentle, kind, loyal, sensitive, sociable, sympathetic, and warm, among many others. As they personify stereotypically feminine sex roles, such characters can be considered, 'feminine,' but they need not be female." (p. 148).

Considering that agency has been defined in stereotypically gendered terms, it is not surprising that some studies have indicated gendered outcomes of agency. For example, Ackerman et al., (2000) used statedly gendered definitions of agency, and consequently found that agency was a stronger predictor of generativity for young adult men and communion was a stronger predictor for young adult women.

While Clausen (1991) did not use a gendered definition of agency, he did find gendered findings. Clausen (1991) found that for men, educational attainment was correlated more strongly with planful competence (i.e. agency) than either SES or IQ. Likewise, male occupational attainment was correlated more strongly with planful competence than either SES or IQ. By contrast, for women, educational attainment was more substantially related to SES and IQ than planful competence, and the self- 
confidence component was not significant. Planful competence was also non-significant as a predictor of occupational attainment for women. Additionally, while Clausen found a relationship between agency and life satisfaction, this finding was also gendered. For men, agency was not related to life satisfaction, but agency did seem to matter for women in satisfaction throughout the life course.

Considering that certain scholars perceive agency to be a gendered term and some outcomes of agency have been found to be gendered, the link between agency and gender warrants further examination. Neumann, Terosky, and Schell (2006) state this call for further research in their article, asking how the strategic responses and agency posttenure vary by gender, race, and other background characteristics.

\section{Potential Outcomes of Faculty Agency}

\section{Individual outcomes.}

Agency contributes to a variety of meaningful individual outcomes, including professional growth, educational/occupational attainment, and life satisfaction. First, while the agency perspective on faculty careers has only emerged recently in the literature, there is already some evidence that agency is linked to faculty learning and strategic response. According to Neumann, Terosky, and Schell (2006), "Both agency and learning require a person - as agent and learner - to attend to the voice of her or his internal meaning-making. Thus agency can be viewed as supportive and constitutive of a constructivist vision of learning" (p. 95). In a three year, longitudinal, qualitative study of post-tenure faculty, Neumann, Terosky, and Schell found that there were three agentic strategies in post-tenure faculty learning: putting it together (integrating parts of one's work-life), containment (strategically restricting, selecting, and optimizing the work-life 
tasks), and invoking design (organizing and cleaning one's environment to conserve energy for important tasks). The strategies helped the faculty member adapt to the new expectations of post-tenure faculty life, and consequently, influenced their learning processes and career satisfaction. In this same study, Neumann, Terosky, and Schell established that "agency, lies at the heart of strategic response" (p. 93).

Additionally, there has been some evidence that planful competence (i.e. psychological term for agency) has an influence on educational and occupational attainment. In a very compelling, 40 year longitudinal study of lifespan theories, Clausen (1991) conducted interviews, observations, tests, and inventories of more than 200 children from Berkeley, California. Clausen found that agency did have an impact on educational and occupational attainment, but that this influence varied by gender (see section on agency and gender). While this is the only known study linking agency to educational and occupational attainment, the compelling nature of this study warrants future research.

Certain social science studies have linked satisfaction, well-being, and developmental outcomes with agency (Ackerman et al., 2000; Alkire, 2005; Clausen, 1991). According to the Ackerman et al. (2000) study, agency predicted generativity in both young and mid-life adults, which predicted positive affectivity, satisfaction with life, and work satisfaction. Clausen (1991) also found a relationship between agentic planful competence and life satisfaction, although this relationship was mediated by gender. Alkire (2005) found that individuals in difficult social contexts (such as extreme poverty) were able to enhance their sense of well-being when they acted with agency. 
Lastly, it is important to acknowledge the possibility that agency could produce negative outcomes. For instance, some agency can be ignored or accommodated with little feedback to the workplace or influence on the individual or organization. If the workplace rejects this behavior, or there is significant backlash it can discourage future agentic behavior, and encourage an individual to withdraw from that workspace. In such cases, agency can be framed as an individual acting outside their station and it could encourage them to be treated furthermore as an outsider (Gomez-Mejia \& Balkin, 1992).

\section{Social outcomes.}

While the process of agency acts mainly on an individual level, individuals acting with agency can produce collective and social change (Alkire, 2005; Sen, 1999; Alsop \& Heinsohn, 2005). Democratic participation is a very basic example of this process: many individuals make an intentional choice of which candidate best represents their needs and takes an action by voting (i.e. acts with agency). The result is two-fold. Individually, the voter might feel empowered regardless of the social outcomes (whether the candidate is elected). Socially, if enough individuals act, social change may be fostered either by a collective sense of empowerment (regardless of the outcome of the election) or through an intended social outcomes (the candidate is elected). Additionally, Rusch and Wilbur (2007) found that human agency could enact organizational change in a case study of a College of Business going through an accreditation process.

The collective, social outcomes are outside of the scope of the present study. However, they are an important facet of the framework on faculty agency. From an institutional perspective, social change outcomes might mean that a group of individuals 
who act with agency could transform departmental cultures or promote a collective sense of well-being.

\section{Measuring Agency}

While the construct of agency is not new in the sociological, psychological, or life span literature, the evidence about the contributing factors of agency, the outcomes of agency, and the very existence of agency in and of itself is surprisingly absent. In the present literature review, there are very few quantitative or empirical studies that investigate the construct of agency. Many of the studies and articles are based simply on postulating or theorizing.

Several prominent scholars on the topic of agency have noted this problem. Meyer and Jepperson (2000) charge that “... there is more abstract metatheory about 'actors' and their 'agency' than substantive arguments about the topic” (p. 101). Additionally, according to Emirbayer and Mische (1998), "the term agency itself...has all too seldom inspired systematic analysis, despite the long list of terms with which it has been associated" (p. 962). Similarly, Marshall (2000) notes, "The term has increasingly popped up in the sociology of aging and the life course, but rarely is it defined or explored in great detail. Even more rarely is agency measured" (p. 2). Some scholars have even given up on the task as impossible. Mayer and Schoepflin (1988) determine that it is impossible to measure either quantitatively or empirically: "an assessment of the role of the state in shaping individual lives is primarily an analytical and theoretical task" (p. 191).

There are three main challenges with the measurement of the construct of agency. First, there has not been one agreed upon definition of agency (see section on agency 
defined). There appear to be two dichotomies of definitions of agency in terms of how it is measured. First, some studies measure intentions, while others measure behavior. Certain, mainly qualitative, studies have attempted to measure intentions, reflection, and meaning-making through interviews (O’Meara \& Campbell, 2011; Neumann, Terosky, \& Schell, 2006). Others, attempt to measure intentional behavior (Dean, Bracken, Allen, 2008; O’Meara \& Campbell, 2011) or behavioral outcomes of agency, such as time commitment or academic achievement (Ambrose, 2010; Ray, 2008). The second dichotomy is whether agency is simply strategic will or requires social resistance. Several studies require a social resistance component to the measurement of agency (Baez, 2000a; Shek, 2010) or an ability to navigate one's environment (Blanchet-Cohen, 2006). Others do not see resistance as a feature of agency, and measure only intentionality (Clausen, 1991).

A second challenge in the measurement of agency is separating the many aspects of intention, meaning-making, and behavior. For example, if I can picture myself doing agentic behavior, do I have agency? If I am socially constrained, but believe that outside of my current situation, I could meet my goals, do I have agency? If I perceive that I have agency, but others do not, do I have agency? If I act in an agentic manner, but do not perceive it as so, do I have agency? How are all of these elusive constructs measured?

The third challenge related to measuring agency is whether agency is best measured through subjective (i.e. perceptual) or objective (directly measurable) measures. Several objective measures have been used as a proxy for agency behavior. However, objective measures require that a specific agentic outcome or behavior is 
specified. A limitation of objective measures is that they assume that a person who exhibits an outcome, such as educational attainment (Alkire, 2005), academic achievement (Ambrose, 2010), or income over which women have decisive spending authority (Alkire, 2005), has agency. Yet, it may be possible to achieve outcomes without exhibiting agency as defined by intentional and strategic behaviors or meaningmaking. The present study views these objective measures as outcomes of agency rather than agentic process itself.

By contrast, subjective measures offer the ability to understand motivations, perceptions, and intentions, which are all components of the agentic process. Alkire (2005) conducted a broad review of the most widely accepted quantitative, subjective measures of agency (i.e. survey instruments). Alkire highlighted instruments that have been validated and have wide reaching applicability. The first is Schwartz's measure of Universal Human Values. One of the values that Schwartz measures is called 'selfdirection,' which closely mirrors the construct of agency. Schwartz uses two types of measures: a values questionnaire, which asks participants to rate the importance of various values and how that value applies to their life. The values that correspond to 'self-direction' include freedom, creativity, independence, choosing own goals, and curiosity. The second measure is called the Portrait Values Questionnaire, which was intended for younger or less educated populations. The PVQ presents brief descriptions of different individuals - their motivations, aspirations, and goals. It then asks the respondent how much the individual presented in the portrait is like themselves. Another measure discussed by Alkire (2005) is the World Values Survey, which (in a number of formats) asks respondents to rate how important certain values are or asks them about 
which characteristics are most like them (ex. I am good at getting what I want). A third measure that Alkire reviewed is Ryff's six domains of psychological well-being: selfacceptance, purpose in life, environmental mastery, personal growth, positive relations with others, and autonomy. Alkire posits that environmental mastery and autonomy relate to agency.

Another set of instruments that Alkire (2005) reviewed was about agency with respect to specific domains instead of a global measure of agency. For example, Bandura's (1982) theory of self-efficacy measures an individual's self-perception of agency on several specific tasks. In another example, the self-determination theory (SDT) of Ryan and Deci (2000) investigates autonomy by asking participants to rate their degree of autonomy (with their defined autonomy scale) on various practices.

There are some weaknesses to using subjective measures to measure agency (or any other construct). The primary weakness is that self-report or perceptual ratings can be biased by one's internal self-conceptions (e.g., self-confidence) or external factors (e.g., social desirability; Alkire, 2005; Simone, Campbell, \& Newhart, 2011). This weakness might cause someone who is over confident to rate their agency as higher than it would be rated by an outsider; or it could cause someone to rate themselves as less agentic if agency behavior is contrary to their culture (e.g., women or Asian faculty might perceive autonomy or discussing accomplishments as a negative trait). Yet, it may also be that agency is in the eye of the beholder-so belief in one's own agency is more important that an outsider's view. This lends to an epistemological discussion on the nature of knowing that is outside the scope of this research. 


\section{The Model: O’Meara, Campbell, and Terosky (2011)Framework of Agency in Faculty Professional Lives}

The present study is guided by the O'Meara, Campbell, and Terosky (2011) framework of Agency in Faculty Professional Lives (Figure 2). The O’Meara, Campbell, and Terosky framework represents findings from a comprehensive review of sociological, psychological, and organizational literature on agency (see, for example, Alkire, 2005; Bandura, 1982; Clausen, 1991; Elder, 1994; Emirbayer \& Mische, 1998; Marshall, 2005). Below, I detail each part of the model and provide examples of how it works in the professional lives of faculty in higher education.

\section{Agentic process.}

The O’Meara, Campbell, and Terosky (2011) framework postulates that there are two forms of agentic process. The first is strategic and intentional behavior. The framework postulates that agency is, as Amartya Sen states, (1985, p. 203) "the ability to act on behalf of goals that matter to [oneself]." Extending this understanding, sociologists have observed that individuals have free will and can influence their own life trajectories or what happens in them (Clausen, 1991; Elder, 1994, 1997; Lerner \& Busch-Rossnagel, 1981; Marshall, 2005; Neumann, Terosky, \& Schell, 2006). As such, a key aspect of agency in the framework is that it is strategic and intentional. This may be strategy in crafting ways to take teaching seriously as has been studied by Terosky (2005), to develop work strategies to balance workload and advance in one's career, to pursue community engaged scholarship when it is not rewarded in the workplace, or to take parental leave despite the fact that it might “mommy track" you in your career (O’Meara 
\& Campbell, 2011). These last examples provide a glimpse into agency in action as described in the framework of agency in faculty professional lives.

According to the O'Meara, Campbell, and Terosky framework, a second form of agentic process is agency perspective; the ability to make meaning of human experiences, to reflect upon them, and to re-construct them internally (Neumann, Terosky, Schell, 2006). The framework posits that agentic process is a key aspect of individual well-being (Alkire, 2005). Agency has intrinsic value, and is one dimension (among others, such as friendship, happiness, health) of an individual's well-being. Take the example of a faculty member has a goal of being tenured while having a satisfying family life and takes a strategic perspective towards achieving this goal. This agentic process is an aspect of the faculty member's well-being - the freedom that the faculty member feels to take concrete actions towards a goal that matters to her/himself. Well-being in the form of agency is a sense of self that an individual has some control over her/his life path or career trajectory.

\section{Agentic content.}

Turning from agency as a process, to what it is about, according to the O'Meara, Campbell and Terosky (2011) framework for agency in faculty professional lives, agency has no particular content- the content will entirely depend on the individual's distinct goals. For one faculty member, it may be that her goal was to achieve tenure by any means necessary, and as a result, she focuses exclusively on her scholarship and the quantity of publications, often at a cost to her teaching and personal life. By contrast, another faculty member may decide that his main goal in his career is to help students and be a good father to his children. He places a lot of emphasis on his teaching and 
being present for his family, and switches institutions to find colleagues that share his values. In both of these examples, the faculty members were agentic in their mindset and actions, even though their goals were different and their outcomes were different.

Theorists have observed that agency is often exercised against some kind of bias or countervailing force or norms such as a reward system, ideal worker assumptions, time constraints, ambiguity in roles, and societal expectations and habitus (Elder, 1994; Heinz, 1996). In these cases, individuals are agentic when they act outside the system, challenge the status quo, or take the road less traveled. For example, Baez (2000a) described faculty of color who were fulfilled by their service responsibilities despite service being less rewarded in the tenure system. In this respect, the agency of certain faculty members may be instigated by the resistance/barriers to success. If the resistance is an impediment to one's desired career path (e.g., tenure), a faculty member might exert agency by either working towards transforming the resistance or accommodating to it.

Yet, the O’Meara, Campbell, and Terosky (2011) framework states that agency can occur simply as individuals exert their will, make choices, and act in self-directed ways toward desired goals (Emirbayer \& Mische’s, 1998; Lerner \& Busch-Rossnagel, 1981; Neumann, Terosky, \& Schell, 2006; Sen, 1985). In this context, agentic process could be a faculty member of color deciding to avoid service-work since it is underrewarded. The faculty member might have a goal of obtaining tenure and make a strategic decision to only focus on the work that is rewarded the most in academe. Here, the agency is exerted within the tenure system instead of resisting the sytem.

Lastly, because individuals define their own goals, agency could be exhibited towards both positive and negative ends. For example, a sexist faculty member might set 
a goal of helping his department become more prestigious. In doing so, he believes that only "mainstream" research in the sciences should be rewarded. Additionally, he might bully women or try to control their behavior, believing that they do not bode well for the "excellence" of his department. In this case, the faculty member is agentic by taking intentional and strategic actions towards his goal. While this kind of agency is exhibited toward questionable objectives, it is agentic nonetheless.

\section{Influencing factors.}

The O’Meara, Campbell, and Terosky (2011) framework posits that societal, organizational, and individual contexts set the stage for the agentic process. Agency is always revealed in a particular social space or social context; the scaffolding of time, constraints, social and historical meaning is never absent. An individual always exercises agency in such "rooms" of meaning, and therefore agency has been described as a navigational strategy through that space, and as a way of making meaning of social spaces. As such their social contexts will always be a powerful set of influencing factors on sense of agency.

\section{Societal.}

In the definition of agency proposed by O’Meara, Campbell, and Terosky (2011), a faculty member's societal context influences one's sense of agency. While the societal factors that shape agency were not included in the current study, they provide important context to understanding the agentic process. Sociologists who study agency generally focus on the macro-level influences on human agency, such as the impact society has on the individual or on a group of individuals in a collective. Sociologists such as Emirbayer and Mische (1998), and the most prominent early sociological theorists, such 
as Pierre Bourdieu and Anthony Giddens, often considered the interplay between person and environment or society. Certain definitions of agency in sociology seem to posit that individual action is entirely constituted by external societal factors (Berger \& Luckman, 1966; Meyer \& Jepperson, 2000).

While the framework attributes agency to the individual, it is also socially constructed. Faculty members' abilities to activate agency, garner power, and exert agency will relate to the resources available for their so doing (Marshall, 2005). Social stratification, for example, has been found to influence individuals' access to contextembedded resources and privileges (Elder, 1994; Neumann, Terosky, \& Schell, 2006). For example, individuals will be influenced by their own personal identities and the meanings those identities hold in society and in work places. Such identities include generation and age, race and ethnicity, gender, sexual orientation, social class, and various accumulated social, political and human capital. A faculty member's status in a research university as untenured or new to a department for example, may influence faculty sense of entitlement to certain work resources or feelings of agency in taking advantage of them.

\section{Organizational.}

According to the O'Meara, Campbell, and Terosky (2011) framework on faculty agency, one of the key contributors to an individual's sense of agency will be the climate and organizational culture of his/her workplace. Organizational contexts that influence agency can be constituted by structural facets of an organization (such as policies) or culture (such as norms). The few studies of organizational influences on agency in higher education demonstrate that organizational context can either facilitate or frustrate 
faculty members' senses of agency in their careers and work lives. Baez (2000a) demonstrated how requests for faculty of color to engage in service is perceived organizationally as a burden, but for certain faculty of color, it can be an agencyenhancing activity. O’Meara, Terosky, and Neumann (2008) considered the importance of agency to faculty professional growth and the ways in which identity, appointment type, work contexts, and reward systems may contribute to faculty sense of agency in their workplaces and careers. O’Meara and Campbell (2011) found that department norms and policies (such as flexibility and parental leave/stop the clock) influenced agency for faculty parents.

\section{Individual.}

The O’Meara, Campbell and Terosky (2011) framework describes several possible influences on agency that reside within an individual, including interior resources (self-efficacy and self-awareness), identities in temporal context, having desired goals and outcomes, and awareness of possibility and familiarity with context. While these individual influences were not included in this study, they do provide important context for understanding faculty sense of agency according to the conceptual framework. I discuss each individual influence, according to the O'Meara, Campbell, and Terosky framework, below.

\section{Interior resources (self-efficacy and self awareness).}

The O'Meara, Campbell, and Terosky (2011) framework posits that internal resources, such as self-efficacy and self awareness, influence a faculty members sense of agency. According to Bandura (1982), "Perceived self-efficacy is concerned with judgments of how well one can execute courses of action required to deal with 
prospective situations' (p. 122). Bandura posits that self-efficacy is a mediator of knowledge and action: "people often do not behave optimally, even though they know full well what to do. This is because self-referent thought also mediates the relationship between knowledge and action.” (p. 122). As such, self-efficacy becomes a critical influencing factor: individuals who feel that they can do something are more likely to assume agency than those who do not.

Similarly, the faculty agency framework posits that a prerequisite for agency is self-awareness (O’Meara, Campbell, \& Terosky 2011). An individual must have an understanding of her/his strengths and weaknesses in order to make goals, take strategic actions, or make meaning of one's experiences. For example, without self-reflective abilities, a woman faculty member might choose a goal that was unrealistic or undervalues her skills. For example, she might set her goal as publishing in three top tier journals in her first year. This goal would only be appropriate if she knew she had the required skills and resources (e.g., quality of writing, time, data, and innovation). Creating this goal necessitates the ability to take a personal inventory of what is possible, what is likely, and what would be too difficult. Even if she chose an appropriate goal, how could she take strategic steps towards the goal without understanding her personal assets and liabilities? She needs a strong bedrock of self-awareness in order to capitalize on her strengths and develop (or minimize) her weaknesses. For example, a faculty member might be a great big picture thinker, but lack a detailed eye. She might strategize to get tenure through an innovative research agenda. If she is self-aware, she might also decide to choose a co-author, confidant, or advisee who excels in being detailed, assisting with checking numbers, formatting, and editing. 


\section{Identities in temporal context.}

O’Meara, Campbell, and Terosky (2011) identified that individual identities in a temporal context shape faculty sense of agency. Emirbayer and Mische (1998)

introduced a temporal context to the construct of agency that relates to lifespan theory: agency is based on past, current, and future plans, experiences, and possibilities. One's agency could change depending on the temporal context. Emirbayer and Mische (1998) further theorize agency as, "the temporally constructed engagement by actors of different structural environments-the temporal-relationship contexts of action-which, through the interplay of habit, imagination, and judgment, both reproduces and transforms those structures in interactive response to the problems posed by changing historical situations (p. 970)." For example, a faculty member could be planning on engaging in community engagement and public work and feel agency to do so, but then feel less agency when they go through their third year review and project that if they do this they may not get tenure (O’Meara \& Campbell, 2011).

Furthermore, O’Meara, Campbell, and Terosky (2011) state that individual identities and sense of professional capital influence the agentic process. Various aspects of individual identities (such as race, gender, sexual orientation, religion, socio-economic status, etc.) are imbedded in social location. This social construction influences the resources that are accessible to individuals, and in turn, faculty agency. O'Meara and Campbell (2011) found that women faculty felt certain assumptions were made about their seriousness as scholars based on their gender and decisions to take parental leave, which in turn influenced their sense of agency in making satisfying work family balance decisions. Additionally, O’Meara and Campbell found that faculty who were confident 
in their level of professional capital (e.g., had prestigious post-docs, had tenure) felt more control over their work-family decisions.

\section{Having desired goals and outcomes.}

According to O’Meara, Campbell, and Terosky (2011) faculty must have desired goals in order to engage in an agentic process. Life span theories on agency focus on the individual differences in agency (planful behavior) and outcomes (life trajectories; Clausen, 1991; Elder, 1994; Mayer \& Schoepflin, 1988). As such, these theories emphasize the intentionality of agency — that it occurs when individuals have a sense of desired goals and then act or make meaning around them. Individuals need a direction for their will. It would be impossible to act strategically or to make meaning of one's life without specific, stated goals or intentions. For example, in order for a faculty member to exhibit agency in career, she/he will need to conceptualize what a satisfactory faculty career might look like: Does it integrate family? Does it give back to a community? Does it mean leadership within higher education? Does it make a large salary? Once the goal is in place, the agentic process can take flight.

\section{Awareness of possibility and familiarity with context.}

According to O'Meara, Campbell, and Terosky's (2011) framework on faculty agency, knowledge is a powerful producer of agency. Before an individual can formulate a goal, strategize to meet that goal, make meaning of that goal, or act on it, one must be aware that the goal exists. For example, O’Meara and Campbell (2011) found that many women faculty parents lacked successful role models. In fact some women were told that it is impossible to create a work-life balance on the tenure track. Without role models or with negative role modeling, a woman faculty member might never even consider the 
possibility of having children or of succeeding on the tenure track. Further, awareness is a powerful aspect of the agency framework because it is changeable - raising awareness of options and possibilities could be done at the individual, departmental, or institutional level. In the previous example, policies could be in place, networks of faculty parents could provide guidance, or published research could all be sources of inspiration and awareness of the possibility of creating a satisfying work-family experience.

Likewise, the faculty agency framework states that knowledge of one's context can provide a vantage point that yields agency behavior (O’Meara, Campbell, \& Terosky, 2011). For example, a faculty member in her first year in a tenure track position, she would start with no knowledge of context and each action might seem tentative: with whom should I collaborate? Where are the campus resources? What are the campus policies? What politics must I navigate in order to get things done? With more experience and more knowledge of one's institutional and departmental context, faculty will likely have greater ease of making meaning of their goals and taking action upon them.

\section{Outcomes.}

Much like the O’Meara, Campbell, and Terosky framework posits that agency is influenced by factors on individual, organizational, and societal levels, so are the outcomes of agency enacted on three levels. The framework notes social science literature that has explored the consequences of individuals acting with agency. On an individual level, Alkire (2005) notes that acting with agency is a key component of wellbeing and a contributor to well-being (Alkire, 2005). The framework posits that for 
faculty, this well-being could take many forms, for example greater satisfaction in job, productivity, organizational commitment, and professional growth.

On an organizational level, the O’Meara, Campbell, and Terosky (2011)

framework posits that agency behavior and perspective can catalyze organizational learning. Some agency can be ignored or accommodated with little feedback to the workplace or influence on the individual or organization. In healthy organizations, it may be that the organizations are open to adapting and accommodating to the perspectives and behaviors of agentic faculty. For example, Rusch and Wilbur (2007) found that human agency could enact organizational change in a case study of a College of Business going through an accreditation process. By contrast, if the workplace rejects the agentic behavior, or there is significant backlash, it could discourage future agentic behavior, and encourage an individual to withdraw from that workspace. In such cases agency can be framed as an individual acting outside their station and it could encourage them to be treated furthermore as an outsider.

The O’Meara, Campbell, and Terosky (2011) framework also argues that both individual and collective agency can produce social change outcomes (Alkire, 2005). For example, an individual voting or speaking out in a public venue could be construed as displays of agency and be instigators of social change. As part of a collective, such as women acting in leadership roles in the STEM fields, or faculty involved in engaged scholarship going up for tenure, the act of agency can contribute to social change within a discipline.

By using the O’Meara, Campbell, and Terosky (2011) framework for agency in faculty professional lives, the present study investigated the influence that organizational 
factors had on faculty agency, whether agency influences faculty career outcomes, and how the framework of faculty agency manifests differently by gender.

\section{Conclusion}

New theoretical tools are necessary in order to understand the new faculty landscape and facilitate faculty success in the $21^{\text {st }}$ century higher education context. Understanding barriers and highlighting challenges, termed the 'narrative of constraint,' no longer meets the needs of faculty. A framework on faculty agency presents a fresh perspective from which to view contemporary faculty issues.

The construct of agency has been an elusive term to define, with a range of definitions presented by scholars. Psychological, sociological, life span, and organizational theories all contribute to our understanding of agency. Definitions vary in terms of who/what controls agency (individuals, society, co-constitution), the content of agency (overcoming resistance or any exertion of will), the process of agency (behavior, intentions, meaning-making) and whether or not agency is a natural part of humans possessed equally by all or a psychological trait that can be varied or exhibited in deferent degrees by each individual.

Due, in part, to the inconsistencies of agency definitions, agency has rarely been measured in empirical studies. Instead, many studies consider agency in a theoretical manner and then apply it to empirical findings without actually attempting to measure the agency itself. It is difficult, if not impossible, to measure something that has not been well-defined. Other measurement challenges are present. Even when agency has been defined in a study, it is often difficult to separate it from other constructs, such as selfefficacy or satisfaction. Additionally, there are problems with measuring agency in 
subjective manners (due to various response biases) and objective ways (because they usually measure outcomes of agency rather than the agency itself).

The studies that have attempted to investigate agency have found that there are several individual, organizational, and societal influences. Other studies have investigated the effects of agency, and found associations with several professional and life outcomes, such as well-being, satisfaction, strategic response, educational attainment, among others.

The present study viewed agency as an individual trait that can be influenced by a number of factors (including individual, organizational, and societal). Agency could be exerted toward any goal that an individual chooses, as long as it is strategic and intentional behavior or perspective. This study assumed that some individuals naturally have more agentic capabilities than others, but that all humans possess agency in some capacity. Likewise, agentic process is alterable.

If agency is alterable, it would be of great interest to institutions, administrators, and policy-makers to ascertain whether certain organizational factors facilitate faculty sense of agency. Likewise, it would be critical to understand whether agency is associated with important faculty outcomes, such as intent to stay, satisfaction, and productivity. Additionally, agency is posited as being particularly important to overcoming resistance. As a result, agency might be a particularly useful tool for the success of women faculty, faculty of color, or other marginalized groups of faculty. Considering that a framework of agency has the potential to contribute to the understanding of the contemporary faculty landscape, it appears that an empirical investigation of the influences on and outcomes of agency for faculty careers is 
particularly poignant. This study investigated the organizational influences on and career outcomes of agency in tenure track faculty at the University of Maryland, and how agency manifested differently for women and men faculty. 


\section{Chapter 3: Methods}

In this chapter I review the purpose of this study and the research questions. Next, I describe how I used the theoretical framework on faculty agency by O'Meara, Campbell, and Terosky (2011) in the research design and data analysis for this study. Then, I describe the site of the study, the University of Maryland, and the sample. Following, I present the procedures, including the survey instrument, survey administration, and analysis for the study. The analytic plan includes a description of the data exploration, missing data analyses, analytic approaches for research questions 1, 2, and 3, and the criteria for fit and invariance. Finally, I consider the strengths and limitations of the present study.

\section{Purpose of the Study and Research Questions}

The purpose of this study was to understand agency in faculty careers and worklives and how agency manifests differently by gender. Using the O'Meara, Campbell, and Terosky (2011) framework on faculty agency, this study examined the organizational influences (tenure process, work-life climate, person-department fit, professional development resources, transparency, and collegiality) on faculty agency (agentic perspective and behavior) and the outcomes of faculty agency (intent to stay, job satisfaction, and perceived productivity). By investigating organizational factors that influence faculty sense of agency, this study provided insight into how colleges or universities might enhance the agency of individuals. Additionally, this study sought to provide a greater understanding of whether agency matters in important faculty career outcomes. Finally, this study determined if and how the model of agency differed for women and men faculty. The following research questions guided this study: 
Research Question 1: What organizational factors influence faculty agency?

Research Question 2: What faculty career outcomes are related to agency?

Research Question 3: How do the influences of and outcomes of agency differ for men and women faculty?

\section{Conceptual Framework}

The conceptual framework is guided by the O'Meara, Campbell, and Terosky (2011) framework of Agency in Faculty Professional Lives (Figure 2). The O’Meara, Campbell, and Terosky framework represents findings from a comprehensive review of sociological, psychological, and organizational literature on agency (see, for example, Alkire, 2005; Bandura, 1982; Clausen, 1991; Elder, 1994; Emirbayer \& Mische, 1998; Gonzales, 2012; Marshall, 2005). O'Meara, Campbell, and Terosky (2011) describe the agentic process as intentional and strategic behavior or perspective. Sociological and higher education literatures describe the agentic process as both intentional behavior and perspective-taking (see, for example, Alkire, 2005; Baez, 2000a; Marshall, 2005;

Neumann, Terosky, \& Schell, 2006). For example, Neumann and associates describe agency in a mindset that some Associate Professors acquire that allows them to continue their scholarly learning in the face of more demands and service commitments.

The O’Meara, Campbell, and Terosky (2011) framework also posits that agency is goal specific, but can be toward any personal goal. The literature has examined agency toward several specific ends, such as career advancement, work-life integration and balance, pursuit of learning and scholarship, full institutional citizenship (voice in shared governance), and managing teaching and service (see, for example, Neumann, Terosky, \& Schell, 2006; O’Meara \& Campbell, 2011; O’Meara, Campbell, \& Terosky, 2011; 
Terosky, 2005). Agency can also be assumed in a context of resistance against structures/norms or as a part of promoting structures/norms. The sociological and higher education literatures examine agency in multiple contexts including overcoming power structures (Baez, 2000a; Elder, 1994; Heinz, 1996) and, more generally, the exertion of will/self-direction/intentional choice-making within the context of a system (Neumann, Terosky, \& Schell, 2006). For example agency can be exhibited by faculty who buck organizational norms and value service commitments or by faculty who put research above all else to achieve tenure, depending on a faculty member's specific career goals and aspirations.

The O’Meara, Campbell, and Terosky (2011) framework posits that faculty agency has influencing factors on three levels: individual, organizational, and societal. The O’Meara, Campbell, and Terosky framework posits that individual level factors (awareness of possibilities, having stated goals, having internal resource, and individual identities in a temporal context), organizational factors (climate, policy, norms, resources), and societal factors (social stratification and resources) all shape the degree to which faculty exhibit agency. For example, being a lesbian faculty member of color, being in a collegial climate, or societal expectations around family and parenting might all shape the degree of agency that a faculty member might feel in achieving their professional goals.

According to the O’Meara, Campbell, and Terosky framework, there are three levels of outcomes of faculty agency: individual, organizational, and societal. Individual career outcomes influenced by faculty sense of agency might include retention, organizational commitment, job satisfaction, productivity and advancement, and 
professional growth. Organizational outcomes of agency could include an organizational culture change to accommodate a faculty member's agency. For example, a faculty member might advocate for a new parental leave plan. The organization could either accept this plan and change the culture to accommodate faculty parents in a new and different way or backlash could ensue against the faculty member and the culture could stay stagnant. Similarly, an individual faculty member could use her research to change societal views of race or class. She could be a part of a broader movement that changes society in some way towards greater acceptance and equity.

While, the O’Meara, Campbell, and Terosky (2011) framework posits that faculty agency has influencing factors and expected outcomes on individual, organizational, and societal levels, it also posits that these factors and outcomes interact and overlap across the three levels. For example, one's organizational climate might shape faculty agency and also one's awareness of possibilities simultaneously. Additionally, while a faculty member's agency is influenced by the organizational climate, the faculty member's agency might simultaneously change the organizational context. For example, a striving institution might cause a faculty member to ratchet up his productivity. Simultaneously, he might exert his agency against a negative work-life climate, advocating for flexibility in his department, and thereby changing the organizational culture. In this way there is a constant interaction across and between agency and the influencing factors and outcomes, and among levels (individual, organizational, and societal).

\section{Use of Conceptual Framework in This Study}

Ideally, all facets of the O’Meara, Campbell, and Terosky (2011) frameworkinfluencing factors and outcomes on all three levels (individual, organizational, and 
societal)—would be included this study. However, I was only able to include select portions of the framework in this study due to several methodological issues, including sample size, power of the analysis, and the available survey items. I chose to focus on three main aspects of the framework: faculty sense of agency, organizational factors that influence faculty sense of agency and the individual career outcomes of agency.

Figure 3 presents a representation of the conceptual model, and how I used the O'Meara, Campbell, and Terosky (2011) framework in the present study. I posit that each organizational factor influences both agency perspective and agency behavior, per the literature that finds that organizational contexts matter in both the way faculty perceive their professional lives and the actions they take in their roles (Lindholm, 2003). Additionally, both sociological and organizational literatures provide compelling evidence that perspectives lead to action (Bandura, 1982; Vroom, 1964). As such, I posit that agency perspective contributes to agency behavior. Finally, the O'Meara, Campbell, and Terosky (2011) framework posits that both agency perspective and behavior have career outcomes for faculty. This study posits that both agency perspective and behavior influence three career outcomes: intent to stay, satisfaction, and productivity. Below I present a description of each of the constructs that I included in the study, how they are measured, and how they relate to the O'Meara, Terosky, and Campbell framework. Specific survey items that map onto each construct will be presented later in the procedures section of Chapter 3 . 


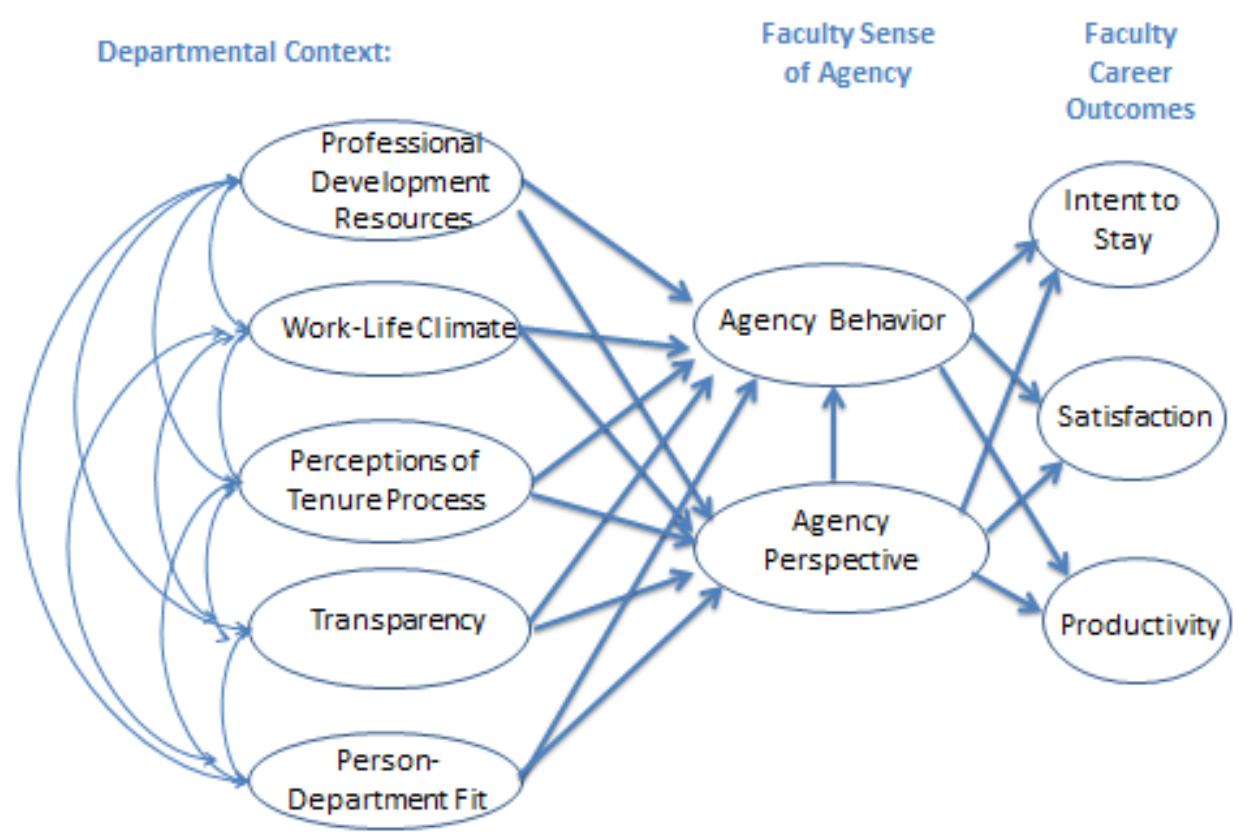

Figure 3. Operationalization of the O'Meara, Campbell, and Terosky (2011) Faculty Agency Framework in the current study.

\section{Faculty agency.}

This study measures faculty agency according to the definition used by O'Meara, Campbell, and Terosky (2011), who describe the agentic process as intentional and strategic behavior or perspective. As a result, two agency constructs were measured here: agency perspective and agency behavior. Additionally, the psychological literature has long described the influence of thoughts and perspectives on actions (Bandura, 1982). Likewise, organizational literature posits that internal motivation leads to action (Vroom, 1964). As such, the present study hypothesizes that agency perspective contributes to agentic behavior.

The O'Meara, Campbell, and Terosky (2011) framework also posits that agentic process can be toward any personal goal (e.g., work-life integration, career advancement, 
voice in shared governance, scholarly learning). This study examined agency toward faculty career advancement and obtaining one's own career goals. The study does not define what these goals should be (for example, tenure and promotion) because career goals are different for each individual faculty member and contextualized by many factors in a faculty member's worklife. Rather, the survey asked questions about a respondent's belief in achieving or taking steps toward achieving one's own career goals, allowing the participants to self-define these goals. By asking the questions in this way, it did not distinguish between agency against resistance or within the current structure. For example, a respondent's career goal could have been to focus on service or to focus on research, and both would be an equal demonstration of agency. Further studies should investigate the model looking at differences between agency as a form of resistance versus as a part of the system.

\section{Organizational influencing factors.}

Of the factors that influence agency (individual, organizational, and societal), I chose to focus on organizational influences of agency. Organizational factors are the most changeable by institutions. While individual identities and societal factors certainly shape faculty agency, institutions have less control over these aspects of the agency framework. Additionally, organizational factors have received less attention in the agency literature, whereas more attention has been paid to the individual (in the psychological literature) and societal (in the sociological literature) levels. Furthermore, survey items could not fully capture all individual or societal influencing factors. As a result, this study focused on organizational factors that influence agency, and individual identities and societal influences were excluded from the analysis. Further studies should 
pursue how the aspects of the faculty agency framework that were studied in this study (organizational influences, agency behaviors and perspectives, and career outcomes) interact with other aspects of the framework (e.g. individual identities, societal influences, and organizational and social change outcomes).

The O’Meara, Campbell, and Terosky (2011) framework posits that organizational climate, structure, or resources can impact faculty sense of agency. For example, being in a collegial department, having resources to support your professional goals, or the experience of good leadership can all impact the agency faculty feel in a variety of areas of worklife and career. While it was not feasible to study every possible organizational context, I chose six dimensions for this study. The six dimensions (tenure and promotion process, transparency, work-life climate, person-department fit, professional development resources, and collegial climate) seem to be highly relevant to faculty agency considering they have all been linked to important faculty outcomes, such as satisfaction, retention, and productivity (Birnbaum, 1988; Bolman \& Deal, 2003; Johnsrud \& Rosser, 2002; Lindholm, 2004; Lindholm, 2008; Mason \& Eckman, 2007; Mason \& Goulden, 2004; Neumann, Terosky, \& Schell, 2006; O'Meara \& Campbell, 2011; Bowen and Schuster, 1986; Bolin, 2000).

\section{Individual faculty career outcomes.}

While the O'Meara, Campbell, and Terosky (2011) framework asserts that there are outcomes of faculty agency on individual, organizational, and societal levels, this study focused only on certain individual outcomes. The framework posits that agency influences a number of individual faculty outcomes, such as well-being, retention, organizational commitment, job satisfaction, productivity and advancement, and 
professional growth. This study focused on three of these five outcomes: retention (via intent to stay), job satisfaction, and perceived productivity.

Retention of faculty is important for institutional efficiency and effectiveness. Faculty turnover is both fiscally and intellectually costly to institutions (Johnsrud \& Rosser, 2002). This study measured faculty intent to leave, which has a high correlation with actual leaving behavior (Bluedorn, 1982). Satisfaction has been found to influence intent to stay (Rosser, 2004; Johnsrud \& Rosser, 2002; Daly \& Dee, 2003). In addition to retention, institutions have a stake in faculty productivity in research, teaching and service. Institutional missions and strategic plans of striving institutions often tout heralding the most reputable, well published scholars. This study measured perceived scholarly reputation and perceived productivity in research, teaching, and service as a proxy for productivity.

\section{Faculty agency framework and gender.}

Women often face an inhospitable climate in academia, and are called upon to be reformers of the academic system (Winkler, 2000). Agency is required in order to navigate systems, shape one's environment, overcome resistance, and succeed in achieving one's goals (Elder, 1994; Heinz, 1996). Yet, agency has been described in masculine terms by several scholars (Ackerman et al., 2000; McAdams, de St. Aubin, \& Logan, 1993). In order to better support women scholars, and all scholars, it will be important to understand how the agentic process manifests differently for men and women. By using the O’Meara, Campbell, and Terosky (2011) framework for faculty agency, this study investigated the influence of organizational factors on faculty agency, whether agency influences faculty career outcomes, and how the framework of faculty 
agency manifests differently by gender. It is important to distinguish that this study did not seek to understand whether gender influences the level of faculty agency (i.e. do women have more or less agency than men?). Instead, this study investigated whether the relationships between organizational factors and agency were different for men and women. Better understanding the role of certain organizational factors in the agency of men and women will help institutions to create policies, norms, and climates that best serve each of these two groups of faculty.

\section{Site}

The site of the study is the University of Maryland College Park (UM), a large, public, research-extensive institution in the mid-Atlantic. UM had 3,080 full-time faculty in the fall of 2010, of whom 1,549 were tenure-track. The demographics of TT faculty at UM in the fall of 2010 (gender, race, rank, and discipline) are presented in Table 2.

Table 2

Demographics of Tenure-Track faculty at the University of Maryland in Fall 2010

\begin{tabular}{|c|c|}
\hline Category & Percent \\
\hline Female & 31 \\
\hline Male & 69 \\
\hline American Indian & $<1$ \\
\hline Asian American & 13 \\
\hline Black/African American & 5 \\
\hline Hispanic & 3 \\
\hline International & 2 \\
\hline White & 73 \\
\hline Two or More Races & $<1$ \\
\hline Unknown & 3 \\
\hline Assistant Professor & 22 \\
\hline Associate Professor & 30 \\
\hline Professor & 47 \\
\hline Agriculture & 11 \\
\hline Architecture & 2 \\
\hline Arts and Humanities & 20 \\
\hline Business & 7 \\
\hline Behavioral and Social Sciences & 11 \\
\hline Computer, Mathematical, \& Natural & 21 \\
\hline Education & 6 \\
\hline Engineering & 12 \\
\hline Journalism & 1 \\
\hline Public Health & 4 \\
\hline Public Policy & 1 \\
\hline Undergraduate Studies & $<1$ \\
\hline Other & 3 \\
\hline
\end{tabular}


The faculty experience at the University of Maryland differs by gender in terms of retention, career advancement, leadership, and rank. Table 3 presents institutional research data that demonstrate the gap in retention of faculty by gender. Women are more likely to resign prior to tenure than men in both STEM and non-STEM disciplines. Additionally, women faculty at UM are under-represented among full professors (Table 4) and are only $17 \%$ of leaders, including Deans, Assistant/Associte Deans, Chairs, and Directors (O’Meara, Lounder, \& Campbell, 2011). The gender disparity at UM mirrors broader national trends in faculty (Glazer-Raymo, 2008).

Table 3

Promotion Rates for Tenured/Tenure Track Faculty Hired between 1993 and 2003

\begin{tabular}{|c|c|c|c|c|c|c|c|}
\hline \multicolumn{8}{|c|}{ STEM } \\
\hline & \multicolumn{2}{|c|}{ Promoted } & \multicolumn{2}{|c|}{ Denied } & \multicolumn{2}{|c|}{ Resigned } & Total \\
\hline Female & 39 & $60 \%$ & 6 & $9 \%$ & 20 & $31 \%$ & 65 \\
\hline Male & 129 & $74 \%$ & 12 & $7 \%$ & 33 & $19 \%$ & 174 \\
\hline Total & 168 & $70 \%$ & 18 & $8 \%$ & 53 & $22 \%$ & 239 \\
\hline \multicolumn{8}{|c|}{ Non-STEM } \\
\hline & \multicolumn{2}{|c|}{ Promoted } & \multicolumn{2}{|c|}{ Denied } & \multicolumn{2}{|c|}{ Resigned } & Total \\
\hline Female & 77 & $50 \%$ & 7 & $5 \%$ & 71 & $46 \%$ & 155 \\
\hline Male & 101 & $56 \%$ & 12 & $7 \%$ & 67 & $37 \%$ & 180 \\
\hline Total & 178 & $53 \%$ & 19 & $6 \%$ & 138 & $41 \%$ & 335 \\
\hline
\end{tabular}

Source: UMD NSF Advance Grant Application (2010) 
Table 4

STEM Tenured/Tenure Track Faculty by Rank, Gender, and Unit

\begin{tabular}{lcccc} 
& $\begin{array}{c}\text { Assistant } \\
\text { Professor } \\
\text { \% Female }\end{array}$ & $\begin{array}{c}\text { Associate } \\
\text { Professor } \\
\text { \% Female }\end{array}$ & $\begin{array}{c}\text { Full } \\
\text { Professor } \\
\text { \% Female }\end{array}$ & $\begin{array}{c}\text { All } \\
\text { Tenure- } \\
\text { Track \% }\end{array}$ \\
$\begin{array}{lccc}\text { Female } \\
\text { Unit }\end{array}$ & 50.0 & 33.3 & 0.0 & 38.9 \\
\hline $\begin{array}{l}\text { Information Studies } \\
\text { (N=18) }\end{array}$ & 22.2 & 22.4 & 14.5 & 17.4 \\
$\begin{array}{l}\text { Computer, Math, Natural } \\
\text { Sciences (N=351) }\end{array}$ & 21.4 & 16.9 & 4.4 & 10.4 \\
$\begin{array}{l}\text { Engineering (N=201_ } \\
\begin{array}{l}\text { STEM Departments } \\
\text { (N=220) }\end{array}\end{array}$ & 42.6 & 23.5 & 19.0 & 26.7 \\
$\begin{array}{l}\text { STEM Related } \\
\text { Department (N=24) }\end{array}$ & 57.1 & 33.3 & 45.5 & 45.8 \\
All STEM Units & 48.0 & 21.7 & 13.7 & 19.2 \\
\hline
\end{tabular}

Source: O’Meara, Lounder, and Campbell (2011)

The University of Maryland received a 3.2 million dollar ADVANCE

Institutional Transformation grant in 2010 from the National Science Foundation (NSF) in order to support, promote, and retain women in the science disciplines (i.e. Science, Technology, Engineering, and Mathematics; STEM). The UM NSF ADVANCE grant seeks to address gaps in several career and advancement areas between men and women. Namely, it aims to improve equity between men and women faculty in retention from assistant to associate, in time to promotion to Full Professor, and Full Professor and leadership roles. The NSF ADVANCE grant includes eight activities (e.g., seed grants, women's leadership council, learning communities) to address the gap in retention. UMD ADVANCE also funds a number of research projects to investigate the experience of women faculty in the STEM disciplines and the organizational environments and conditions that best facilitate, support, and retain women faculty. While the NSF grant focuses on STEM faculty, the Provost at the institution (PI of the ADVANCE grant at 
UMD) and all non-STEM college Deans agreed to support the ADVANCE grant by contributing funds for the activities to occur in all colleges across campus.

Understanding the site of the research is critical to this study. UMD is an institution that has had historical problems with retaining and promoting women faculty. Yet, as evidenced by the ADVANCE grant, there is a commitment by the UMD leadership to address this problem. For example, simply revealing the problematic data with respect to gender and retention of faculty is a step toward increasing transparency. The historical problems with retaining women and the current movement toward institutional transformation by the ADVANCE grant provide important context for elucidating the findings of this study, particularly with regard to understanding the organizational dynamics and the influence of gender on the agency model. The context also makes the site a particularly appealing setting for the study because the historical inequities by gender mirror national trends (Glazer-Raymo, 2008) and yield the possibility that faculty sense of agency might act differently for men and women at UM.

\section{Sample}

The target population for the study was all full-time, tenure track faculty at the University of Maryland in fall of 2010 ( $N=1549)$. The sample was all full time, tenure track faculty at the University of Maryland who participated in the 2011 UMD ADVANCE Grant Faculty Work Environment Survey ( $n=488$ ), yielding a 32\% response rate. While a response rate of $32 \%$ is not ideal, it is a common response rate faculty for surveys at UMD. Additionally, national surveys of faculty experiences, such as the HERI, have a response rate of $42 \%$ (Milem, 1999). 
A smaller response rate does not necessarily yield an unrepresentative sample (Groves, 2006; Groves \& Peytcheva, 2008). The National Center for Education Statistics (2012) gives standards of rigor for non-respondent analyses to determine whether a sample is representative of a population, and if not, the magnitude of the bias. Nonresponse analyses can determine whether data are missing at random (i.e. have no pattern to their missingness, thereby exerting no bias; Croninger \& Douglas, 2005). NCES suggests several strategies to assess the impact of nonresponse on survey results, including comparing non-response rates across sub-groups of the population, using multivariate modeling, conducting interviews or a follow up survey with non-responders, and comparing respondents to known population characteristics. Due to time and monetary constraints, I conducted nonresponse analyses across sub-groups and comparing to known population characteristics.

Non-respondent analyses demonstrated that women were over-represented in the respondents when compared to the populations of UMD faculty in $2010(\mathrm{p}<.05)$. Additionally, White and Hispanic faculty were overrepresented in this sample when compared to their representation of all 2010 UMD faculty $(\mathrm{p}<.05)$. Asian American and Black/African American faculty were underrepresented in this sample when compared to their representation in the population $(\mathrm{p}<.05)$. The respondents were representative by rank of the population of 2010 TT faculty. Respondents also differed across disciplines $(\mathrm{p}<.05)$, with a higher response rate from respondents in the colleges of agriculture, business, mathematical and natural sciences, education, and journalism. By contrast, arts and humanities, behavioral and social sciences, engineering, and public health faculty were underrepresented in this sample. 
Nonresponse analyses demonstrated that the survey does exhibit bias by gender, race, and discipline, but not by rank. These biases provide helpful context for the findings of this study. Some of these response biases are trends with many surveys. For example, women are more likely to respond to surveys than men (Sax, Gilmartin, and Bryant, 2003). Additional nonresponse analyses at the item-level are presented in the data exploration section of Chapter 4 .

\section{Procedures}

The study utilized a quantitative, cross-sectional, survey methodology (Groves, et al, 2004). A cross-sectional survey methodology obtains data at one point in time from a sample (in this case, the faculty who participated in the UM Work Environment Survey) in order to try and generalize to a population (TT faculty at UMD). It is cross-sectional in that it looks at faculty across all ranks and groups at one snapshot in time (Spring 2011) as opposed to taking a longitudinal view. Data were collected as a part of the UM Faculty Work Environment Survey, administered by the University of Maryland NSF ADVANCE grant research team in April of 2011. Data were analyzed using EQS software to conduct a Structural Equation Modeling approach. Details about survey development, survey administration, and data analysis follow below.

\section{Survey instrument.}

The UM Faculty Work Environment Survey (O’Meara \& Campbell, 2011) was developed with the purpose of measuring faculty perceptions of their own professional growth, the departmental and institutional investments in professional growth, institutional climate for diversity and work-life, and various faculty outcomes (e.g., job satisfaction, intent to leave). The survey instrument is detailed in Appendix A. It was 
developed using a comprehensive literature review on faculty, women in higher education, and professional growth. Items from the survey that assessed professional growth included faculty agency, opportunities for faculty learning, professional relationships, and commitments. While the survey explored multiple areas of faculty worklife and professional growth, the survey was developed with a key focus on faculty agency and the institutional and departmental supports for faculty agency.

The survey was reviewed by a panel of eleven experts in related subject areas (e.g., faculty, gender, organizational commitment) for content and construct validity. Construct validity determines whether the items in the survey measure the intended constructs (Cronbach \& Meehl, 1955; Fowler, 1998; AERA, APA, \& NCME, 1999). Content validity is a form of construct validity, which determines whether all aspects of a particular construct were measured and ensures there are no extraneous items that are irrelevant to the construct of interest. Each expert was assigned a portion of the survey (or the entire survey) that matched their area of expertise (e.g., learning, agency). Two experts on faculty agency reviewed the survey items for the agency construct. They were asked to review the items and determine whether all aspects of the construct were measured by the items, and whether any items did not accurately portray the construct. Secondly, they were asked to denote which items tap particular dimensions of each construct (e.g., agentic behavior vs. perspective).

After review by the expert panel, the survey underwent an internal review of administrators and three faculty who are on the steering committee of the Advance grant. They were asked to review the survey for clarity and to comment based on their expertise with the university, institutional policy, diversity, and faculty matters. 
Finally, after the internal review, the survey was pilot tested by a small sample of five external faculty/educators for response process validity. Response process validity ascertains the clarity of the items and whether the interpretation of the items by respondents matches the intended interpretation by the survey developer (AERA, APA, \& NCME, 1999). Pilot respondents were asked to take the survey, comment on the time for completion of the survey and the clarity of the items. Then, they were asked to qualitatively describe how they responded to three of the items that were intended to tap the construct of agency (i.e. describe their thinking that helped them arrive to the response that they chose on those items). This exercise ascertained the degree to which the pilot respondents' answers to the three pilot agency items accurately reflected the degree of agency they exhibited.

Table 5, below, details the specific items in each of the five organizational constructs (perceptions of the tenure and promotion process, transparency, work-life climate, professional development resources, person-department fit, and collegiality), the two agency constructs (perspective and behavior), and the three outcome measures (productivity, intent to stay, and satisfaction). 
Table 5

Construct-item map

\begin{tabular}{|c|c|c|}
\hline $\begin{array}{c}\text { Facet of } \\
\text { Framework }\end{array}$ & Construct & Survey Items \\
\hline \multirow{5}{*}{$\begin{array}{l}\text { Organiza- } \\
\text { tional } \\
\text { Context }\end{array}$} & $\begin{array}{l}\text { Perceptio } \\
\text { ns of the } \\
\text { Tenure } \\
\text { and } \\
\text { Promotion } \\
\text { Process }\end{array}$ & $\begin{array}{l}\text { - In my unit, the tenure requirements are clear. } \\
\text { - In my unit, the promotion requirements for advancing to Full } \\
\text { Professor are clear. } \\
\text { - In my unit, the tenure process is fair. } \\
\text { - In my unit, the promotion process for advancing to Full Professor is } \\
\text { fair. }\end{array}$ \\
\hline & Transparency & $\begin{array}{l}\text { - Resource allocation in my unit (e.g., space, funded research } \\
\text { assistants) is transparent. } \\
\text { - Decisions regarding salary increases in my unit are transparent. } \\
\text { - Information is available to understand my relative standing among } \\
\text { my peers. } \\
\text { Please indicate the extent to which you are satisfied or dissatisfied with } \\
\text { the following resources or conditions at UM: } \\
\text { - The transparency of decision-making within my unit }\end{array}$ \\
\hline & $\begin{array}{l}\text { Work-Life } \\
\text { Climate }\end{array}$ & $\begin{array}{l}\text { - I am satisfied with my unit's culture around work-life balance. } \\
\text { - There are role-models in my unit of how to create a satisfying work- } \\
\text { life balance. } \\
\text { - The amount of work my unit expects me to perform makes work-life } \\
\text { balance difficult. * } \\
\text { - In my unit it is generally expected that people need to make work } \\
\text { their top priority. * } \\
\text { - The institution does what it can to make family life and the tenure } \\
\text { track compatible. } \\
\text { - My unit supports faculty scheduling work commitments around family } \\
\text { schedules. } \\
\text { - In my unit, faculty can be honest with colleagues about family/life } \\
\text { roles and responsibilities. } \\
\text { - There is NO bias against family care-giving in my unit. }\end{array}$ \\
\hline & $\begin{array}{l}\text { Person- } \\
\text { Department } \\
\text { Fit }\end{array}$ & $\begin{array}{l}\text { - Faculty in my unit value my teaching contributions. } \\
\text { - Faculty in my unit value my research/scholarship. } \\
\text { - Faculty in my unit value my service contributions. } \\
\text { - Faculty in my unit are aware of the service that I do for our program. } \\
\text { Please indicate the extent to which you are satisfied or dissatisfied with } \\
\text { the following resources or conditions at UM: } \\
\text { - The sense of fit between my values and those of my unit }\end{array}$ \\
\hline & Collegiality & $\begin{array}{l}\text { - I feel isolated in my department. * } \\
\text { - I am satisfied with the collegiality in my unit. } \\
\text { - I am satisfied with the amount of professional interaction I have with } \\
\text { senior colleagues at the University. } \\
\text { - I have been effectively mentored by someone in my unit. } \\
\text { - I receive useful feedback from colleagues at UM that improves my } \\
\text { work. } \\
\text { - Major decisions in my unit are made with adequate input from } \\
\text { faculty. } \\
\text { - I feel that I can voice my opinions openly in my unit, even if my } \\
\text { colleagues disagree with me. } \\
\text { - I have a voice in decision-making that affects the direction of my } \\
\text { department. }\end{array}$ \\
\hline
\end{tabular}




\begin{tabular}{|c|c|c|}
\hline \begin{tabular}{|c|} 
Facet of \\
Framework
\end{tabular} & Construct & Survey Items \\
\hline $\begin{array}{l}\text { Organiza- } \\
\text { tional } \\
\text { Context }\end{array}$ & $\begin{array}{l}\text { Professional } \\
\text { Develop- } \\
\text { ment } \\
\text { Resources }\end{array}$ & $\begin{array}{l}\text { - My unit has financially supported my learning in my field or discipline } \\
\text { (e.g., provided funds to attend conferences, buy software, books or } \\
\text { equipment for my research). } \\
\text { Please indicate the extent to which you are satisfied or dissatisfied with } \\
\text { the following resources or conditions at UM: } \\
\text { - Assistance with finding grants } \\
\text { - Amount of access to TAs, RAs } \\
\text { - Professional assistance for improving teaching } \\
\text { - Assistance with research administration in your unit }\end{array}$ \\
\hline \multirow[b]{2}{*}{ Agency } & $\begin{array}{l}\text { Agency } \\
\text { Behavior }\end{array}$ & $\begin{array}{l}\text { - I have been strategic in achieving my career goals. } \\
\text { - I seize opportunities when they are presented to me to advance in } \\
\text { my career. } \\
\text { - I have intentionally made choices to focus my career in ways that } \\
\text { are personally meaningful to me. } \\
\text { - I have taken strategic steps toward creating a satisfactory work-life } \\
\text { balance. }\end{array}$ \\
\hline & $\begin{array}{l}\text { Agency } \\
\text { Perspective }\end{array}$ & $\begin{array}{l}\text { - I feel stuck in my ability to advance in my career. * } \\
\text { - In general, I feel that I have little control over whether I advance in } \\
\text { my career. * } \\
\text { - Managing my teaching responsibilities is largely under my control. } \\
\text { - I feel in control of my participation in service activities (the amount } \\
\text { and level of participation). } \\
\text { - I am in charge of the direction of my research agenda. } \\
\text { - In general, I feel I have control over creating a satisfying work-life } \\
\text { balance. }\end{array}$ \\
\hline \multirow[b]{3}{*}{ Outcomes } & $\begin{array}{l}\text { Intent to } \\
\text { Stay at } \\
\text { UMD }\end{array}$ & $\begin{array}{l}\text { - To what extent are you likely to leave the University in the next two } \\
\text { years? }\end{array}$ \\
\hline & $\begin{array}{l}\text { Career } \\
\text { Satisfaction }\end{array}$ & $\begin{array}{l}\text { Please indicate the extent to which you are satisfied or dissatisfied with } \\
\text { the following resources or conditions at UM: } \\
\text { - My overall experience working in my unit } \\
\text { - My overall experience working at UM }\end{array}$ \\
\hline & Productivity & $\begin{array}{l}\text { In thinking briefly about your productivity, during the last } 2 \text { years, } \\
\text { please provide approximate estimates of the following: } \\
\text { - The number of publications you authored/co-authored (peer- } \\
\text { reviewed articles, book chapters, etc.) } \\
\text { - The number of other creative works you created (e.g., exhibitions, } \\
\text { performances) } \\
\text { - Using the criteria above, how would you rate your overall productivity } \\
\text { compared to researchers in your field and at your rank nationwide? } \\
\text { - Using these same criteria, how do you think your unit views your } \\
\text { level of productivity, compared to researchers in your field and at } \\
\text { your rank nationwide? }\end{array}$ \\
\hline
\end{tabular}

\section{Notes:}

Response scales for items are 1 (strongly disagree or very dissatisfied) - 5 (strongly agree or very satisfied) unless otherwise noted.

* Reverse scored 


\section{Survey administration.}

The UM Faculty Work Environment Survey was administered through a partnership between the UM NSF Advance Grant team and the Office of Institutional Research, Planning, and Assessment. All full-time faculty at UM were sent a recruitment email for the survey from the Interim Provost in late March of 2011, which invited them to participate via an online link. The link took participants to a website that required them to log in with their university identification and password, so that responses could be linked to institutional data. Participants were given an informed consent form prior to participation, which assured the confidentiality of the data (see Appendix A). Participants who did not complete the survey were sent three reminder emails up to four weeks after the survey launched. Participant data was captured using an online survey system developed and maintained by the Office of Institutional Research, Planning, and Assessment. Data was exported into excel and SPSS for analysis for the UMD ADVANCE Grant. Data for this study was extracted into a sub-dataset, including only the variables of interest (listed in Table 5).

\section{Data exploration.}

Prior to the analyses of the research questions, I ran initial descriptive analyses to explore the data, with a focus on variability, normality, kurtosis, and missing data. First, univariate normality analyses were conducted on each of the variables in the study. Based on descriptive frequencies, 10 items had less than $4.5 \%$ of respondents selecting either the lowest or highest response option. As a result, each of these was recoded to collapse two response categories, leaving four response categories with sufficient variance across response categories for analysis. One variable did not have sufficient 
variability across response options, and two categories were collapsed, leaving only three response options. This variable was categorized as categorical in the subsequent analyses. I also reverse-coded eight items with opposite directionality of response scales. For example, in the agency perspective construct, the "I feel stuck..." item was reverse scored so that all items in that scale had a positive directionality.

Finally, I conducted missing data analyses on each survey item to determine which items that had the highest number of missing responses. Missing data analyses are important for two reasons. First, such analyses ensured that items do not have a pattern of missing data that could be explained by a confounding variable, introducing endogeneity and error. For example, if an item had a high proportion of missing responses, and the missing responses were mainly men, that would influence results. Secondly, in a complex analysis, such as structural equation modeling, having a high enough sample size is imperative. Listwise deletion was used in the analysis. Therefore, if one item has a large number of missing responses, those respondents would be excluded from the entire analysis, thereby lowering the overall sample size, the power of the analysis, and also introducing bias if there is a pattern to the missingness. Pairwise descriptive analyses were run on the missing data, via EQS software.

These analyses revealed that six items (four items in work-life climate and two in tenure and promotion) had a substantial proportion of missing data. The two tenure and promotion items each had about $1 / 5$ of responses as missing. Furthermore, chi-squared analyses revealed that these data were not missing at random. The two tenure and promotion items with high proportion of missing data were regarding promotion to full professor. Chi-squared analyses compared the proportion of missing responses by rank 
and found that Assistant professors were far more likely to skip those items than Associate or Full Professors $(\mathrm{p}<.001)$. Similarly, the items in the work-life climate construct with high proportions of missing data were regarding work-family balance (as opposed to work-life balance, more broadly). Chi-squared analyses revealed that these items had proportionally lower responses from respondents without children $(\mathrm{p}<.05)$. As a result, in order to retain the highest sample size possible, and reduce non-responder bias, these six items (two promotion and tenure, and four work-life climate items) were excluded from analyses.

\section{Data Analysis}

Data were analyzed using Structural Equation Modeling (SEM; Byrne, 2006; Mueller \& Hancock, 2008). I used robust statistics in order to provide correct standard errors and parameter estimates in a model with non-normal and categorical data. Structural Equation Modeling is an approach that combines multiple regression analysis, path analysis, and confirmatory factor analysis. The marriage of these three techniques into SEM gave rise to a technique that has several unique and advantageous attributes.

First, SEM is a confirmatory method that allows the testing of a posited model that is theoretically derived, such as the O’Meara, Campbell, and Terosky (2011) framework. It has the ability to confirm two aspects of posited models. First, it can confirm the construct validity and reliability of a latent construct (Byrne, 2006; Mueller \& Hancock, 2008). A latent construct is a construct for which there are no direct measures (e.g., agency). Instead of measuring agency directly, the UM Faculty Work Environment Survey measures faculty perceived sense of agency via several survey items. SEM has the ability to estimate how much variation in the survey items is 
explained by the latent construct. For instance, how much variation in the UM Faculty Work Environment Survey items is explained by the construct of agency. SEM also estimates the reliability of a scale (i.e. how well the items in a scale hang together).

The ability to estimate the construct validity and reliability was essential for this study because the scales in the UM Faculty Work Environment Survey have not been previously validated. Exploratory methods, such as principal components analysis, do not have the ability to confirm pre-established, theory driven scales, such as the ones in the UM Faculty Work Environment Survey. Another important strength of SEM is its ability to estimate and account for measurement error, which is crucial in a survey of perceptions. Surveys that are perceptual in nature are open to a number of error possibilities and biases (ex. social desirability, self-confidence, memory biases). SEM accounts for measurement error and estimates the proportion of variation that is attributed to error versus the construct of interest.

The second confirmatory aspect of SEM is the ability to confirm theoretically driven, hypothetical relationships (Byrne, 2006; Mueller \& Hancock, 2008). For example, the faculty agency framework posits that there are factors that influence agency and outcomes of agency. Based on this theoretical model, SEM can determine the structural paths for each aspect of the model. For example, what is the strength of the relationships between organizational factors and agency? Other, exploratory methods (such as multiple regression) do not start with pre-established theoretical relationships, and instead can often lead to fishing expeditions where multiple independent variables are tested and rejected based on exploratory estimates. 
Furthermore, SEM allows for the study of multiple endogenous or dependent variables, which is necessary in the present study. The present study intends to investigate five endogenous variables: agency behavior, agency perspective, job satisfaction, perceived productivity, and intent to stay. Using another method, such as multiple regression or hierarchical linear modeling, would not allow for simultaneously investigating relationships between multiple exogenous and endogenous variables.

An additional unique aspect to SEM is that it can compare how models hold for different groups (Byrne, 2006; Mueller \& Hancock, 2008), which is necessary to compare how the O'Meara, Campbell, and Terosky (2011) framework acts for men and women. Instead of including gender as an independent variable, which would be the case in multiple regression analysis, SEM allows for testing how an entire model holds for men and women and compares the differences (called testing for "invariance"). For example, suppose that agency matters more for men than women in its impact on satisfaction, but less in its impact on productivity. A comparative SEM approach would demonstrate the strengths of these relationships for each group (men and women) and could then test whether the two models (the one for men and women) are statistically different.

\section{Analytic approach for research questions 1 \& 2.}

According to the literature in Structural Equation Modeling, there are several steps in order to ascertain the fit of a causal model and to determine the importance of causal paths in that model (Byrne, 2006; Mueller \& Hancock, 2008). First, one must ascertain the psychometric properties by running confirmatory factor analyses for each of the latent constructs. This allows the researcher to make modifications to the construct to 
ensure a strong fit and reveals the error among the construct's items and the reliability of the latent construct. When all latent constructs are individually validated, next, the researcher must run a second order confirmatory factor analysis, to ascertain the intercorrelations among the latent constructs. This process reveals preliminary relationships among latent constructs and also may draw attention to potential collinearity problems. Finally, the structural paths are entered into the model, thereby ascertaining relationships among latent constructs and whether the predicted model is a good fit to the data, while accounting for measurement error.

The analysis for this study followed the procedure described by Byrne (2006). First, I ran Confirmatory Factor Analyses (CFA) on each of eleven latent constructs in the hypothesized model: six organizational factors (promotion and tenure, transparency, person-department fit, work-life balance, collegiality, and professional development), two agency factors (behavior and perspective), and three outcome measures (job satisfaction, intent to leave, and productivity). In these analyses, I freed the error variance terms and the loadings of each item, but constrained the variance of the latent factor to 1 . I also reported the Coefficient $\mathrm{H}$, which is a value of reliability for latent constructs. Then, I made modifications as necessary to obtain adequate fit among each latent construct. Next, I ran a confirmatory factor analysis, freeing co-variances among all eleven latent constructs. Then, I ran a series of structural models to test the relationships among the influences and outcomes of agency. In each structural model, I constrained the loading of the item with the highest loading for each construct to one, and freed the variance of the latent factor. I used the Lagrange Multiplier (LM) test to assist in model re-specification, where necessary. 


\section{Analytic approach for research question 3.}

Once I obtained a final structural model with an appropriate fit, I proceeded to test the invariance of the model by gender. By testing the invariance of the model, I was able to ascertain whether the relationships among the constructs in the model were similar for men and women. For example, does work-life climate matter contribute more to the agency in career advancement of women than men? A test of invariance also allows a statistical determination of whether the model, in its entirety, holds for men and women (Byrne, 2006). It can test for both structural invariance (whether the posited relationships between constructs in the model hold for men and women) and also the psychometrics of the model (whether the item loadings for each construct are similar for men and women).

In order to test for invariance, I followed Byrne's (2006) procedures. First, I ran the model for men and women separately, establishing a baseline model of good fit for each gender. Then I ran a test for configural invariance, whereby I included both the model for men and for women, but did not include any equality constraints. The configural model establishes whether there is a good fit among both models (for men and women) simultaneously in terms of the numbers of loadings and structural parameters. It does not test whether the relationships among the constructs or the loadings are equal for men and women. Next, I tested a model that constrained all loadings and all structural paths in the model. If there is a good fit with this model, I would retain the same model for men and women. If there is not a good fit with the model, I would use the Lagrange Multiplier test to determine which parameters (either loadings or structural paths) should be freed. In other words, the LM test would indicate which relationships among 
constructs or item loadings were different by gender. Then, based on the LM test results, I could make model respecifications, and re-run for good fit.

\section{Criteria for analyses/fit indices.}

The present study relied on five measures of fit to judge the CFA model and the SEM models. These indices include: a) the Satorra-Bentler Scaled estimate of chi-square ( $S$ - $\left.B \chi_{2}\right)$, b) the Yuan-Bentler Residual-based F-Statistic c) the Comparative Fit Index (CFI), d) the Non-Normed Fit Index (NNFI), and e) the Root Mean Square Error of Approximation (RMSEA). The Satorra-Bentler Scaled estimate of chi-square $\left(S-B \chi_{2}\right)$ and the Yuan-Bentler Residual-based F-Statistic are estimates of absolute fit. The CFI and the NNFI are estimates of incremental fit. The RMSEA is an estimate that takes into account the parsimony of the model. According to Byrne (2006), considering multiple forms of fit indices are critical to having a full understanding of model fit. Particularly, there has been a debate in the SEM literature regarding whether the absolute fit measures are too sensitive for real world data and also evidence that the chi-squared statistic is unduly sensitive to sample size. The YuanBentler Residual-Based F-Statistic is an absolute fit statistic that is meant to be less sensitive to sample size (Byrne, 2006). The RMSEA is meant to be more applicable to real work data. Additionally, the incremental fit statistics were created as a compliment to absolute fit statistics. The CFI is an incremental index that takes sample size into account and the NNFI takes into account model complexity.

I based my selection of goodness of fit values on recommendations from the SEM literature (Byrne, 2006; Hu \& Bentler, 1999). The Satorra-Bentler Scaled estimate of chisquare $\left(S-B \chi_{2}\right)$ and the Yuan-Bentler Residual-based F-Statistic should be less than .05 to retain the hypothesized model. CFI and NNFI values of 0.95 or higher would signify an excellent fit; and values greater than .90 would signify an appropriate fit. In terms of 
RMSEA, values ranging from 0 to .05 would be excellent; but RMSEA values less than .08 would also be suitable. In addition, the present study would estimate $90 \%$ confidence intervals to check that RMSEA values do not fall beyond the cut off value of .10, signifying the rejection of the model.

\section{Strengths and Limitations}

There are both strengths and limitations to the present study. The main strengths are seven-fold. First, the study contributed uniquely to the faculty literature base through a new theoretical lens of faculty agency, which has rarely, if ever, been investigated using quantitative methods. Second, the study is intrinsically linked to practice because it investigates organizational climates and factors that are actionable by departments and institutions. This study also investigated outcomes that are particularly important for institutions (faculty satisfaction, intent to stay, and productivity) and has the ability to contribute to our understanding of the faculty experience by gender. Thirdly, the study contributed to the validity of the theoretical framework on faculty agency. Fourth, the study used advanced statistical modeling techniques, which allow for simultaneously modeling multiple influencing factors, multiple outcomes of agency, and different models based on gender. Fifth, the advanced statistical modeling approach controls for (and measures) measurement error, allowing the estimation of the relationships among constructs to be more direct. Sixth, the study utilized a survey that was administered to all full-time faculty at the University of Maryland (and this study used only tenure-track respondents), allowing for a large enough sample size for such an elaborate model. Seventh, the creation of the UM Faculty Work Environment Survey was based on the faculty agency framework and the professional growth framework. As a result, the items on the survey are theoretically driven and tap the exact constructs of interest in the 
present study (i.e. survey items were originally intended to measure agency, rather than using other kinds of items as proxy for agency).

While the strengths of the present study are considerable, there are also several noteworthy limitations. First, as Porter (2009) and Pascarella, Seifert, and Blaich (2009) describe, using perceptual, self-reported surveys have several potential pitfalls, including social desirability and self-confidence biases. While this study asks respondents about several experiences and behaviors in addition to attitudes and perceptions, these experiences are still as reported by the individual faculty member, and therefore individual bias can be introduced. For example, the present study asks faculty to rate their own agency from within oneself. An extension of the present study would be to assess the agency of a faculty member (or the organizational climate) by an observer, colleague, or department chair, but this is outside the scope of this research. Additionally, while perceptual and self-reported responses can be flawed, SEM takes measurement error into account in the analysis, which limits the effect of these biases. Similarly, participants rated their own experiences and perceptions about the organizational climate, culture, and conditions, rather than measuring at the group level (i.e. there would be one measure for each unit instead of measures of the organizational climates for each individual respondent). While this is a limitation, there is a lot of evidence that an individual's perception of an organizational or institutional culture is very important to individual faculty outcomes (Johnsrud \& Rosser, 2002; Lindholm, 2004; Lindholm, 2008; Mason \& Eckman, 2007; Mason \& Goulden, 2004; O’Meara \& Campbell, 2011). 
Secondly, representativeness of the analytic sample is a concern because of low response rate (32\%). Additionally, missing data analyses revealed that certain groups were overrepresented in the data compared to the population (e.g., women, White faculty). However, a response rate such as this is typical in the higher education/faculty literature. Additionally, a limitation of the present study could be that the sample is from one, single institution instead of a broader, national sample. As a result, results should be considered context specific and should only be generalized to similar institutions (large, public, research-extensive institutions). By contrast, having a singular institution in the sample could also prove to be a strength of the study, in that, results can be contextualized in the policies and the specific climate of the institution, which could provide additional insights and applicability.

Another limitation of the study is that it does not include all aspects of the faculty agency framework. For example, out of desire for parsimony and power with the limited sample size as well as limitations in the types of items in the survey, this study focuses on the organizational influences of agency, but does not include individual or societal level forces that impact agency and faculty outcomes. While it does investigate how the influence of organizational factors on faculty agency differs by gender, it does not investigate the influence of gender on faculty agency. Only testing part of the faculty agency model is a particularly noteworthy limitation of the study considering previous literature that demonstrates the importance of individual identities, internal resources, and social place on agency (Baez, 2000b; Elder, 1994, Myer \& Jepperson, 2000; O’Meara, Campbell, \& Terosky, 2011). If all constructs in the faculty agency framework (individual, organizational, and societal influences and outcomes) were entered into the 
model, estimates could be different, and the full model should be confirmed in subsequent studies.

Lastly, it is important to be cautious about assigning causality when assessing the relationships in a confirmatory model. Data are correlational in nature. The theoretical framework posits causality (e.g., organizational factors cause an increase or decrease in faculty agency). The present study can provide support for (not prove) these causal relationships. This underlying assumption is important, and should be kept in mind when interpreting results. Beyond confirming the relationships among influencing factors, agency, and outcomes, this study also tested the invariance of the model for men and women, demonstrating which parts of the model are most important for each gender.

\section{Conclusion}

By using the O'Meara, Campbell, and Terosky (2011) framework for faculty agency, this study investigated the organizational influences on faculty agency, whether agentic behavior and persepective influences important faculty career outcomes, and how the framework of faculty agency manifests differently by gender. The study contributed to our understanding of the theoretical framework of faculty agency. It examined one aspect of a model on faculty agency that has been posited in mainly qualitative studies (e.g., O’Meara, Campbell, and Terosky, 2011; Neumann, Terosky, \& Schell, 2006; Baez, 2000a).

This study also offered implications for what institutions can do to help women faculty and all faculty thrive in the twenty-first century academic landscape. Situated in a large, public, mid-Atlantic institution, the study used data from a survey of all full-time faculty, which yielded a sufficient sample size to perform advanced statistical techniques, 
such as comparative Structural Equation Modeling. By the use of advanced statistical techniques, the study investigated the effects of departmental cultures on faculty agency and outcomes while simultaneously controlling for measurement error. Lastly, it also provided insight into specific intervention strategies to enhance the career agency of women and men faculty, which is crucial to a diversifying professoriate. 


\section{Chapter 4: Results}

\section{Introduction}

This chapter details the results of the study. First, the results of the descriptive analyses are presented. This section details the Ns, means, and, standard deviation for each item for the total sample and also by gender. Notably, respondents were about neutral or slightly positive on items relating to agency, and few items demonstrated differences by gender. Then, I present the results of the analyses of the psychometric properties of the constructs. After certain items were removed due to low loading or intercorrelated errors, the final psychometric model demonstrated excellent fit. Next, I present the results from the structural models, answering research questions one and two (which organizational factors influence agency and whether agency influences faculty outcomes). Results demonstrated that certain organizational factors (work-life climate, person-department fit, professional development resources) directly influence agentic perspective and indirectly influence agentic behavior. Finally, I present the results of the test of invariance by gender, which addresses research question three. I found that the model did not vary by gender.

\section{Descriptive Results}

Table 6 presents means, Ns, and standard deviations for each item within a posited construct for all respondents, for men, and for women. This descriptive analysis allows for an understanding of the absolute value of each of the items within constructs. For example, it appears that with regard to the organizational factors, participants were slightly favorable about the tenure process, person-department fit, and collegiality and neutral about transparency, work-life climate, and professional development. With 
regard to the agency factors, participants were slightly favorable about exhibiting agentic behaviors and having agency perspective - the average score was between "neutral" and "agree" on all agency related items.

Finally, participants rated themselves favorably on each of the outcome measures. Descriptive statistics show that on average, respondents fall between "unlikely" and "definitely will not" on the intent to leave scale and between "satisfied" and "very satisfied" in both satisfaction with unit and the university. Similarly, they rated themselves highly in the productivity scales with about eleven publications, on average, and rating themselves as between "slightly more" and "much more" productive than the average faculty member at their rank and in their field, nation-wide.

I also conducted t-tests to determine whether items were different by gender. I found that there were several items that differed by gender $(\mathrm{p}<.05)$. Women were less favorable than men about two items in work-life climate (satisfaction with work-life climate and role models for work-life balance) and two items in collegiality (voicing opinions openly and feeling isolated). Women also gave lower ratings to three other individual items (research administration, feeling of control over service, and number of publications). There were no items where men were statistically significantly lower than women. It is also noteworthy that while several items did show significant differences by gender, the majority of items did not show significant differences. Overall, it appears that there may be some organizational contexts (work-life and collegiality) where women's experiences were less favorable than men's. However, most of the items that comprise transparency, recognition, professional development resources, agency behavior, agency perspective, productivity, satisfaction, and intent to stay did not differ by gender. 
Table 6

Means of items within constructs by gender.

\begin{tabular}{|c|c|c|c|c|c|c|c|c|c|c|}
\hline \multirow[b]{2}{*}{$\begin{array}{c}\text { Constr } \\
\text { ucts }\end{array}$} & \multirow[b]{2}{*}{ Survey Item } & \multicolumn{3}{|c|}{ Male } & \multicolumn{3}{|c|}{ Female } & \multicolumn{3}{|c|}{ Total } \\
\hline & & Mean & $\mathrm{N}$ & $\begin{array}{l}\text { Std. } \\
\text { Dev. }\end{array}$ & Mean & $\mathrm{N}$ & $\begin{array}{l}\text { Std. } \\
\text { Dev. }\end{array}$ & Mean & $\mathrm{N}$ & $\begin{array}{l}\text { Std. } \\
\text { Dev. }\end{array}$ \\
\hline \multirow{2}{*}{ 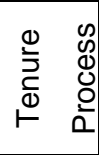 } & $\begin{array}{l}\text { In my unit, the tenure } \\
\text { requirements are clear. }\end{array}$ & 3.68 & 257 & 1.163 & 3.70 & 194 & 1.136 & 3.69 & 451 & 1.150 \\
\hline & $\begin{array}{l}\text { In my unit, the tenure } \\
\text { process is fair. }\end{array}$ & 3.77 & 252 & 1.175 & 3.78 & 180 & 1.043 & 3.78 & 432 & 1.121 \\
\hline \multirow{4}{*}{ 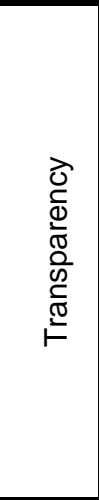 } & $\begin{array}{l}\text { The transparency of } \\
\text { decision-making within my } \\
\text { unit }\end{array}$ & 2.92 & 251 & 1.280 & 2.83 & 192 & 1.273 & 2.88 & 443 & 1.276 \\
\hline & $\begin{array}{l}\text { Resource allocation in my } \\
\text { unit (e.g., space, funded } \\
\text { research assistants) is } \\
\text { transparent. }\end{array}$ & 2.80 & 253 & 1.180 & 2.84 & 192 & 1.202 & 2.82 & 445 & 1.188 \\
\hline & $\begin{array}{l}\text { Decisions regarding salary } \\
\text { increases in my unit are } \\
\text { transparent. }\end{array}$ & 2.81 & 251 & 1.135 & 2.73 & 190 & 1.211 & 2.78 & 441 & 1.168 \\
\hline & $\begin{array}{l}\text { Information is available to } \\
\text { understand my relative } \\
\text { standing among my peers. }\end{array}$ & 2.98 & 251 & 1.135 & 2.80 & 186 & 1.203 & 2.91 & 437 & 1.166 \\
\hline \multirow{4}{*}{ 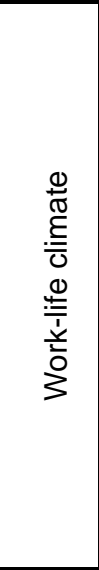 } & $\begin{array}{l}\text { I am satisfied with my unit's } \\
\text { culture around work-life } \\
\text { balance. * }\end{array}$ & 3.15 & 256 & 1.163 & 2.93 & 192 & 1.185 & 3.06 & 448 & 1.176 \\
\hline & $\begin{array}{l}\text { There are role-models in my } \\
\text { unit of how to create a } \\
\text { satisfying work-life balance. } \\
\text { * }\end{array}$ & 2.98 & 256 & 1.095 & 2.73 & 194 & 1.111 & 2.87 & 450 & 1.107 \\
\hline & $\begin{array}{l}\text { The amount of work my unit } \\
\text { expects me to perform } \\
\text { makes work-life balance } \\
\text { difficult. REVERSE CODED }\end{array}$ & 2.70 & 256 & 1.148 & 2.54 & 197 & 1.132 & 2.63 & 453 & 1.142 \\
\hline & $\begin{array}{l}\text { In my unit it is generally } \\
\text { expected that people need } \\
\text { to make work their top } \\
\text { priority. }\end{array}$ & 2.45 & 258 & .974 & 2.41 & 194 & .963 & 2.43 & 452 & .968 \\
\hline \multirow{5}{*}{ 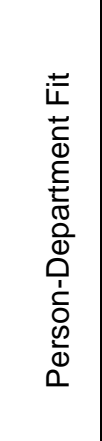 } & $\begin{array}{l}\text { The sense of fit between my } \\
\text { values and those of my unit }\end{array}$ & 3.29 & 251 & 1.183 & 3.23 & 190 & 1.225 & 3.27 & 441 & 1.200 \\
\hline & $\begin{array}{l}\text { Faculty in my unit value my } \\
\text { teaching contributions. }\end{array}$ & 3.42 & 253 & 1.101 & 3.49 & 190 & 1.017 & 3.45 & 443 & 1.065 \\
\hline & $\begin{array}{l}\text { Faculty in my unit value my } \\
\text { research/scholarship. }\end{array}$ & 3.62 & 252 & 1.107 & 3.64 & 192 & 1.039 & 3.63 & 444 & 1.077 \\
\hline & $\begin{array}{l}\text { Faculty in my unit value my } \\
\text { service contributions. }\end{array}$ & 3.35 & 252 & 1.106 & 3.43 & 190 & 1.165 & 3.38 & 442 & 1.131 \\
\hline & $\begin{array}{l}\text { Faculty in my unit are aware } \\
\text { of the service that I do for } \\
\text { our program. }\end{array}$ & 3.43 & 253 & 1.109 & 3.55 & 191 & 1.089 & 3.48 & 444 & 1.101 \\
\hline
\end{tabular}




\begin{tabular}{|c|c|c|c|c|c|c|c|c|c|c|}
\hline \multirow[b]{2}{*}{$\begin{array}{c}\text { Constr } \\
\text { ucts }\end{array}$} & \multirow[b]{2}{*}{ Survey Item } & \multicolumn{3}{|c|}{ Male } & \multicolumn{3}{|c|}{ Female } & \multicolumn{3}{|c|}{ Total } \\
\hline & & Mean & $\mathrm{N}$ & $\begin{array}{l}\text { Std. } \\
\text { Dev. }\end{array}$ & Mean & $\mathrm{N}$ & $\begin{array}{l}\text { Std. } \\
\text { Dev. }\end{array}$ & Mean & $\mathrm{N}$ & $\begin{array}{l}\text { Std. } \\
\text { Dev. }\end{array}$ \\
\hline \multirow{8}{*}{ 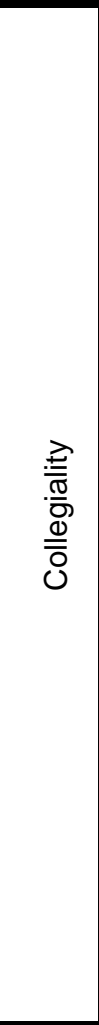 } & $\begin{array}{l}\text { I feel that I can voice my } \\
\text { opinions openly in my unit, } \\
\text { even if my colleagues } \\
\text { disagree with me. }{ }^{*}\end{array}$ & 3.60 & 252 & 1.151 & 3.32 & 193 & 1.245 & 3.48 & 445 & 1.200 \\
\hline & $\begin{array}{l}\text { Major decisions in my unit } \\
\text { are made with adequate } \\
\text { input from faculty. }\end{array}$ & 3.31 & 252 & 1.271 & 3.33 & 193 & 1.292 & 3.31 & 445 & 1.279 \\
\hline & $\begin{array}{l}\text { I feel isolated in my } \\
\text { department. REVERSE } \\
\text { CODED * }\end{array}$ & 3.63 & 271 & 1.281 & 3.38 & 203 & 1.328 & 3.52 & 474 & 1.306 \\
\hline & $\begin{array}{l}\text { I am satisfied with the } \\
\text { amount of professional } \\
\text { interaction I have with } \\
\text { senior colleagues at the } \\
\text { University. }\end{array}$ & 3.16 & 270 & 1.159 & 2.97 & 204 & 1.255 & 3.08 & 474 & \\
\hline & $\begin{array}{l}\text { I am satisfied with the } \\
\text { collegiality in my unit. }\end{array}$ & 3.37 & 273 & 1.342 & 3.15 & 204 & 1.325 & 3.28 & 477 & \\
\hline & $\begin{array}{l}\text { I have a voice in decision- } \\
\text { making that affects the } \\
\text { direction of my department. }\end{array}$ & 3.52 & 253 & 1.143 & 3.44 & 192 & 1.147 & 3.49 & 445 & \\
\hline & $\begin{array}{l}\text { I receive useful feedback } \\
\text { from colleagues at UM that } \\
\text { improves my work. }\end{array}$ & 3.08 & 272 & 1.139 & 3.13 & 205 & 1.210 & 3.10 & 477 & \\
\hline & $\begin{array}{l}\text { I have been effectively } \\
\text { mentored by someone in } \\
\text { my unit. }\end{array}$ & 2.79 & 269 & 1.265 & 2.71 & 204 & 1.397 & 2.75 & 473 & \\
\hline \multirow{5}{*}{ 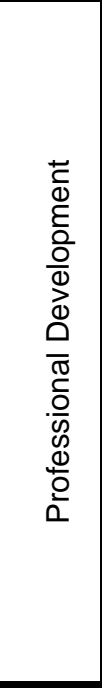 } & $\begin{array}{l}\text { Assistance with finding } \\
\text { grants (four point scale; top } \\
\text { two categories collapsed) }\end{array}$ & 2.66 & 254 & 1.039 & 2.59 & 193 & 1.002 & 2.63 & 447 & 1.023 \\
\hline & $\begin{array}{l}\text { Professional assistance for } \\
\text { improving teaching (four } \\
\text { point scale: top two } \\
\text { categories collapsed) }\end{array}$ & 3.05 & 251 & .847 & 3.06 & 189 & .876 & 3.05 & 440 & .859 \\
\hline & $\begin{array}{l}\text { My unit has financially } \\
\text { supported my learning in my } \\
\text { field or discipline (e.g., } \\
\text { provided funds to attend } \\
\text { conferences, buy software, } \\
\text { books or equipment for my } \\
\text { research). }\end{array}$ & 2.87 & 275 & 1.399 & 3.01 & 205 & 1.358 & 2.93 & 480 & 1.382 \\
\hline & $\begin{array}{l}\text { Amount of access to TAs, } \\
\text { RAs }\end{array}$ & 2.81 & 248 & 1.217 & 2.67 & 193 & 1.170 & 2.75 & 441 & 1.198 \\
\hline & $\begin{array}{l}\text { Assistance with research } \\
\text { administration in your unit * }\end{array}$ & 3.12 & 251 & 1.211 & 2.83 & 187 & 1.193 & 3.00 & 438 & 1.210 \\
\hline
\end{tabular}




\begin{tabular}{|c|c|c|c|c|c|c|c|c|c|c|}
\hline \multirow[b]{2}{*}{$\begin{array}{c}\text { Constr } \\
\text { ucts }\end{array}$} & \multirow[b]{2}{*}{ Survey Item } & \multicolumn{3}{|c|}{ Male } & \multicolumn{3}{|c|}{ Female } & \multicolumn{3}{|c|}{ Total } \\
\hline & & Mean & $\mathrm{N}$ & $\begin{array}{l}\text { Std. } \\
\text { Dev. }\end{array}$ & Mean & $\mathrm{N}$ & $\begin{array}{l}\text { Std. } \\
\text { Dev. }\end{array}$ & Mean & $\mathrm{N}$ & $\begin{array}{l}\text { Std. } \\
\text { Dev. }\end{array}$ \\
\hline \multirow{4}{*}{ 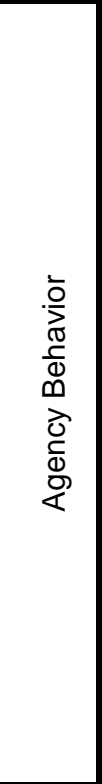 } & $\begin{array}{l}\text { I have been strategic in } \\
\text { achieving my career goals } \\
\text { (four point scale; bottom two } \\
\text { categories collapsed) }\end{array}$ & 2.69 & 261 & .968 & 2.76 & 198 & 1.033 & 2.72 & 459 & .996 \\
\hline & $\begin{array}{l}\text { I seize opportunities when } \\
\text { they are presented to me to } \\
\text { advance in my career (four } \\
\text { point scale; bottom two } \\
\text { categories collapsed) }\end{array}$ & 2.98 & 264 & .885 & 2.94 & 200 & .875 & 2.97 & 464 & .880 \\
\hline & $\begin{array}{l}\text { I have intentionally made } \\
\text { choices to focus my career } \\
\text { in ways that are personally } \\
\text { meaningful to me (four } \\
\text { point scale; bottom two } \\
\text { categories collapsed) }\end{array}$ & 3.172 & 262 & .6983 & 3.056 & 198 & .8795 & 3.12 & 460 & .7827 \\
\hline & $\begin{array}{l}\text { I have taken strategic steps } \\
\text { towards creating a } \\
\text { satisfactory work-life } \\
\text { balance (four point scale; } \\
\text { bottom two categories } \\
\text { collapsed) }\end{array}$ & 2.70 & 258 & .934 & 2.67 & 196 & 1.041 & 2.69 & 454 & .981 \\
\hline \multirow{6}{*}{ 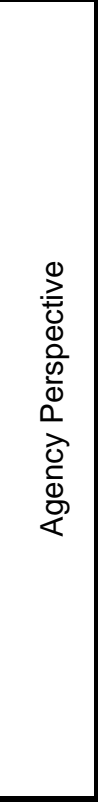 } & $\begin{array}{l}\text { I am in charge of the } \\
\text { direction of my research } \\
\text { agenda (three point scale; } \\
\text { bottom three categories } \\
\text { collapsed) }\end{array}$ & 2.36 & 252 & 691 & 2.40 & 194 & .629 & 2.37 & 446 & .664 \\
\hline & $\begin{array}{l}\text { I feel stuck in my ability to } \\
\text { advance in my career. } \\
\text { REVERSE CODED }\end{array}$ & 3.49 & 262 & 1.089 & 3.36 & 198 & 1.249 & 3.43 & 460 & 1.161 \\
\hline & $\begin{array}{l}\text { I have little control over } \\
\text { whether I advance in my } \\
\text { career. REVERSE CODED }\end{array}$ & 3.65 & 262 & 1.120 & 3.54 & 197 & 1.140 & 3.61 & 459 & 1.129 \\
\hline & $\begin{array}{l}\text { I feel in control of my } \\
\text { participation in service } \\
\text { activities (the amount and } \\
\text { level of participation). * }\end{array}$ & 3.36 & 256 & 1.104 & 3.06 & 194 & 1.123 & 3.23 & 450 & 1.120 \\
\hline & $\begin{array}{l}\text { Managing my teaching } \\
\text { responsibilities is largely } \\
\text { under my control. }\end{array}$ & 3.64 & 254 & 1.086 & 3.63 & 191 & 1.067 & 3.64 & 445 & 1.077 \\
\hline & $\begin{array}{l}\text { In general, I feel I have } \\
\text { control over creating a } \\
\text { satisfying work-life balance. }\end{array}$ & 3.29 & 257 & 1.077 & 3.09 & 195 & 1.167 & 3.21 & 452 & 1.120 \\
\hline 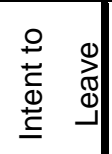 & $\begin{array}{l}\text { To what extent are you } \\
\text { likely to leave the University } \\
\text { in the next two years? (four } \\
\text { point scale) }\end{array}$ & 2.79 & 253 & .803 & 2.73 & 189 & .719 & 2.76 & 442 & .768 \\
\hline
\end{tabular}




\begin{tabular}{|c|c|c|c|c|c|c|c|c|c|c|}
\hline \multirow{2}{*}{$\begin{array}{l}\text { Constr } \\
\text { ucts }\end{array}$} & \multirow[b]{2}{*}{ Survey Item } & \multicolumn{3}{|c|}{ Male } & \multicolumn{3}{|c|}{ Female } & \multicolumn{3}{|c|}{ Total } \\
\hline & & Mean & $N$ & $\begin{array}{l}\text { Std. } \\
\text { Dev. }\end{array}$ & Mean & $\mathrm{N}$ & $\begin{array}{l}\text { Std. } \\
\text { Dev. }\end{array}$ & Mean & $\mathrm{N}$ & $\begin{array}{l}\text { Std. } \\
\text { Dev. }\end{array}$ \\
\hline \multirow{2}{*}{ 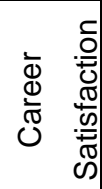 } & $\begin{array}{l}\text { My overall experience } \\
\text { working in my unit }\end{array}$ & 3.60 & 253 & 1.179 & 3.44 & 192 & 1.091 & 3.53 & 445 & 1.144 \\
\hline & $\begin{array}{l}\text { My overall experience } \\
\text { working at UM }\end{array}$ & 3.55 & 253 & 1.138 & 3.48 & 193 & .974 & 3.52 & 446 & 1.070 \\
\hline \multirow{4}{*}{$\begin{array}{l}\sum_{0}^{2} \\
\frac{0}{0} \\
\frac{0}{2} \\
0\end{array}$} & $\begin{array}{l}\text { The number of publications } \\
\text { you authored/co-authored } \\
\text { (peer-reviewed articles, } \\
\text { book chapters, etc.) in the } \\
\text { last two years. (no response } \\
\text { options: fill in the blank) * }\end{array}$ & 12.27 & 254 & 22.57 & 8.99 & 191 & 18.14 & 10.86 & 445 & 20.83 \\
\hline & $\begin{array}{l}\text { The number of other } \\
\text { creative works you created } \\
\text { (e.g., exhibitions, } \\
\text { performances) in the last } \\
\text { two years.(no response } \\
\text { options: fill in the blank) }\end{array}$ & 23.63 & 254 & 40.90 & 36.85 & 191 & 47.42 & 29.30 & 445 & 44.25 \\
\hline & $\begin{array}{l}\text { How would you rate your } \\
\text { overall productivity } \\
\text { compared to researchers in } \\
\text { your field and at your rank } \\
\text { nationwide? (four point } \\
\text { scale) }\end{array}$ & 3.38 & 245 & 1.234 & 3.29 & 185 & 1.207 & 3.34 & 430 & 1.222 \\
\hline & $\begin{array}{l}\text { How do you think your unit } \\
\text { views your level of } \\
\text { productivity, compared to } \\
\text { researchers in your field } \\
\text { and at your rank } \\
\text { nationwide? (four point } \\
\text { scale) }\end{array}$ & 3.03 & 244 & 1.200 & 3.01 & 179 & 1.320 & 3.02 & 423 & 1.250 \\
\hline
\end{tabular}

Notes:

Response scales for items are 1 (strongly disagree or very dissatisfied) - 5 (strongly agree or very satisfied) unless otherwise noted.

* difference by gender $\mathrm{p}<.05$

\section{Analysis of Psychometric Properties-The Measurement Model}

I ran Confirmatory Factor Analyses (CFA) on all eleven constructs of interest to determine the proportion of each survey item that is explained by the latent construct of interest in comparison to the proportion of the item that is attributable to error. Ensuring sound measurement of constructs contributes to a sounder structural model. In each CFA, I freed the loading and error term associated with each item and then constrained the variance of the factor as one. 
The results of the confirmatory factor analyses suggested that certain adjustments needed to be made for fit. In the person-department fit construct, the RMSEA was greater than one and the Lagrange Multiplier test indicated intercorrelated errors among two items. As a result, one item was removed to improve fit (Faculty in my unit are aware of the service that I do for our program). When I investigated the wording of this item, it does not seem to tap the same construct as the other items, which deal with feeling valued by the department or a sense of fit with departmental values. In the professional development construct, two items had loadings below .5 and were removed (professional assistance for improving teaching and financial support for scholarly learning). Low loadings indicated that those items had a lower proportion of variance that was explained by the construct of interest (i.e. they did not sufficiently tap the professional development resources). The collegiality factor contained intercorrelated errors among several items. I removed three items with intercorrelated errors according to the LM test results: I have been effectively mentored by someone in my unit; I receive useful feedback from colleagues at UM that improves my work; I have a voice in decision-making that affects the direction of my department. When these items were removed the problem with errors was resolved.

In the agency behavior and perspective constructs, there were low loadings on one item in agency behavior (I have taken strategic steps towards creating a satisfactory work-life balance) and three items in agency perspective. I removed these four items. It is interesting that the items that related to agency behavior or perspective in work-life balance or service had low loadings, while the items regarding agency in career (e.g., I have been strategic in achieving my career goals) had higher loadings. This pattern 
seems to support O'Meara, Campbell, and Terosky (2011) contention that agency is domain specific. For example, agency in work-life balance and teaching are different constructs than agency in career advancement. A person could have high agency in family life and low agency in career. The final agency constructs included items regarding agency perspective and agency behavior in career advancement. One item in the agency perspective construct was more specifically related to feeling in charge of own's research agenda. It makes theoretical sense that this item would hang well with other career advancement items at a research institution where research productivity is highly valued in reward structures. Finally, the productivity factor had one item with very low loading $(<.2)$, and it was removed (The number of other creative works you created (e.g., exhibitions, performances) in the last two years). Creative works may not be as closely linked to productivity because not all disciplines include creative works in scholarship.

Once the adjustments had been made to the individual constructs within the model, I ran a confirmatory factor analysis model that allowed all eleven constructs to correlate freely. This model had several errors and would not run. In order to determine the next steps in the model process, I investigated the intercorrelations among the constructs (Table 7). The intercorrelations revealed that two constructs (collegiality and satisfaction) had extremely high correlations with all of the organizational factors. This would lead to multicollinearity problems in the model. It may be that the collegiality and satisfaction factors were proxys for an omnibus organizational factor, and as a result, the variance explained by these constructs was already explained by the other organizational factors in the model. 
Table 7

11 Factor Confirmatory Factor Analysis Intercorrelations

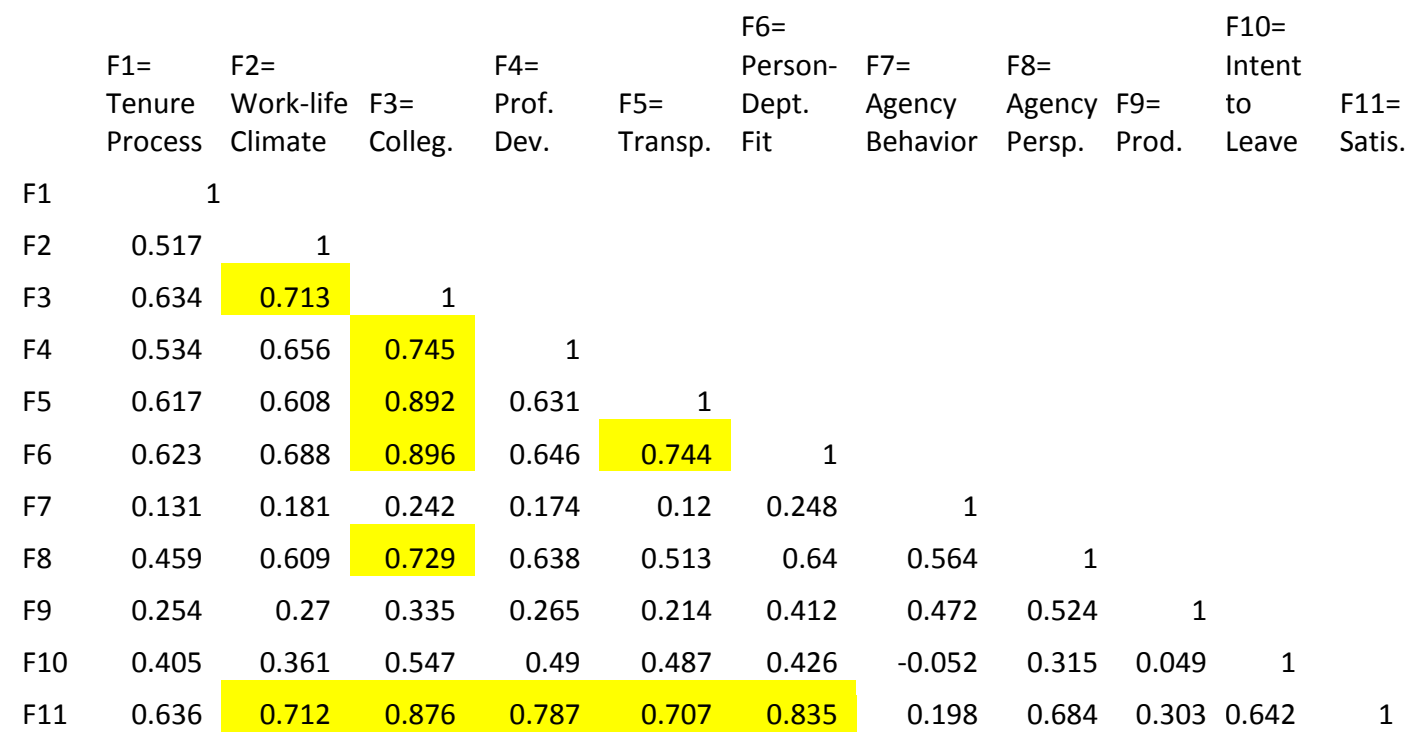

Based on these results, I re-ran the CFA model excluding the collegiality and satisfaction construct. The new CFA model included five organizational climate factors (tenure process, work-life climate, professional development, transparency, and persondepartment fit), two agency constructs (behavior and perspective), and two outcome measures (productivity and intent to stay). This new model showed much improved intercorrelations among the constructs. However, there were linear dependency issues with the productivity construct and the LM Test recommended cross loadings with one of the items from this construct and several of the organizational factors. Reviewing the wording of the item, the reason why this item might co-vary with the organizational factors becomes apparent: "How do you think your unit views your level of productivity, compared to researchers in your field and at your rank nationwide?" This item deals with self-perceived ratings of a unit. 
Based on the suggested cross loadings and the linearity concerns, I decided to remove the productivity construct, and re-run the CFA with eight factors. Once again, there was linear dependency with the outcome measure: intent to leave. However, the intent to leave construct had linear dependency with agency perspective. Based on these several results, I had no choice but to remove all outcome measures from the model.

There may be something about self-perceived outcome measures that causes linear dependency, intercorrelations among constructs, and intercorrelated errors with other perception-based organizational and agency constructs. For example, satisfaction and productivity had linear dependency with organizational constructs. When I examined the items within these constructs, it appears that they measure perceptions of one's unit. For example, one of the items in the satisfaction construct was "satisfaction with unit" and one of the items in the productivity construct was "How do you think your unit views your level of productivity?" There may be linear dependency because the satisfaction and productivity constructs tap a broader sense of one's unit, which is also mirrored in the organizational factors. The linear dependency concerns do not indicate that outcomes are unrelated to agency, but rather, that outcomes need to be measured in a different way in future studies (e.g. CV document analysis for productivity or actual leaving behavior rather than intent to leave). In fact, outside of measurement concerns, it is possible that the nature of the linearity between agency perspective and intent to stay indicates that agency and outcomes are fully intertwined. The simple correlations between agency perspective and the three outcome measures are moderate to strong and positive. The dynamic interplay between these constructs could be investigated in future qualitative studies. 
Finally, I ran a CFA model that included only the five organizational and two agency constructs. This corrected the linear dependency issues, and allowed for excellent model fit on robust statistics $(\mathrm{NNFI}=.975, \mathrm{CFI}=.980, \mathrm{RMSEA}=.053, \mathrm{CI}(.045, .061))$. Additional evidence of a strong psychometric model lies in the loadings. The model had standardized loadings that range from .498 to .890 . Only one item had less than .5 loading and 16 out of 22 items had greater than .7 loadings. Investigation of the intercorrelations among the benchmarks suggests that the seven constructs in the model, while related, were distinct (Table 8). The only two constructs with very high intercorrelations were transparency and person-department fit. However, considering the strength of the model fit, and the absence of linearity in the model, I accepted this as the final measurement model. The final model standardized loadings and factor reliabilities can be found in Table 9.

Table 8

Intercorrelations among 7 Constructs

\begin{tabular}{|c|c|c|c|c|c|c|c|}
\hline & $\begin{array}{l}\mathrm{F} 1= \\
\text { Tenure } \\
\text { Process }\end{array}$ & $\begin{array}{l}\mathrm{F} 2= \\
\text { Work-life } \\
\text { Climate }\end{array}$ & $\begin{array}{l}\text { F3= } \\
\text { Prof. } \\
\text { Dev. }\end{array}$ & $\begin{array}{l}\text { F4= } \\
\text { Transp. }\end{array}$ & $\begin{array}{l}\text { F5= } \\
\text { Person- } \\
\text { Dept. } \\
\text { Fit }\end{array}$ & $\begin{array}{l}\text { F6= } \\
\text { Agency } \\
\text { Behavior }\end{array}$ & $\begin{array}{l}\text { F7= } \\
\text { Agency } \\
\text { Persp. }\end{array}$ \\
\hline F1 & 1 & & & & & & \\
\hline $\mathrm{F} 2$ & 0.524 & 1 & & & & & \\
\hline F3 & 0.51 & 0.651 & 1 & & & & \\
\hline $\mathrm{F} 4$ & 0.624 & 0.597 & 0.629 & 1 & & & \\
\hline F5 & 0.637 & 0.683 & 0.643 & 0.743 & 1 & & \\
\hline F6 & 0.096 & 0.201 & 0.163 & 0.096 & 0.226 & 1 & \\
\hline F7 & 0.434 & 0.591 & 0.605 & 0.502 & 0.621 & 0.564 & \\
\hline
\end{tabular}


Table 9

Item Loadings and Reliabilities for the Final Seven Factor CFA Model

\begin{tabular}{|c|c|c|c|}
\hline Constructs & Survey Item & $\begin{array}{c}\text { Item } \\
\text { Loading }\end{array}$ & $\begin{array}{c}\text { Coefficient } \\
\mathrm{H}\end{array}$ \\
\hline \multirow{2}{*}{ 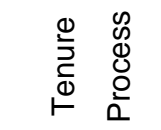 } & In my unit, the tenure requirements are clear. & .802 & \multirow[t]{2}{*}{.876} \\
\hline & In my unit, the tenure process is fair. & .917 & \\
\hline \multirow{4}{*}{ 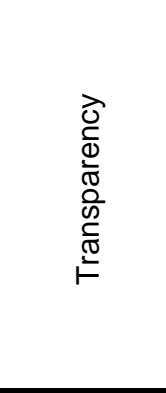 } & & .873 & \multirow[t]{4}{*}{.880} \\
\hline & $\begin{array}{l}\text { Resource allocation in my unit (e.g., space, funded research } \\
\text { assistants) is transparent. }\end{array}$ & .820 & \\
\hline & $\begin{array}{l}\text { Decisions regarding salary increases in my unit are } \\
\text { transparent. }\end{array}$ & .720 & \\
\hline & $\begin{array}{l}\text { Information is available to understand my relative standing } \\
\text { among my peers. }\end{array}$ & .710 & \\
\hline \multirow{3}{*}{ 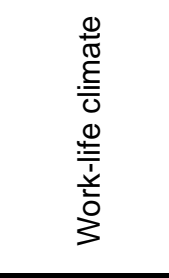 } & I am satisfied with my unit's culture around work-life balance. & .860 & \multirow[t]{3}{*}{.817} \\
\hline & $\begin{array}{l}\text { There are role-models in my unit of how to create a satisfying } \\
\text { work-life balance. }\end{array}$ & .749 & \\
\hline & $\begin{array}{l}\text { The amount of work my unit expects me to perform makes } \\
\text { work-life balance difficult. REVERSE CODED }\end{array}$ & .503 & \\
\hline \multirow{3}{*}{ 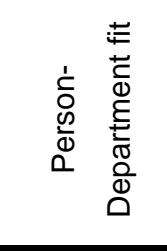 } & The sense of fit between my values and those of my unit & .893 & \multirow[t]{3}{*}{.871} \\
\hline & $\begin{array}{l}\text { Faculty in my unit value my teaching contributions. } \\
\text { Faculty in my unit value my research/scholarship. }\end{array}$ & $\begin{array}{l}.605 \\
.743\end{array}$ & \\
\hline & Faculty in my unit value my service contributions. & .711 & \\
\hline \multirow{3}{*}{ 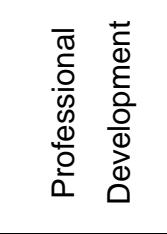 } & Assistance with finding grants & .489 & \multirow[t]{3}{*}{.648} \\
\hline & Amount of access to TAs, RAs & .569 & \\
\hline & Assistance with research administration in your unit & .715 & \\
\hline \multirow[b]{2}{*}{ 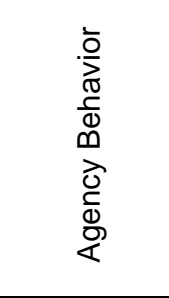 } & I have been strategic in achieving my career goals & .890 & \multirow[t]{2}{*}{.750} \\
\hline & $\begin{array}{l}\text { I seize opportunities when they are presented to me to } \\
\text { advance in my career } \\
\text { I have intentionally made choices to focus my career in ways } \\
\text { that are personally meaningful to me }\end{array}$ & .526 & \\
\hline \multirow{2}{*}{ 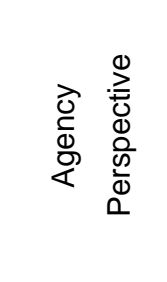 } & $\begin{array}{l}\text { I am in charge of the direction of my research agenda } \\
\text { I feel stuck in my ability to advance in my career. REVERSE } \\
\text { CODED }\end{array}$ & .568 & \multirow[t]{2}{*}{.797} \\
\hline & $\begin{array}{l}\text { I have little control over whether I advance in my career. } \\
\text { REVERSE CODED }\end{array}$ & .735 & \\
\hline
\end{tabular}




\section{Results for Structural Models}

After ascertaining the psychometric properties of the model and determining adequate model fit, I proceeded with testing the posited structural model in order to answer research questions one and two. It is important to note that adjusting the psychometric properties of the model had important implications for the causal structure. Mainly, the new model, presented in Figure 4, required the removal of collegiality from the organizational factors and the removal of the outcome variables (explained in the preceding section, Analysis of Psycometric Properties).

There are also good theoretical reasons, in addition to psychometric reasons, for excluding the collegiality and outcome constructs. For example, Birnbaum (1988) describes collegiality in terms that seem complementary to issues of transparency and feeling a good fit in one's environment (i.e. they may not be distinct constructscollegiality could be an omnibus climate factor). Additionally, self-reported outcome measures in surveys have received recent attention in the higher education literature because they introduce the possibility of bias and error, such as social desirability, selfefficacy, and memory recall problems (Porter, 2011; Simone, Campbell, \& Newhart, 2012). While the removal of the collegiality factor and the outcome variables in this study was important for obtaining a sound model, this kind of post-hoc modification to a model must be considered when interpreting results, particularly because SEM is a confirmatory approach. Future research should investigate whether the model would hold with outcome measures - using alternative forms of measurements of outcomes (e.g., observations, unobtrusive measures, $\mathrm{CV}$ document analyses). 


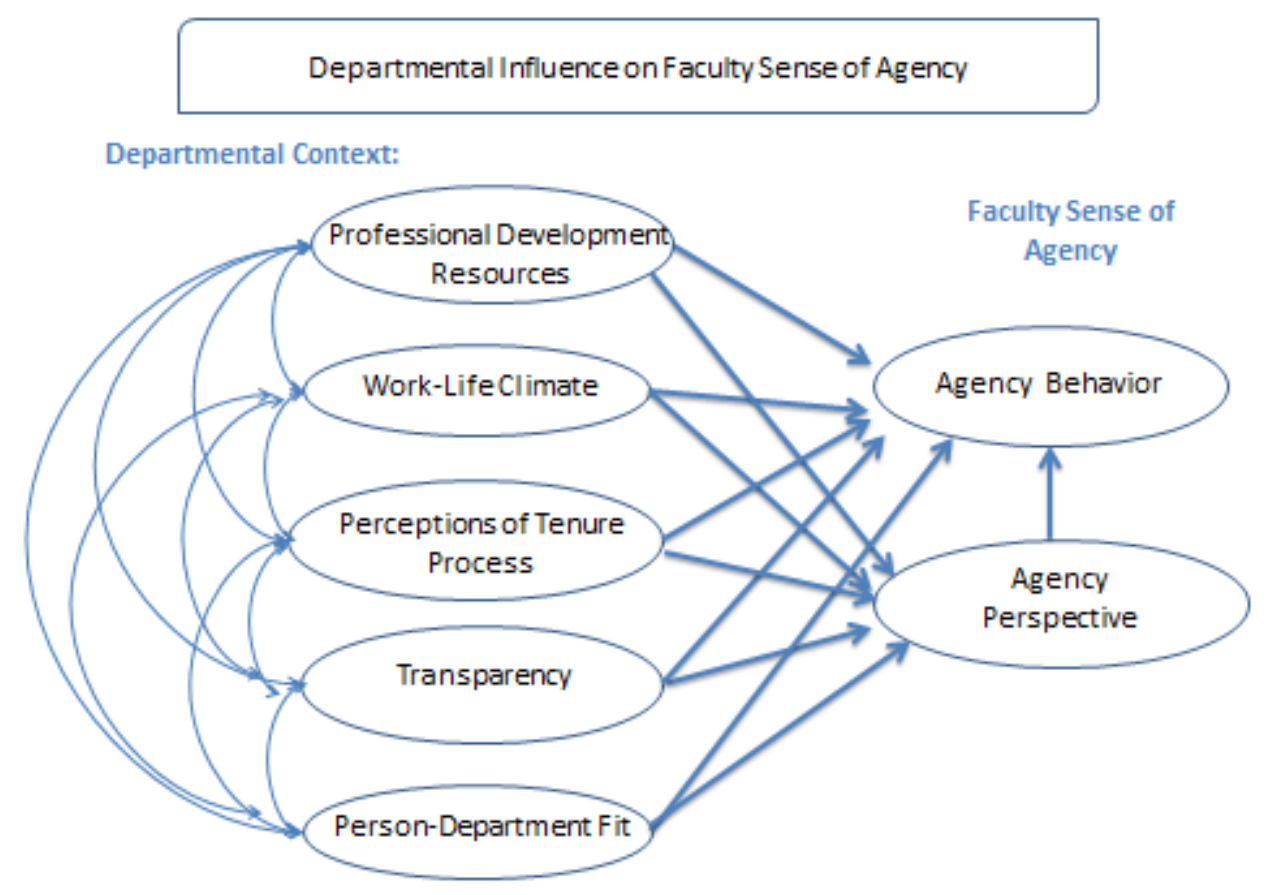

Figure 4. New model of departmental influences on faculty agency.

\section{Results of research question 2.}

While out of order, I will discuss the results of research question two first.

Research Question two asked, "What faculty outcomes (career) are related to agency?"

Unfortunately, due to the psychometric properties of the model, the faculty career outcomes were removed from the model, and research question two could not be fully pursued. The results of the measurement model suggest high intercorrelation and collinearity between the outcome measures and the organizational and agency constructs. Satisfaction and productivity were linearly dependent on organizational factors and intent to stay was linearly dependent on agency perspective. It is likely that these intercorrelations are due to the perceptual, self-reported nature of the survey. For example, satisfaction, transparency, and work-life climate all deal with perceptions of the 
organizational environment. In another example, intent to stay and agency perspective both underscore a respondent's mindset with regard to their career.

It is important to note that while I could not pursue research question two due to intercorrelations and the measurement model, this does not signify that agency is not related to outcomes. Rather, this study indicates that correctly assessing the association between agency and outcomes requires alternative methods. Future studies should use methods other than self-reported surveys to test the hypothesis that agency in career goals influences important faculty outcomes, such as retention, satisfaction, and productivity. For example, a study could use observational methods to see how agentic faculty do or do not have better career outcomes than non-agentic faculty, or use a measure of actual leave-taking behavior (rather than intentions) or a count of publications from a $\mathrm{CV}$ (rather than self-reports). The problem that I encountered in this study, measuring outcomes with self-reports, has been documented as problematic in surveys that assess self-reported outcomes in a number of studies (see Porter, 2011; Simone, Campbell, \& Newhart, 2012).

\section{Results of research question 1.}

Next, I turn to the results of research question 1, which asks, "What organizational factors influence faculty agency?" To answer this question, I tested a posited model (Figure 4) using Least Squares Structural Equation Modeling with robust standard errors in order to account for a categorical variable and issues with multivariate normality. In this model, I constrained the item with the highest loading in each construct to one and allowed the variance of the factors to be free. 
Results showed excellent model fit. While the Satorra-Bentler Scaled estimate of chi-square was significant $(S-B \chi 2=128.84, \mathrm{df}=64)$, the Yuan-Bentler Residual-based FStatistic was not significant $(\mathrm{F}=.0461, \mathrm{p}>.05)$ and the NNFI (.975), the CFI (.980), and the RMSEA $(.053, \mathrm{CI}(.045, .061))$ were all excellent. All intercorrelations among the five organizational factors were statistically significant $(\mathrm{p}<.05)$. Regarding the causal model, the only factor that had a significant influence on agentic behavior was agentic perspective. No organizational factors had a significant influence on agentic behavior. By contrast, three of five organizational factors had a significant influence on agentic perspective. Work-life climate, professional development, and person-department fit were significant contributors to agentic perspective. Below are the standardized structural equations for the model:

$\mathrm{F} 6=.775 * \mathrm{~F} 7-.057 * \mathrm{~F} 1-.051 * \mathrm{~F} 2-.176 * \mathrm{~F} 3-.143 * \mathrm{~F} 4+.036 * \mathrm{~F} 5+.783 \mathrm{D} 6$ (r-squared .387)

$\mathrm{F} 7=-.003 * \mathrm{~F} 1+.207 * \mathrm{~F} 2+.290 * \mathrm{~F} 3-.048 * \mathrm{~F} 4+.331 * \mathrm{~F} 5+.723 \mathrm{D} 7 \quad(\mathrm{r}-$ squared $=.478)$

Note: Tenure process (f1) Work-life climate (f2), Professional development (f3), Transparency (f4), Person-department fit (f5) Agency behavior (f6), Agency perspective (f7)

While the fit for this model was strong, there were several non-significant paths. In addition, the Lagrange Multiplier test suggested removing paths from all of the organizational factors to behavior with the exception of professional development resources. As a result, I decided to respecify the model by removing those paths and also removing the non-significant factors (transparency and fair tenure process) to create greater parsimony (i.e. to create the simplest model with no unnecessary constructs). 
The resulting model, presented in Figure 5, demonstrated excellent fit to the data. While the Satorra-Bentler Scaled estimate of chi-square $(S-B \chi 2=174.46, \mathrm{df}=96)$ and the Yuan-Bentler Residual-based F-Statistic $(\mathrm{F}=1.40, \mathrm{df}=96)$ were significant $(\mathrm{p}<.05)$, the NNFI (.979), CFI (.983), and RMSEA $(.045$, CI $(.034, .056))$ indicated excellent fit for the data. In addition, all model parameters, including individual paths and intercorrelations were significant. Professional development exerted a moderate positive influence on agentic perspective, but a moderate negative influence on agentic behavior. Work-life climate and person-department fit exhibited small, but non-trivial influences on agentic perspective. Finally, agentic perspective had a very strong positive influence on agentic behavior. In all, the model explained $37 \%$ of the variance in agentic behavior and $48 \%$ of the variance in agentic perspective. Direct, indirect, and total effects of each organizational factor on agentic behavior and perspective can be found in Table 10. Due to the excellent fit of this model, I retain this as the final, specified model. Below are the standardized structural equations for the model:

$$
\begin{aligned}
& \mathrm{F} 4=.752 * \mathrm{~F} 5-.336 * \mathrm{~F} 2+.797 \mathrm{D} 4 \quad(\mathrm{r}-\text { squared } .365) \\
& \mathrm{F} 5=\mathrm{F} 5=.209 * \mathrm{~F} 1+.327 * \mathrm{~F} 2+.251 * \mathrm{~F} 3+.723 \mathrm{D} 5 \quad(\mathrm{r} \text {-squared } .477)
\end{aligned}
$$

Note: Work-life climate (f1), professional development (f2), person-department fit (f3) agency behavior (f4), agency perspective (f5) 


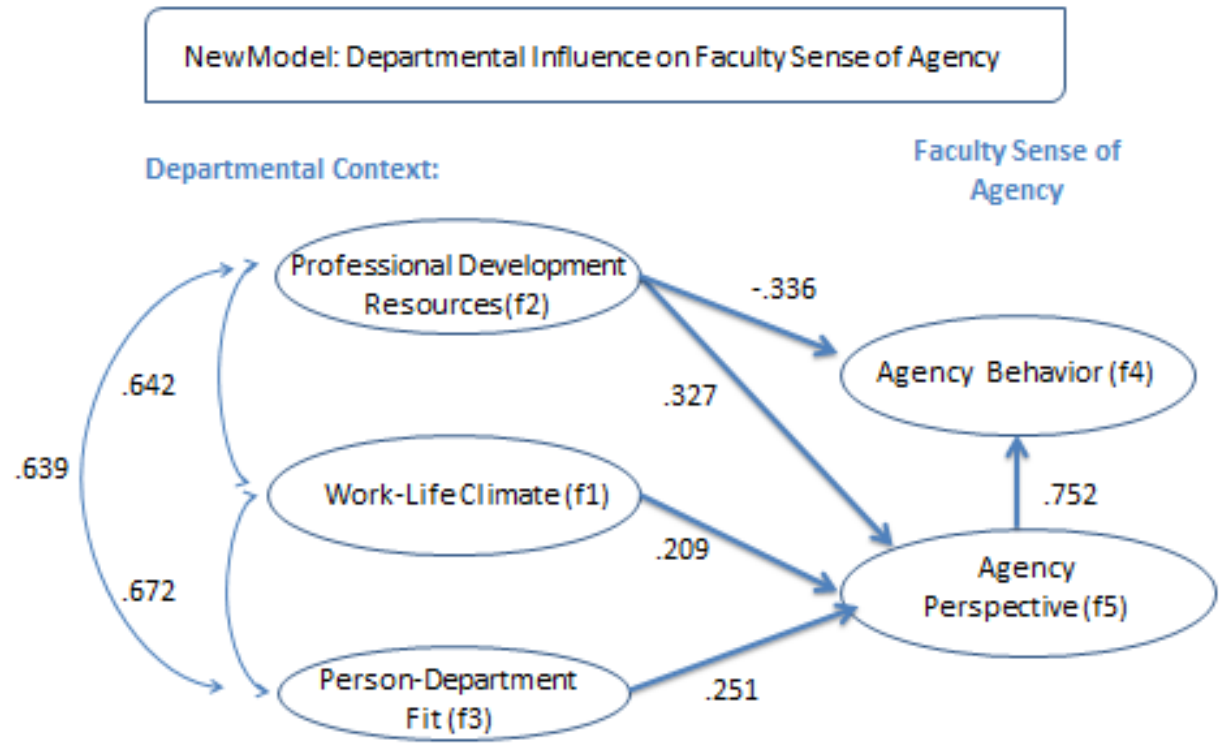

Figure 5. Revised model of departmental influence on faculty sense of agency.

Table 10

Direct, Indirect, and Total Effects of Organizational Factors on Agency

\begin{tabular}{|l|c|c|c|c|c|c|}
\hline \multirow{2}{*}{ Construct } & \multicolumn{3}{|c|}{ Agency Behavior } & \multicolumn{3}{c|}{ Agency Perspective } \\
\cline { 2 - 7 } & Direct & Indirect & Total & Direct & Indirect & Total \\
\hline $\begin{array}{l}\text { Professional } \\
\text { Development }\end{array}$ & -.336 & .246 & -.09 & .327 & --- & .327 \\
\hline $\begin{array}{l}\text { Work-Life } \\
\text { Climate }\end{array}$ & --- & .157 & .157 & .209 & --- & .209 \\
\hline $\begin{array}{l}\text { Person- } \\
\text { Department } \\
\text { Fit }\end{array}$ & --- & .189 & .189 & .251 & --- & .251 \\
\hline
\end{tabular}

\section{Results from research question 3.}

After ascertaining a final model of faculty agency with appropriate fit, I proceeded to run the test of invariance by gender. The first step of the invariance test is to run the model for each gender separately. However, when I ran the model for men and women separately, the model had errors for both men and women. In addition, the 
variance of one item in the agency perspective construct (the only categorical variable in the model) was set to zero. In order to proceed with the analysis by gender, I decided to remove the item "I am in charge of the direction of my research agenda." While this item does have face validity with the other two items regarding agency perspective in career, there may be some concern regarding how this item acts across genders. The item was not problematic in the analysis when all participants were included, but when the model was run with men and women separately, the variance of this item was set to zero. Additionally, while the means of this item are similar between men and women, the variance of the item for men was slightly greater than for women. For all of these reasons, I decided to remove the item before proceeding with the test of invariance. The agency perspective construct still held up well without this item, as evidenced by the strong loadings.

The final model for the test of invariance was slightly respecified. All of the structural paths were the same as the final model of faculty organization and agency (Figure 5). However, the measurement model was changed with the removal of the item from the agency perspective construct. The results of the new model for the test of invariance are shown in Figure 6. The model fit was excellent. While the Satorra-Bentler Scaled estimate of chi-square $(S-B \chi 2=132.84, \mathrm{df}=82)$ was significant $(\mathrm{p}<.05)$, the YuanBentler Residual-based F-Statistic $(\mathrm{F}=1.24, \mathrm{df}=82)$ was not significant $(\mathrm{p}<.05)$, and other indices of fit were very strong $(\mathrm{NNFI}=.985, \mathrm{CFI}=.989 ; \mathrm{RMSEA}=.039, \mathrm{CI}(.026$, .051)). All paths and intercorrelations were significant. 
$\mathrm{F} 4=.603 * \mathrm{~F} 5-.196 * \mathrm{~F} 2+.853 \mathrm{D} 4 \quad(\mathrm{r}-$ squared .272$)$

$\mathrm{F} 5=.226 * \mathrm{~F} 1+.228 * \mathrm{~F} 2+.283 * \mathrm{~F} 3+.764 \mathrm{D} 5 \quad(\mathrm{r}-$ squared .416$)$

Note: work-life climate (f1), professional development (f2), person-department fit (f3) agency behavior (f4), agency perspective (f5)

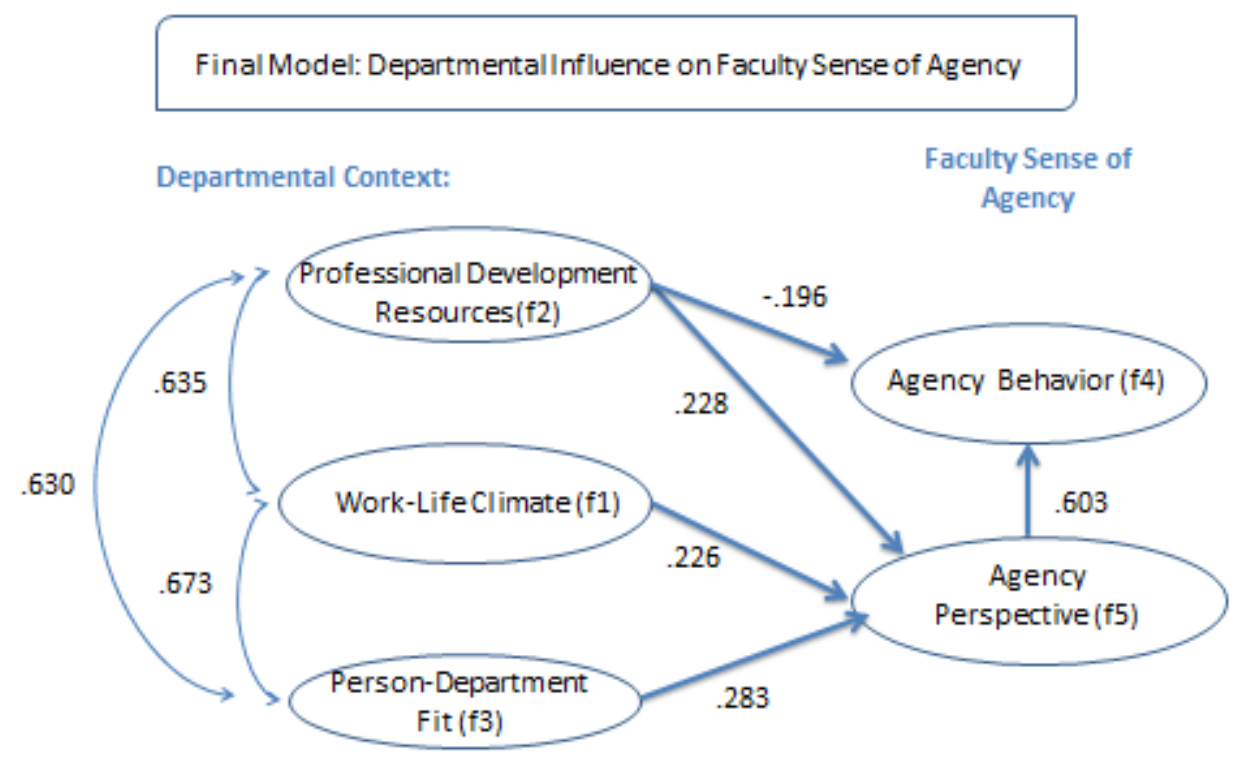

Figure 6. Final model for test of invariance by gender.

\section{Baseline models by gender.}

After obtaining this new model, I proceeded with running the same model for men and women. The results of the model for men are based on 233 participants. The model fit is exceptional. The Satorra-Bentler Scaled estimate of chi-square $(S-B \chi 2=90.74 .46$, $\mathrm{df}=82)$ and the Yuan-Bentler Residual-based F-Statistic $(\mathrm{F}=.84, \mathrm{df}=82)$ were not significant $(p>.05)$. The other indices of fit also indicate very strong fit $(\mathrm{NNFI}=.996, \mathrm{CFI}=.997$; RMSEA $=.021, \mathrm{CI}(.000, .044))$. Interestingly, for the model for men, while the fit was very strong, none of the organizational paths were significant in influencing either agency behavior or perspective (Figure 7). This may mean that for men, the organizational 
constructs, together, are important for the model of agency, but each organizational construct on its own is not a statistically significant contributor. Similar to the model for all participants, agency perspective did have a strong positive contribution to agentic behavior for men. Below are the standardized structural equations for the model for men: $\mathrm{F} 4=.541 * \mathrm{~F} 5-.197 * \mathrm{~F} 2+.888 \mathrm{D} 4 \quad(\mathrm{r}-$ squared .212$)$ $\mathrm{F} 5=.205 * \mathrm{~F} 1+.224 * \mathrm{~F} 2+.265 * \mathrm{~F} 3+.780 \mathrm{D} 5 \quad(\mathrm{r}-\mathrm{squared} .391)$

Note: Work-life climate (f1), professional development (f2), person-department fit (f3) agentic behavior (f4), agentic perspective (f5)

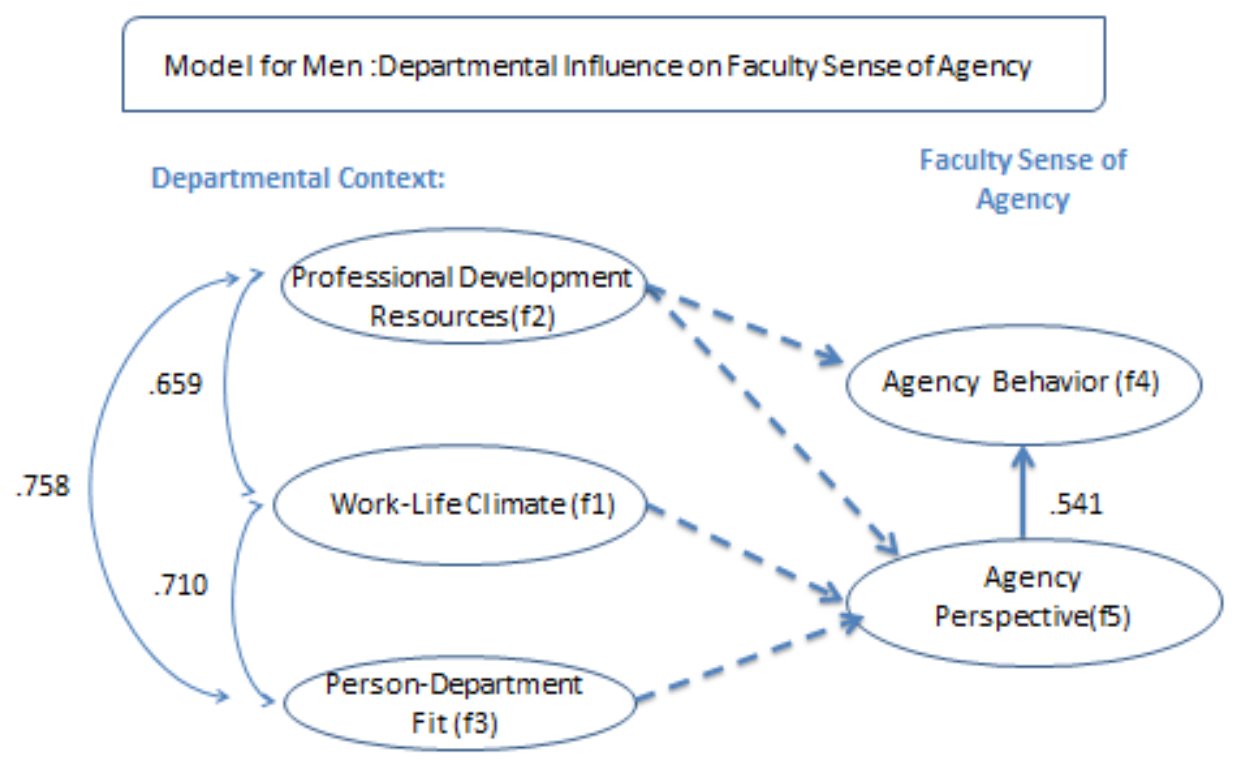

Figure 7. Model of organizational influence on faculty agency for men.

After ascertaining the model fit for men, I ran the same model for women, based on 171 participants. Once again, the model fit is strong. The Satorra-Bentler Scaled estimate of chi-square $(S-B \chi 2=102.02, \mathrm{df}=82)$ and the Yuan-Bentler Residual-based FStatistic $(\mathrm{F}=.92, \mathrm{df}=82)$ were not significant $(\mathrm{p}>.05)$. The other indices of fit also indicate very strong fit $(\mathrm{NNFI}=.985, \mathrm{CFI}=.988 ; \mathrm{RMSEA}=.038, \mathrm{CI}(.000, .060))$. While the model 
fit is very strong, the only significant path from the organizational factors to the agency constructs is the path from person-department fit to agency perspective (Figure 8). This suggests that, together, the organizational factors have an influence on agency perspective, but of the three, only one (person-department fit) exerted a statistically significant effect on agency perspective on its own. It appears that feeling valued and a having a congruence between one's own values and the values of the organization (i.e. person-department fit) is particularly important in the agentic perspective of women. The model for women also shows a very strong influence of agency perspective on agency behavior. The standardized structural path equations are as follows:

$\mathrm{F} 4=.631 * \mathrm{~F} 5-.142 * \mathrm{~F} 2+.821 \mathrm{D} 4 \quad(\mathrm{r}$-squared .325$)$

$\mathrm{F} 5=.245 * \mathrm{~F} 1+.235 * \mathrm{~F} 2+.310 * \mathrm{~F} 3+.747 \mathrm{D} 5 \quad(\mathrm{r}$-squared .442$)$

Note: Work-life climate (f1), professional development (f2), person-department fit (f3) agency behavior (f4), agency perspective (f5)

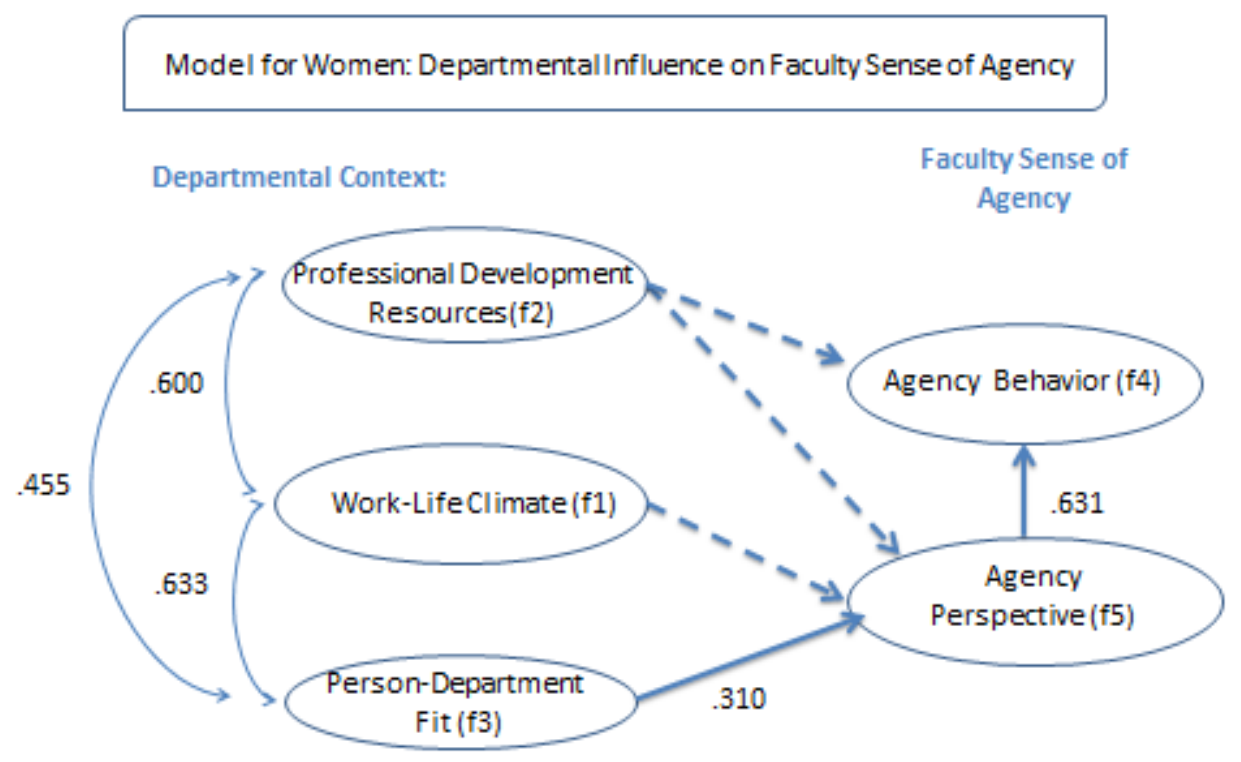

Figure 8. Model of organizational influence on faculty agency for women. 


\section{Configural invariance model.}

After establishing baseline models and appropriate model fit for each gender separately, I then ran a test for configural invariance. In this model I included both the model for men and for women, but did not include any equality constraints. The configural model establishes whether there is a good fit among both models (for men and women) simultaneously in terms of the numbers of loadings and structural parameters. It does not test whether magnitude of the relationships among the constructs or the loadings are equal for men and women (which is done in the final test of invariance).

The results of the configural invariance model showed excellent fit statistics. While the Satorra-Bentler Scaled estimate of chi-square $(S-B \chi 2=211.55, \mathrm{df}=164)$ was significant $(\mathrm{p}<.05)$ indicating less than ideal fit, the other four indices of fit indicated excellent fit. The Yuan-Bentler Residual-based F-Statistic $(\mathrm{F}=1.210, \mathrm{df}=82)$ was not significant ( $\mathrm{p}>.05)$, and the NNFI (985), the CFI (.988), and the RMSEA (.038, CI (.021, .052)) all indicate very strong fit. The standardized structural equations are below and the model can be seen in Figure 9.

Women:

$$
\begin{aligned}
& \mathrm{F} 4=.649 * \mathrm{~F} 5-.152 * \mathrm{~F} 2+.814 \mathrm{D} 4 \quad(\mathrm{r} \text {-squared } .325) \\
& \mathrm{F} 5=.241 * \mathrm{~F} 1+.254 * \mathrm{~F} 2+.300 * \mathrm{~F} 3+.740 \mathrm{D} 5
\end{aligned}
$$

Men:

$$
\begin{aligned}
& \mathrm{F} 4=.535 * \mathrm{~F} 5-.201 * \mathrm{~F} 2+.893 \mathrm{D} 4 \quad(\mathrm{r} \text {-squared .203) } \\
& \mathrm{F} 5=.205 * \mathrm{~F} 1+.251 * \mathrm{~F} 2+.245 * \mathrm{~F} 3+.774 \mathrm{D} 5 \quad(\mathrm{r} \text {-squared } .400)
\end{aligned}
$$

Note: Work-life climate (f1), professional development (f2), person-department fit (f3) agency behavior (f4), agency perspective (f5) 


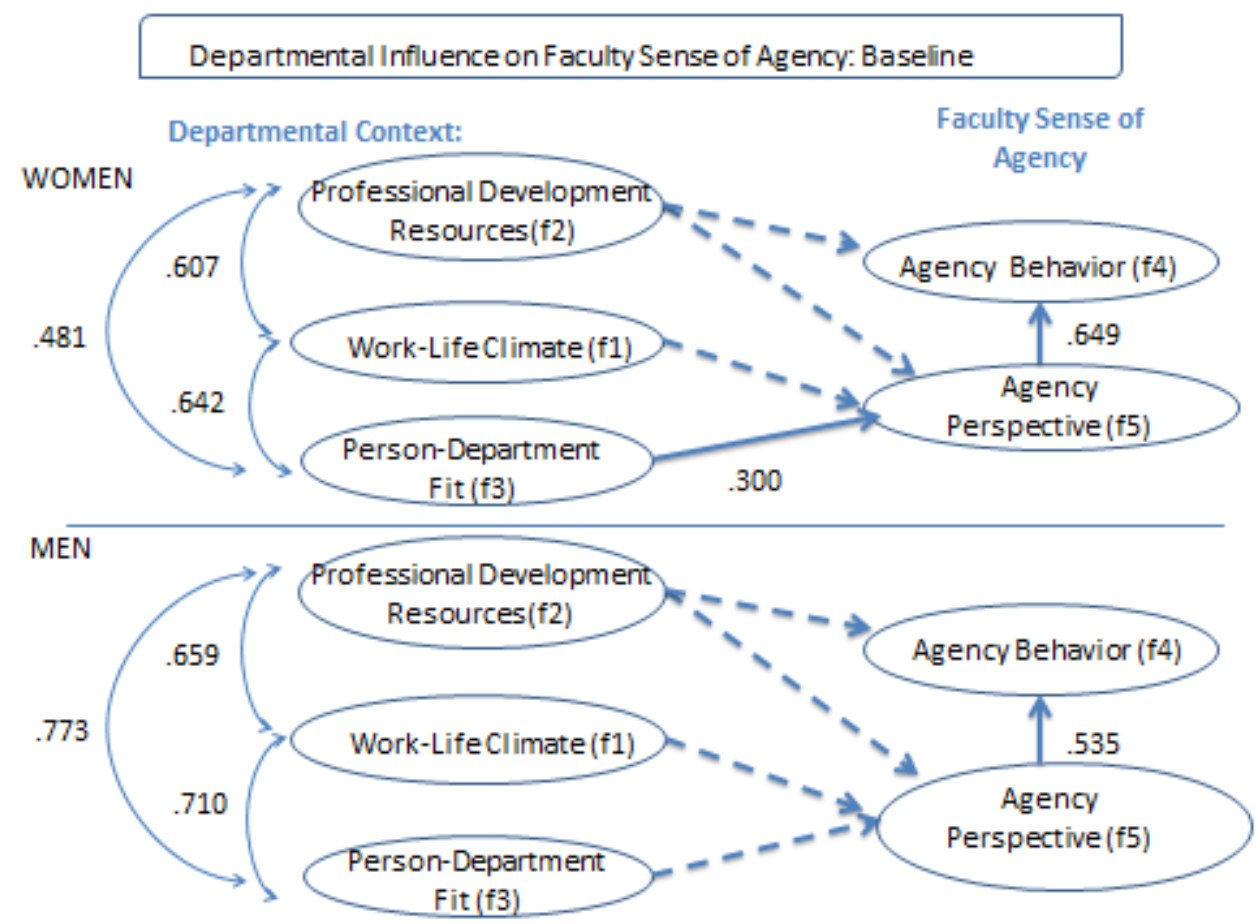

Figure 9. Model for test of configural invariance.

\section{Test for invariance.}

After finding appropriate fit in the configural model, I proceeded to test a fully constrained model for invariance. In essence, this tests whether every aspect of the model (both the measurement model and the structural model) are the same for men and women. I entered both models simultaneously for men and women, as I had done for the configural model. However, in this test, I added constraints across men and women for all loadings, paths, and co-variances.

Surprisingly, this highly constrained model showed excellent fit statistics. While the Satorra-Bentler Scaled estimate of chi-square $(S-B \chi 2=225.6507, \mathrm{df}=182)$ was significant $(\mathrm{p}<.05)$ indicating less than ideal fit, the other four indices of fit indicated excellent fit. The Yuan-Bentler Residual-based F-Statistic ( $\mathrm{F}=1.163, \mathrm{df}=182)$ was not significant ( $\mathrm{p}>.05)$, and the NNFI (.988), the CFI (.989), and the RMSEA $(.035$, CI $(.016, .048))$ all 
demonstrated strong fit as well. Additionally, the Lagrange Multiplier test results indicate that freeing constraints would not cause a significant improvement in fit. As a result, I retained the fully constrained model as the final of invariance by gender. Below are the standardized structural equations for the test of invariance, and the parameter estimates can also be seen in Figure 10.

Women:

$\mathrm{F} 4=.641 * \mathrm{~F} 5 \quad-.212 * \mathrm{~F} 2+.832 \mathrm{D} 4 \quad(\mathrm{r}$-squared .308$)$

$\mathrm{F} 5=.207 * \mathrm{~F} 1+.234 * \mathrm{~F} 2+.256 * \mathrm{~F} 3+.788 \mathrm{D} 5 \quad(\mathrm{r}-\mathrm{squared} .378)$

Men:

$\mathrm{F} 4=.635 * \mathrm{~F} 5-.246 * \mathrm{~F} 2+.851 \mathrm{D} 4 \quad(\mathrm{r}$-squared .275$)$

$\mathrm{F} 5=.230 * \mathrm{~F} 1+.275 * \mathrm{~F} 2+.285 * \mathrm{~F} 3+.721 \mathrm{D} 5 \quad(\mathrm{r}-$ squared .481$)$

Note: Work-life climate (f1), professional development (f2), person-department fit (f3) agency behavior (f4), agency perspective (f5)

The finding of invariance on a fully constrained model indicated that both the measurement model and the structural model were the same for men and women.

Regarding the measurement model, the finding of invariance by gender suggested that the way that the items related to their respective constructs was the same for men and for women. For example, the way that men answered the items in the work-life construct (e.g., "I am satisfied with my unit's culture around work-life balance") seems to tap the work-life construct in the same way that the items tap the construct for women. It is important to note that invariance did not mean that the absolute value of the response to the work-life items was not different for men or women-for example, it could be that women rated the work-life climate lower than men. Rather, the relationship between the items and the work-life construct (i.e. the percent of the items that was attributable to 
error versus tapping the actual construct of interest) was the same for men and women. Ensuring that the measurement model is the same for men and women was critical in understanding the causal model by gender. If the measurement model had been different by gender, it could have been that for men or women, certain items were irrelevant to the constructs of interest, thereby introducing additional error.

The invariance in the structural model indicates that the relationships in the model between organizational factors and agency constructs were the same for men and women. For example, the same three organizational constructs (work-life climate, professional development resources, and person-department fit) had a significant influence on agentic perspective for both men and women, and the size of this influence was not significantly different for men and women. Similarly, there was a large effect of agency perspective on agency behavior for men and women. Again, it is important to note that invariance indicated that the relationships and the size of the relationships among constructs were the same for men and women, but the absolute value of these constructs could have been different for men and women. For example, it could be that work-life climate exerted a small influence on agency perspective for both men and women, but that women rated both work-life climate and their own agency perspective as lower than men did. This study did not test whether there was difference in the absolute value of the constructs. Future research should use latent means modeling to determine whether the value of the constructs was different between men and women. However, this study did contribute to our understanding of the relationship among constructs, and found that organizational influences on agency perspective and the way that agency perspective influence agency behavior was the same for women and men. 


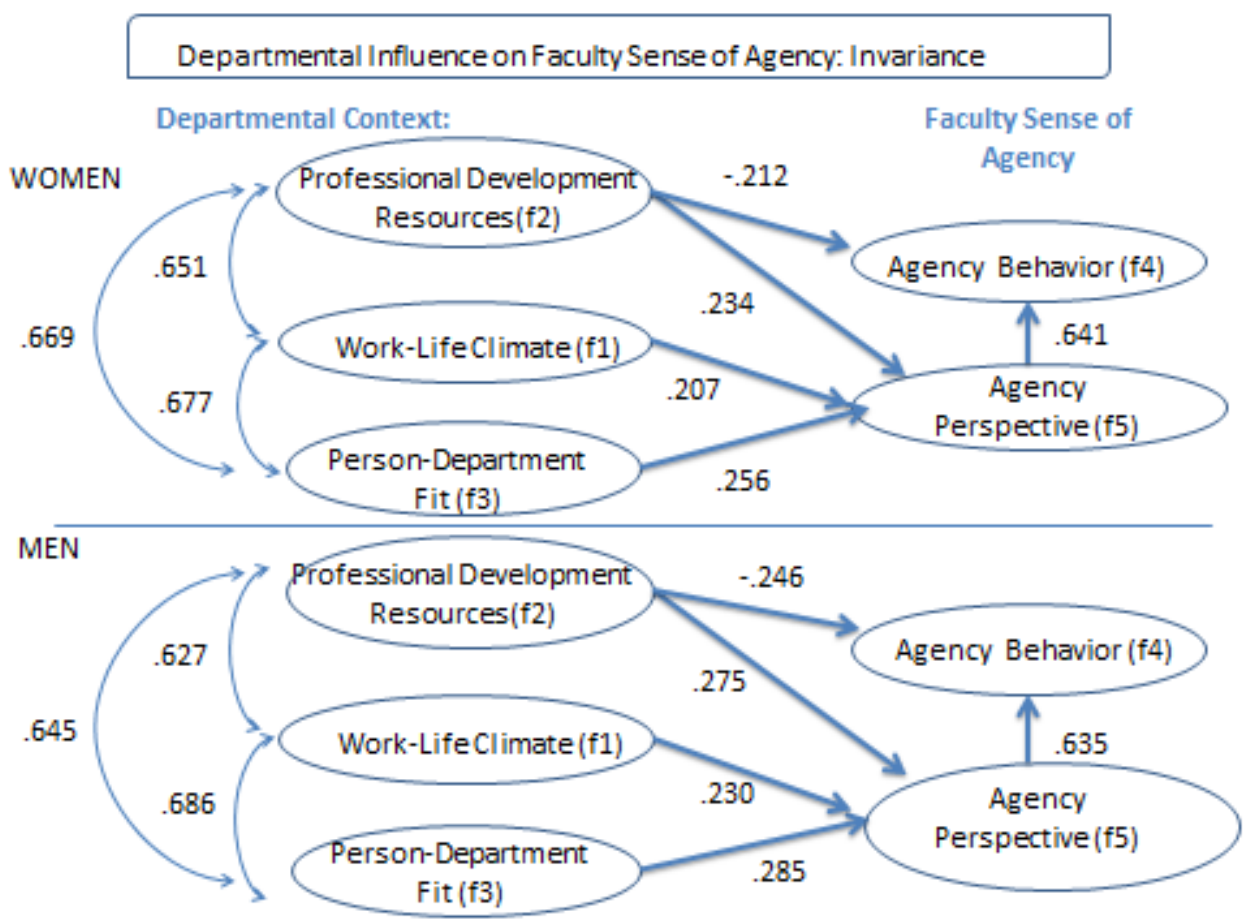

Figure 10. Model for test of full structural and psychometric invariance.

\section{Summary}

This chapter presented the results of the analyses of the psychometric and structural models to answer the three research questions in this study. Results of this study suggest four critical findings that enhance understanding of faculty agency. First, faculty agency can be measured through a survey. Results show that faculty agency is domain specific (this study focused on faculty career agency) and seems to have two distinct, but related constructs: agency perspective and agency behavior. Second, certain organizational factors exert a direct influence on agency perspective, but they mainly only exert indirect influences on agency behavior via agency perspective. Third, faculty agency perspective exerts a very strong influence on agency behavior. Finally, fourth, the model of organizational influences on faculty agency holds in the same way for both men and women. 
Regarding the measurement model, Confirmatory Factor Analyses revealed that several items needed to be removed from individual constructs in the model in order to avoid linearity problems and intercorrelated errors. Next, the eleven factor CFA revealed that one organizational construct (collegiality) and all three outcome measures (intent to stay, productivity, and satisfaction) were highly intercorrelated with other factors in the study. Collegiality, productivity, and satisfaction were all highly intercorrelated or linearly dependent with several organizational factors. The intent to stay factor was linearly dependent on the agency perspective factor. These four constructs were removed prior to analyses of the structural model (see section on Analysis of Psychometric Properties). The final psychometric properties demonstrated excellent fit to the data and moderate correlations among constructs.

Of particular interest, the constructs on faculty agency (perspective and behavior) demonstrated sound psychometric properties. This was the first, or among the first, time that the construct of faculty agency was measured in a quantitative way, and the finding of sound psychometric properties offers broader support for these constructs in the O’Meara, Campbell, and Terosky (2011) framework. Additionally, removing the items that were not related to agency in career (e.g., the items related to agency in work-life balance) improved the soundness of the constructs, providing support for O'Meara, Campbell, and Terosky's contention that agency is a construct that is context specific. For example, a faculty member might feel more agency in career than in work-life balance.

Once I determined the measurement model had appropriate fit, I proceeded to test the structural model and move to answer research questions one and two. Unfortunately, 
because the three outcome measures were removed from the model due to high intercorrelations, I could not include them in the structural model, and therefore could not fully answer research question two, regarding the influence that agency behavior and agency perspective have on faculty outcomes. Future research should use alternative methods to measure faculty outcomes, such as counts of publications from a faculty member's CV to measure productivity or actual leaving behavior instead of intent to leave or measuring overall job satisfaction rather than satisfaction with unit. These kinds of measures might avoid the measurement problems that were present in this study, and allow for future studies to determine the influence of agency on faculty outcomes.

The remaining structural model investigated the influence of five organizational factors (faculty perception of tenure process, work-life climate, professional development, person-department fit, and transparency) on both agency behavior and perspective and also whether agency perspective had an influence on behavior. This model demonstrated good fit of the data, but there were several non-significant paths. This model showed that of the five organizational variables, only professional development exerted a direct influence on agency behavior, and that influence was negative. By contrast, three of the five constructs (work-life climate, professional development, and person-department fit) were significant in predicting agency perspective. Transparency and perceptions of the tenure process did not contribute significantly to either agentic perspective or behavior. Agency perspective had a strong positive influence in predicting agentic behavior. I respecified a model that included only the significant paths, with excellent fit results. 
The newly respecified model was then tested for invariance. The baseline model held for both men and women. The configural model, which simultaneously estimates both the male and female model, also showed a strong fit. Finally, the most constrictive test of invariance, where all measurement and structural paths were constrained across the models for men and women held with excellent fit and no modifications necessary, as determined by the Lagrange Multiplier. In essence, this indicates that the organizational factors (e.g., work-life climate, professional development resources, and persondepartment fit) have a similar influence on agentic perspective and behavior for women as they do for men. Likewise, the results provide support for the relationship between agentic perspective and agentic behavior being the same for women and men. Finally, the test for invariance retained the same model of loadings and percent error within the items and constructs for women as for men, meaning that the way that the items tapped the constructs of interest was the same for men and women.

While the results of this study gave good insight into the model of agency in faculty professional lives and the organizational influences of agency, there are several considerations that contextualize these results. If different organizational factors had been included (e.g., diversity representation) or the constructs in this study had been measured differently (e.g., policies for work-life climate rather than perceptions of worklife climate), findings could have been different. Additionally, this study was set in a research institution in the mid-Atlantic area when the institution had recently been awarded an NSF ADVANCE grant that focuses on the retention of women faculty. If this study had been done with a different type of institution, in a different geographic location or with this same institution at a different point in time (e.g., prior to the grant), 
results may have been altered. Even with these considerations in mind, this study provided important insight into understanding that the organizational climate, norms, and resources do matter in faculty sense of agency, and also that agency perspective has a strong bearing on agency behavior. Finally, according to this study, organizational factors influence agency perspective for both men and women. 


\section{Chapter 5: Discussion and Conclusion}

This chapter highlights key findings that respond to each of the three research questions, and connects these findings to the literature on agency and faculty. I discuss the theoretical implications from this study for understanding the faculty agency framework. Finally, I describe implications for practice from this study and areas for further research.

\section{Discussion of Research Question 1}

The findings of this study indicated that organizational factors influenced faculty sense of agency in their careers. What is particularly noteworthy about this finding, however, is that the organizational factors only impacted agency behavior via their impact on agency perspective. Of the five organizational factors (tenure process, worklife climate, professional development resources, transparency, and person-department fit), only professional development resources had a direct impact on behavior and this impact was small and negative. By contrast, three organizational factors exerted a positive influence on agency perspective (work-life climate, professional development resources, and person-department fit). In all, organizational factors make a strong contribution to agency, explaining about half of the variance in agency perspective, and the model explains about a third of the variance in agency behavior.

Previous work on faculty demonstrates the role of institutional and organizational contexts in the professional work lives of faculty (Ambrose, Huston, \& Norman, 2005; Bode, 1999; Huston, Norman \& Ambrose, 2007; Lindholm, 2003; Neumann, 2009; Trower \& Chait, 2002). The literature has predominantly focused on the influence of organizational context on satisfaction and intent to leave. For example, Olsen, Maple, 
and Stage (1995) found that satisfaction with department and institutional support was associated with job satisfaction. Johnsrud and Rosser (2002) found that perceptions of work-life environment (priorities and rewards, administrative support, and quality of benefits and services) influenced faculty morale at both the individual and institutional levels and also influenced intent to leave at the individual level. Another study by Johnsrud (2002) shared similar findings that work-life (technical support, administrative support, and professional development) contributed directly to satisfaction and indirectly to intent to leave. Both of the Johnsrud studies were based on a large sample from the National Study of Post Secondary Faculty and used advanced quantitative methods such as multi-level structural equation modeling. The findings from the present study extended this work by considering the effects of organizational context on a different kind of outcome-agency perspective and agency behavior.

This study found that organizational contexts had a particular influence on faculty agency perspectives. This study defined agency perspective as taking an intentional or strategic view towards goals that matter to oneself. Agency perspective requires the ability to make meaning of human experiences, to reflect upon them, and to re-construct them internally (Neumann, Terosky, \& Schell, 2006). This study found that organizational contexts may shape the degree to which faculty take an intentional and strategic view towards their own career goals. For example, feeling a sense of fit and recognition in a department can influence a faculty member's sense that they can and will achieve their career goals and to see ways to accomplish advancement goals. Likewise, being in a context where work-life balance and integration is supported appears to limit the feeling of being 'stuck' in one's career. The link between organizational contexts and 
agency perspective is supported by literature on faculty that demonstrates a connection between work environment and faculty attitudes and perceptions. Johnsrud (2002) conducted an extensive literature review on worklife contexts for faculty and associated outcomes, and found that many studies purported an association between faculty worklife contexts and faculty perceptions and attitudes. For example, Lease (1999) found an association between role overload and faculty stress among three research institutions in the south. Hagedorn (1994) found that several organizational contexts, such as workhours, perceived support of colleagues, and satisfaction with salary, influenced faculty satisfaction. Olsen, Maple, and Stage (1995) found an association between recognition and support and satisfaction. All of these studies represent a broader finding that departmental and institutional contexts have the power to alter the perspectives and attitudes of faculty. Similarly in the present study, work-life climate, person-department fit, and professional development resources influenced faculty sense of agency in their careers.

Yet, the findings in the present study provided an interesting contrast to literature within higher education that demonstrates the connection between organizational factors and faculty behaviors (Lindholm, 2004). The present study found that the organizational contexts in this study (professional development resources, person-department fit, worklife climate, transparency, perceptions of the tenure process) mainly do not influence agency behavior directly. Instead, organizational contexts influence agency behavior indirectly via their influence on agency perspective. It is possible that other organizational contexts, not included in this study, may have direct links with agency behavior (e.g. discriminatory climates, supportive leadership). Yet, the lack of 
connection between organizational contexts and faculty agency behavior in this study is noteworthy.

While few, if any, past studies used a quantitative lens to study the impact of organizational contexts on faculty agency, many studies have found that organizational contexts have direct influences on other faculty career behaviors. For example, Xu (2008) found that work environment variables were significant predictors of turnover intentions across all disciplines. Xu (2008b) found similar results for STEM faculty; that certain work environment variables were important in the retention of men (e.g., faculty leadership) and women faculty (e.g., research support, free expression of ideas). Smeby and Try (2005) found that departmental context (cooperating climate and innovating climate) influence a faculty member's productivity. In each case, these studies shed light on the interplay of organizational context on faculty career behaviors without using a statistical technique that allows for investigating multiple endogenous variables or outcomes (e.g., multiple regression or hierarchical linear regression instead of SEM). Therefore, these studies were not able to determine the simultaneous influence of departmental context on both perceptions and actions.

The present study found that agency perspective serves as an important intermediary between departmental context and agency behavior. This resonates with the extant literature that investigates faculty perspective as an intermediary between environmental factors and other forms of faculty behavior. Rosser (2004) found that work environment factors (administrative support and professional development resources) only influenced intent to leave (i.e. leave-taking behavior) via the faculty member's satisfaction (a perception of the environment). Johnsrud (2002) had similar 
findings that worklife (administrative support, technical support, and professional development) had direct effects on satisfaction and indirect effects on intent to leave via satisfaction. The present study mirrors these findings in that organizational factors influence agency behavior via agency perspective.

The sociological and psychological literature posits that the connection between perspective and action is intertwined (Clausen, 1991; Marshall, 2005). Bandura (1982) posits that agency mediates self-referent thought (i.e. self-efficacy) and action, which corroborate the findings of the present study. For example, a faculty member might believe she has the skill to publish in a top tier journal (i.e. self-efficacy), but what keeps her from submitting her manuscript is her lack of strategic mindset towards this goal (i.e. sense of agency). Maybe due to identity politics or lack of social capital, she does not believe it would actually be published (lack of agency perspective) or she doesn't take steps to understand the reviewer process (agency behavior). Likewise, organizational and management literature has posited that organizations can play a role in motivating employees, which in turn influences action (Vroom, 1964). For example, according to Vroom's theory, the expectation that hard work would result in tenure might motivate a faculty member to take actions towards their goal of tenure. This study resonates with both Bandura and Vroom, demonstrating that agency perspectives and action were intertwined and that there were organizational contexts that shaped faculty agency perspectives. This study suggests that supportive contexts (resources for professional development, positive work-life climate, and strong person-department fit) may provide the harbor that a faculty member needs to believe in her/his ability to take risks in one's career, to take actions toward one's goals, and to resist pressures that pull her/him away 
from achieving one's desired career success. Then, once faculty have a clear and empowered view, they themselves set sail.

\title{
Specific organizational contexts.
}

In addition to addressing whether organizational contexts influence faculty sense of agency, this study provided insight into which organizational contexts matter. While neither this study or any could account for every potential influencing factor, this study was able to examine carefully six organizational variables (work-life climate, perceptions of the tenure process, professional development resources, person-department fit, and collegiality) and how they mattered for faculty agency. One of the advantages of using an advanced statistical technique, such as structural equation modeling, is that it simultaneously accounts for the influence of the six organizational factors on both forms of faculty agency (behavior and perspective) while also estimating intercorrelations among the organizational constructs. The high intercorrelations among the organizational factors illustrated the dynamic interplay of facets of faculty environments, and the importance of this interplay in understanding faculty agency. I have developed a faculty vignette, "Jason," based on the results of this study to illustrate how the organizational factors in this study work together to create an environment that facilitates faculty agency.

\author{
The Case of Jason
}

Jason is a pre-tenure faculty member at a prestigious research extensive institution in the northeast. He knew when he took the job that the tenure process would be somewhat of an enigma. However, he heard that faculty in his department were 
supportive of each other. He has now been at the institution for two years, and his expectations have been fulfilled. While there is a lack of transparency around tenure requirements and other aspects of decision making in Jason's department, he has experienced support in the way that his colleagues value his research and he feels a fit between his scholarly interests and those in his department. He also takes care of his aging mother and finds that his department honors family commitments. He is slightly frustrated by the lack of resources to support his research and grants, but he has found ways to overcome the lack of administrative support. Jason just received a major early career award in his field. All in all, Jason believes he can make his own path at this institution, and in his field.

\section{Work-life climate.}

Previous studies of faculty have found that institutions and departments with positive work-life climates facilitate success for faculty, especially women faculty and faculty parents (O’Meara \& Campbell, 2011; Mason \& Ekman, 2007; Mason \& Goulden, 2004). This study finds that work-life climate exerts a small direct effect on agency perspective and a small indirect effect on agency behavior via agency perspective. In the case of Jason, feeling a support for taking care of his aging mother may have relieved some stress with figuring out how to balance his work commitments and his family concerns. This support my have made space for him to take the actions to care for his mother while still facilitating his research success. 


\section{Person-department fit.}

This study found that a greater sense of fit in the department (i.e. feeling valued by departmental colleagues and a fit between one's own scholarly values and those of the department) positively influenced faculty sense of agency in their professional goals. According to Lindholm (2003), "person-organization fit, reflects congruency between the values, interests, needs, and abilities of an individual and corresponding characteristics of the organization within which he or she works" (p. 128). Lindholm discusses that the organizational setting for faculty is often departmental contexts, especially in research institutions where departments can be large. The present study measured certain aspects of person-department fit that related to feeling valued in one's scholarship, teaching and service, and also a good fit between one's own scholarly values and the values of the department. This mutual sense of valuing resonates with the literature on personenvironment fit. It is important to note that person-department fit is not only shaped by making good hiring choices--a "fit" is not something that necessarily occurs "with the right people.” Instead, person-department fit requires departmental colleagues to express support and recognition of other faculty in their department. It means helping other faculty to see themselves in the values of the department. These kinds of supportive actions can be constructed within a departmental context by faculty colleagues or leaders (e.g., department chairs). Hagedorn (1994) found perceived support of colleagues related to level of stress, satisfaction with academe and enthusiasm with one's profession. Olsen, Maple, and Stage (1995) found that recognition and support of an institution was related to job satisfaction, and that perceived control over career development influenced recognition and support. 
In this study, the results regarding the importance of person-department fit for men and women deserve further scrutiny. In the first step of testing invariance, the baseline model for women demonstrated that there was a significant effect of persondepartment fit on agency perspective, whereas person-department fit was not a significant predictor in the baseline model for men. However, the final, full structural invariance model (including both genders and all causal and psychometric paths constrained) indicated that this difference between genders was non-significant, and in fact, persondepartment fit was equally significant in predicting agency perspective for both men and women. If there had been a difference between men and women, this would have resonated with Lindholm (2003) who found that finding a good fit was particularly difficult and also particularly important for women faculty and faculty of color. However, the final invariance model in this study demonstrated that person-department fit did, in fact, have an equally significant effect on agency perspective for both women and men.

In the case of Jason, having the support of his colleagues and feeling a sense of belonging in his department allowed him to believe in his ability to succeed despite the lack of transparency about the tenure process. Jason felt that his colleagues valued his scholarship and his teaching. He had an underlying trust that if he did his best work and his colleagues valued his work and research, he would be able to succeed.

\section{Professional development resources.}

This study found an interesting paradox about the relationship between professional development resources and faculty sense of agency. Professional development resources had a modest positive influence on faculty agency perspective. 
By contrast, they had a moderate negative direct influence on agency behavior. Overall, when the direct negative effect and the positive indirect effect (via agency perspective) were both taken into account, professional development resources had a negligible influence on agentic behavior. It is important to note that the form of resources that was included in the final construct was administrative support for research and grants and access to Research Assistants and Teaching Assistants.

Let us consider the finding that professional development exerts a positive influence on perception, but overall a negligible influence on behavior in the context of the extant literature. Several studies have found an important positive link between forms of professional development resources or administrative support on faculty attitudes and experiences. Hagedorn (1994) found that perceived administration support related to both stress level and satisfaction in academe. Lindholm (2003) reported that physical and institutional resources for nurturing professional ambition were an important contributor to a feeling of fit within a department. Rosser (2004) also found that administrative support and professional development resources matter for faculty satisfaction. While these studies highlight the importance of professional development resources on faculty attitudes (satisfaction, stress), few of these studies included faculty behavioral outcomes. This study found that while professional development resources did have a positive influence on agency perspective, it had a negative direct influence on agency behavior.

Returning to Jason, he believes that he does not have the administrative support that he needs for his grant management, which might make him feel frustrated with his career advancement (i.e. agency perspective). However, he exerts agency and finds ways to overcome this problem to succeed in his research by working with his mentor who had 
successfully implemented a multimillion dollar grant (i.e. agency behavior). The converse could be true. In an environment where administrative and student support is plentiful, the resources might help a faculty member see new grant or research possibilities (i.e. agency perspective), but also require less strategic behavior because the resources are presented to the faculty member and they don't have to "seize opportunities" (i.e. agency behavior). Future qualitative studies should investigate why and how professional development exerts a positive influence on agency perspective, but a negative direct influence on agency behavior.

While the findings regarding professional development resources can be contextualized within the context of a research institution, there are also possible limitations to this finding. While the construct appears to be reasonably sound based on the loadings $(.489, .569, .715)$ and reliability (Coefficient $\mathrm{H}=.648)$, it is also the least sound construct in the model. All other constructs in the model had all loadings greater than .5 and reliability greater than or equal to .750 . Additionally, the professional development resources construct was modified from its original form. Two items had to be removed during construct validation in order to improve the psychometrics of this construct (see section on Analysis of Psychometric Properties in Chapter 4). It is possible that the measurement of this construct influenced the findings regarding the influence of professional development resources on agency perspective and agency behavior in career.

\section{Perceptions of the tenure process.}

Scholars who study tenure have recommended an overhaul of the tenure process. They recommend reform in clarity of requirements, recognition of multiple forms of 
scholarship, and greater flexibility in time to earn tenure (O’Meara \& Rice, 2005; Rice \& Sorcinelli, 2002). Interestingly, this study found that perceived clarity and fairness of the tenure process was not a significant contributor to agency perspective or behavior. This finding resonates with other literature on faculty at research institutions. Olsen, Maple, and Stage (1995) found that perceived clarity and fairness of tenure process was not related to job satisfaction or perceived control over career development (note that locus of control is one aspect of agency). Similarly, August and Waltman (2004) found that clarity and fairness of the tenure process was not related to career satisfaction for women faculty at a research I institution in the mid-west. It appears that, for research institutions, there may be other organizational factors that are more important, such as a feeling of fit or positive work-life climate. It is also possible that faculty at research institutions may enter institutions with less expectation of clarity in the tenure process. Finally, most of the faculty in this study were tenured (only $24 \%$ were Assistant Professors), so it may be that the clarity and fairness of the tenure process was less relevant to respondents' current experiences.

In the case of Jason, he did not expect clarity about the tenure process when he entered the institution. He felt valued and supported by his colleagues, and trusted that if he worked hard, he would be rewarded with tenure. He didn't need to know exactly what the tenure requirements and process would look like in order to believe that he could progress and to make strategic decisions about his own career advancement. A supportive climate, rather than step by step instructions on tenure, was the scaffolding that he needed to achieve his career goals. 


\section{Transparency.}

Previous literature has highlighted the importance of transparency to both external and internal stakeholders in higher education and also on academic and shared decisionmaking (Birnbaum, 1988; Eckel \& Kezar, 2006). Interestingly, this study found that transparency with regard to salary increases, information sharing, resource allocation, and decision-making within one's unit was not a significant contributor to agency perspective or behavior. While few studies have investigated the role of transparency of decisionmaking or information sharing in faculty professional lives, the studies that do examine transparency usually focus on the clarity of the tenure process or whether the institution communicates openly with faculty (Daly \& Dee, 2006). Cipriano (2011) describes the importance of transparent decision-making by department chairs for faculty satisfaction and collegiality.

This study did not find transparency to be a significant predictor of agency perspective or behavior. It may be that at a research institution, feeling supported in one's scholarship is more important than transparency of information, resource allocation, and decision-making. Possibly, as long as a faculty member feels she can trust her colleagues and feels valued, she might not need to have a hand in local governance or a behind the scenes understanding of how decisions are made in her department. Returning to the case of Jason-Jason does not feel privy to all of his department's decisions. Yet, he believes that his scholarly values are similar to those of his department. This congruence of values leads him to feel like an "insider" and to believe that his perspective will be represented in decisions, regardless of whether he is a part of the decision-making process. 


\section{Collegiality.}

Collegiality could not be included in the final model for this study because it had extremely high correlations with four of the five other organizational constructs (transparency, work-life climate, professional development resources, and persondepartment fit). These high correlations might indicate that collegiality is an omnibus construct related to these other kinds of organizational supports. The literature supports this proposition: according to Birnbaum (1998) and Berquist (1992), transparency, feeling valued, faculty shared governance, and mutual respect are all facets of collegial climate. The importance of collegiality is underscored by studies which show that junior faculty indicate a powerful and often unmet need to experience an effective mentoring environment and a sense of collegiality (Ambrose, Huston, \& Norman, 2005; Bilimoria, Perry, Liang, Stroller, Higgins and Taylor, 2006; Boice, 1992; Huston, Norman \& Ambrose, 2007; Zachary, 2000). Additionally, women have been found to be consistently less satisfied than men faculty with the collegiality they find at their institutions (Bode, 1999; Neumann, 2009; Trower \& Chait, 2002). Creamer (1998) further observes that networks play a key role in reinforcing the perceived legitimacy of scholars, which in turn influences their productivity.

While collegiality could not be included in the final model due to multicollinearity, it does show strong linear correlations with both faculty agency perspective and job satisfaction (i.e. as collegiality increases, so does agency perspective and job satisfaction). Further research on the influence of collegiality on faculty agency is warranted. Also, based on the present study, creating a broader understanding of the constructs that underlie collegiality would be worthwhile. 


\section{Discussion of Research Question 2}

The second research question in this study asked whether faculty agency perspective and behavior are related to faculty career outcomes. Unfortunately, all three outcome measures (intent to leave, job satisfaction, and productivity) were removed from the final model due to linearity concerns. Linearity concerns indicated that when the outcome constructs were included in the model, they were entirely explained by other constructs in the model — they were not distinct from other constructs. For example, it appears that intent to leave is entirely explained by agency perspective (i.e. linearly dependent). As a result, the model cannot determine the relationship between these two constructs - they were not distinct enough in this analysis.

While I could not include the outcome constructs in the model, the intercorrelations from the confirmatory factor analyses demonstrated that agency perspective was moderately positively related to intent to leave and strongly positively related to both productivity and satisfaction. Agency behavior was also moderately positively related to productivity. Caution must be used when interpreting these intercorrelations - they are not causal and the multicollinearity can inflate estimates. Yet, these intercorrelations suggest that future research is warranted to better understand the relationship between faculty agency and outcomes.

Additionally, the linearity problems with the outcome measures in this study raise broader concerns about the nature of self-rated outcome measures. This study asked participants to rate their level of satisfaction with their department and the institution. Similarly, it asked participants to state how their unit perceives their productivity. It may be that there is an aspect to both of these outcomes that is more associated with concerns 
of self-ratings than the actual outcome of interest - for example instead of responses being about productivity, they may have been about social desirability or self-confidence (Simone, Campbell, \& Newhart, 2012). Future studies should investigate the connection between agency and outcomes using both subjective and more objective measures, and using multiple kinds of data collection-e.g., surveys, observations, interviews, and unobtrusive measures.

\section{Discussion of Research Question 3}

Possibly the most surprising finding from this study is that the relationships among organizational factors and agency perspective and behavior are invariant by gender. While the separate models for men and women initially appeared different (e.g. person-department fit was significant for women and not men), the final model that included constraints across men and women for both the psychometric and the causal models was completely invariant. In other words, the model where work-life climate, person-department fit, and professional development resources contribute to agency perspective, and agency perspective and professional development resources contribute to agency behavior holds the same for men and women faculty.

While this is a very important finding, there are a few caveats that are important to report. First, this study did not investigate the absolute level of agency or the absolute level of organizational factors by gender (i.e. whether women have more or less agency than men. For example, it could be that while the relationships among the constructs hold true for both men and women (e.g., work-life climate would have a similar influence on agency for men and women), women have greater agency than men overall. Further study warrants an investigation of whether the level of agency was greater for women or 
men (i.e. latent means analysis to study whether agency differs by gender). Instead, this study focused on whether the relationship between organizational factors and faculty agency differed by gender.

The finding of gender invariance in the model is surprising considering the backdrop of barriers that women face, as documented by decades of literature on women faculty. For example, women are underrepresented at all ranks in the academy, and are least represented in the most prestigious and powerful positions and institutions (GlazerRaymo, 2008). Additionally, women seem to experience the academy in different ways than men. Women parents have particular concerns, with the tenure clock often ticking at the same time as women's biological clocks (Wolf-Wendel \& Ward, 2003).

Additionally, women with children do more work in their careers and in their home lives compared to non-parental male counterparts (Mason \& Ekman, 2007). Women also teach more and research less than men, which can be problematic in reward structures (Bellas \& Toutkoushian, 1999). Finally, women may experience a "chilly climate" where subtle and overt discrimination foster an inhospitable environment (Caplan, 1993; Sandler, 1986; Winkler, 2000). By contrast, certain studies have found no effect of gender on the level of stress (Lease; 1999) or time spent on research, satisfaction, and autonomy (Olsen, Maple, \& Stage, 1995), especially when discipline, rank, and institutional type are controlled (Trower \& Bleak, 2004).

Yet, in each of these studies, the finding by gender is about quantity: women teach more, women experience more discrimination, women work more, there are fewer women. These studies offer great insights into the experience of women. However, the present study offers a slightly different vantage point: not how much agency do men and 
women have, but what can influence the level of agency for women and men? The emphasis is on the difference by gender in the relationship between constructs instead of the level of the construct itself. The findings of the present study indicated that the organizational factors that influence faculty agency are the same for men and women, and that the magnitude of the effects of these factors on agency are the same across genders.

While the finding of invariance provides important insights into the importance of organizational contexts in faculty agency perspective, the context of this study is an important backdrop for this finding. Respondents were tenured or tenure track faculty at a research institution. Findings may have been different if I had included non-tenure track faculty or if I had chosen a different site for the research, such as a different institutional type. It may be that tenured/tenure track women and men at this particular research institution have simultaneously self-selected into and been shaped by a prestigious research institution environment that made their organizational needs more similar than different by gender. Additionally, further research should investigate whether this model of organizational influences on faculty agency would hold within groups of women and men (e.g. by race or rank).

Implications for Theory

The findings in this study attempt to fill in an important section of a larger map of O'Meara, Campbell, and Terosky (2011) faculty agency framework regarding how various factors influence faculty sense of agency. This study makes three theoretical contributions to the understanding of how agency manifests in faculty careers. First, while other studies focus on the role of individual and/or societal factors on agency—this study focuses on organizational context. Certain supportive departmental contexts 
(work-life climate, person-department fit, and professional development resources) have a positive influence on agency perspective, while other organizational factors (clarity and fairness of tenure process, transparency) do not have a significant influence. From this study, it is clear that understanding the organizational context for a faculty member will be an important backdrop to understanding a faculty member's agency in her/his career, and this is important regardless of gender.

Second, while not a major focus of the research questions, this study provides important evidence of the connection between agency perspective and action. This study found that agency perspective exerts a very strong influence on agency behavior. This finding resonates with literature in both psychological (Bandura, 1982) and organizational (Vroom, 1964) disciplines that demonstrate that internal perspectives shape action. This finding provides further evidence that in studies of faculty behavior, faculty perspectives must be included as an intermediary variable. Additionally, while agency behavior is likely an intermediary to other important faculty outcomes (such as productivity), the findings from this study indicate that agency behavior is an outcome of agency perspective.

Finally, this study contributes to our understanding of how the faculty agency framework operates for men and women. Not only are the relationships between organizational factors and agency the same for men and women, but the measurement model is also invariant by gender. This implies that the items are just as important to each of the constructs for both men and women. This is critical in survey research because if there was different error associated with the items for men and women, it could change the estimates of the relationships between constructs. It also provides 
initial evidence that aspects of the faculty agency framework work for both men and women. Although, if individual or societal variables or outcome measures had been included, there could have been differences by gender. More research needs to be done with a larger sample size to determine whether the entire O’Meara, Campbell, and Terosky (2011) framework would act the same for women and men.

\section{Implications for Practice}

This study found that there are organizational factors that influence faculty agency, regardless of gender. These results have three particularly important implications for practice: the organizational contexts that influence faculty agency are changeable by institutions, faculty who exhibit agency may be particularly strong assets to institutions and departments, and finally supportive organizational environments can facilitate faculty agency for both men and women faculty.

First, the organizational contexts identified in this study as important influencers of faculty agency are changeable by institutions. The three organizational factors that were predictors of faculty agency (person-department fit, work-life climate, and professional development resources) are all aspects of an institution that could be influenced at the departmental level by faculty colleagues or a department chair. The finding that person-department fit matters in agency has important implications, particularly considering the way that person-department fit was measured in this study. In this study, person-department fit was measured by the faculty respondent having a sense that their department valued their work (scholarship, teaching and service) and that their own scholarly values were congruent with those of the department. Administrators and faculty colleagues can help other faculty to feel that their work is valued. This 
organizational adjustment has no financial cost and can be implemented by a single faculty or administrator advocate or by a climate of valuing and appreciation. Additionally, departments could institutionalize a norm of valuing faculty work and create a sense of belonging via orientation practices (e.g. connecting faculty across campus with similar scholarly interests), mentoring activities (intentionally assigning mentor matches with similar scholarly values), and recruitment (seeking a good fit with scholarly values and promoting this congruence in interview practices).

Similarly, facilitating a positive work-life climate helped faculty in this study to have a sense of agency in their professional lives. Administrators and faculty colleagues can work to facilitate departmental norms that are flexible and understanding of work-life balance. While there is often a fear that a culture of balance will lead to lower productivity, this study provides evidence that facilitating a positive work-life climate leads to agency in obtaining career goals. Concrete actions could include ensuring that departmental meetings are not held at times that would conflict with family responsibilities, promoting honesty around care-taking, and highlighting role models of work-life balance. Other institutional policies, such as paid parental leave, part-time tenure track policies, and dual career hiring practices may also engender an agency perspective via a positive work-life climate (O’Meara \& Campbell, 2011).

Professional development resources had a significant positive influence on agency perspective and a negligible influence on agency behavior (when both direct and indirect effects via perspectives are taken into account). It may be that the symbolic value of professional development resources shows investment in the faculty career, and frames faculty agency perspective. Of the three significant organizational factors that were 
significant contributors to agency in this study, professional development resources is, arguably, the most financially costly, and may have the least influence on agency behavior. For example, investing in administrative support for research or access to TAs/RAs is costly. If the ultimate influence on agency behavior is negligible, it may be more important for administrators to focus on changing the departmental work-life culture or helping faculty to feel they are valued in their departments. However, this assumes that agency behavior has more influence than agency perspective on important faculty outcomes, such as productivity and retention. Future research needs to investigate the role of professional development resources and the influence of agency perspective on important faculty outcomes. If agency perspective does influence such faculty outcomes, it may well be worthwhile to invest in professional development resources (which have a positive bearing on agency perspective) even if professional development resources do not have a substantive influence on agency behavior.

A second aspect of this study that has important implications for practice is that faculty who exhibit agency may be particularly helpful to organizational goals. Deans and department chairs should consider how to cultivate agency among faculty in their colleges and departments. While more research needs to be done on the outcomes of faculty agency perspective and behavior, provosts and department chairs could benefit from faculty who have a "can-do mentality" in their careers. Agentic faculty have the ability to pursue their goals and to galvanize other faculty to pursue goals. The ability to achieve goals will be particularly beneficial when faculty share similar professional values, goals, and work ideals as those of the institution and department. For example, Gonzales (2012) found in her study of organizational change at an institution that certain 
faculty operationalized the new institutional goals and exerted agency to achieve them. Agentic faculty were a positive force in driving the institution's new mission in Gonzalez's study. Additionally, agentic faculty may be more likely to push systems toward progress and to question and rethink old assumptions (Gonzales \& Rincones, 2008; Baez, 2000a; O’Meara \& Campbell, 2011), promoting innovation in a department or an institution.

Lastly, there are also important implications of the finding of invariance by gender. The finding of gender invariance indicated that institutions and departments can work towards a positive work-life climate or a strong person-department fit and see results with both men and women faculty. While other studies have sought to illuminate the gender disparity in academia (Winkler, 2000; Mason \& Goulden, 2007), the present study sought to determine how departmental context could support faculty agency—and whether these supports would be different for men and women faculty. This study showed that the same factors that support men faculty also support women faculty. In some respects, this is excellent news: it means that departments, administrators, and faculty colleagues can all work together to create positive work-life climates, a better sense of valuing each other's work, and to promote professional development through supportive administrative practices. It means, in terms of the departmental contexts studied in this research, the same strategies that will enhance agency for women faculty will work for men faculty. However, if there is a disparity in the level of agency between women and men faculty, facilitating these contexts will not change the gap, it will simply elevate the level for both men and women. This is an area for further research. 


\section{Future Research}

The findings from this study raised interesting questions about the aspects of the faculty agency framework that were not studied in this research. First, the context of this study is important in situating findings and future research. This research was based on tenured/tenure-track faculty at a single, large, research-extensive institution. Would departmental climates influence agency in different ways in other institutions or in other institutional types? A second consideration, relates to the kinds of department contexts examined in this study. Many national and international faculty development programs (e.g., Lilly Fellows, Advance programs, peer mentoring) have attempted to "intervene" to affect faculty agency. If we had asked about their participation in such programs instead of more general climate might this have influenced the issue of action over perspective? Likewise, would other organizational factors that were not included in this study have an impact on agency? Of particular interest are organizational factors that have previously been found to be important to faculty professional lives but not addressed in this study, such as discriminatory climates (Winkler, 2000), leadership styles (Bess \& Dee, 2012), reward structures that emphasize unconventional forms of scholarship (Schuster \& Finkelstein, 2006), or institutional supports for scholarly learning (Neumann, Terosky, \& Schell, 2006). Additionally, the present study investigated the influence of individual faculty perceptions of departmental climate, would the result be different if group-level departmental climate constructs (e.g., aggregated climate measures) were used?

There was also a significant amount of unexplained variance in the model, especially with regard to agency behavior. Further studies should investigate whether individual or societal level variables have a greater influence on agency behavior in 
comparison to the organizational level, which was investigated in the present study. Of particular interest would be whether the framework varies across identities and demographics other than gender such as race, rank, sexual orientation, appointment type, religion, among others. Also, because the model was altered (i.e. collegiality construct was removed due to multicollinearity), these results should be considered exploratory and should be replicated by future studies.

Another consideration relates to the relative importance of agency perspective or agency behavior in faculty outcomes of satisfaction, retention, productivity, and advancement. This study was not able to adequately address the question about how faculty agency influences pertinent faculty career outcomes. Further studies with larger samples, using multiple methods (not only perceptual—e.g. unobtrusive, observation, interviews, longitudinal tracking of advancement) to assess faculty outcomes are warranted. Which is more important believing in one's ability to realize one's goals or making them actionable? And, does the relative importance of agency perspective and agency behavior on faculty outcomes (such as productivity and retention) differ for women, faculty of color, and faculty at different career appointment types, stages, and disciplines?

Finally, the findings of this study underscore the large effect of agency perspective on agency behavior. This finding is thought provoking, and calls for a deeper understanding of the meaning of agency perspective and how it gives way to agency behavior. Qualitative work that looks in depth at the experiences of faculty who exhibit an agency perspective and also those who lack an agency mentality is warranted. This qualitative work could also contribute to understanding exactly how agency perspective 
translates into action in different domains and under what conditions an agency perspective shapes agency behavior.

While there are several avenues of further research that need to be pursued to fully understand the role of agency in faculty professional lives, this study calls for particular attention to three lines of inquiry. First and foremost, the question of whether agency perspective and behavior lead to positive individual and organizational outcomes is critical to understanding the importance of agency for faculty. Next steps should use qualitative methods and unobtrusive methods (such as CV document analysis) to tease out exactly how agency related to important faculty outcomes such as productivity, scholarly reputation, retention, and job satisfaction. This study of outcomes should also tease out the difference between the outcomes of agency enacted in synergy with organization goals (operalization; Gonzales, 2012) and the outcomes of agency enacted as resistance to organizational goals (Elder, 1994; Heinz, 1996). Secondly, the incredibly strong effect of agency perspective on behavior warrants further study-exactly how does agency perspective translate into action? Finally, more research needs to be done to understand the dynamics of agency for different populations - investigating whether there are certain groups of faculty that exhibit more agency than others. This could be accomplished through a latent means analysis of agency by gender, race, sexual orientation, rank, appointment type, or leadership status.

\section{Conclusion}

The present study suggests that certain departmental contexts (e.g., resources for professional development, positive work-life climate, strong person-department fit) influence faculty to see themselves as drivers of their career trajectory. The importance 
of work-life climate and feeling valued may have to do with the need for a safe environment in order to feel agentic. Agency is often described in ways that go against resistance (Elder, 1994; Heinz, 1996). For example, faculty of color may resist the norms of foregoing service because it is meaningful to them. In this way, agency can be seen as a risk-taking behavior. The "can-do" mentality requires a belief in one's self. Risk taking and self-confidence are scaffolded by safe environments. Findings from this study underscore the importance of environments where one's teaching, research, and service are valued and where one feels a fit with the values of the environment. This kind of supportive work context could provide the type of safe space and individual validation that makes faculty believe in their ability to take their goals by the horns.

Navigating difficult terrain requires a strong will, strategic mindset, and action. Thriving in the challenges of the professoriate depends upon faculty agency. For example, Neumann, Terosky, and Schell (2006) state, "How faculty respond to such shifts in professional contexts and the extent to which they exert agency... appear[s] to frame professors' future identities as learners and possibly their scholarly learning” ( $\mathrm{p}$. 131). We know from much research in human development and psychology that faculty sense of agency is influenced by individual characteristics and some faculty may be predisposed to act with a sense of agency in any given situation (Bandura, 1982; Clausen, 1991). In addition, we know from organizational and sociological literature that habitus and field are likely to socialize faculty toward a certain set of behaviors-whether they be to exercise of agency or to remain stuck in untenable situations (Bourdieu, 1971; Clark, 1987; Deil-Amen \& Tevis, 2010; Morphew, 2009). 
In a context of constrained resources and high demands, institutions must learn what environments enable faculty to blossom, achieve, and be satisfied in their roles. A supportive or hostile environment could either facilitate or frustrate faculty members' senses of agency in their careers and work lives. Some department contexts are likely to influence faculty agency more than others. Guided by the O'Meara, Campbell, and Terosky (2010) framework on faculty agency, this empirical study used an advanced quantitative technique (SEM) to examine specific departmental influences on faculty agency. The specific departmental influences that this study investigated are changeable by institutions and administrators (e.g., person-department fit, work-life climate, and professional development resources). This study found that certain organizational conditions facilitate agency perspective. Departments and institutions can emulate these best practices (fostering mutual valuing of work, appreciating work-life balance, providing administrative research support), thereby providing scaffolding for faculty success, and possibly their retention and institutional commitment. Understanding contexts that facilitate agency provides policy-makers, academic administrators, and faculty with a better roadmap for improving work environments. 


\section{Appendix A. UM Faculty Work Environments Survey}

\section{UM FACULTY WORK ENVIRONMENT SURVEY}

As part of the NSF funded Advance Grant for Inclusive Excellence we seek the assistance of all full-time faculty on campus.

A central premise of the project is that supportive academic environments are also places that retain faculty and see them more satisfied, committed to their institutions, and performing at the highest levels. We are assessing specific aspects of faculty experiences at UM, such as faculty perceptions of their own professional growth, work environment for professional growth, climate for work and life balance, and diversity.

This information will be used by the Advance Grant to design project activities and will be shared (in aggregate only) with the Office of Faculty Affairs and Office of Diversity to guide long-term program and policy decisions across the University. We will repeat the survey in 2013 and 2015 to see if UM has improved in any of the areas measured. Your input is therefore critical and would be greatly appreciated and valued.

Your participation in this confidential survey is strictly voluntary. You may refuse to participate, refuse to answer certain questions or discontinue participation at any time without penalty. Refusal to participate will not affect your employment in any way. The survey will only take about 25 minutes of your time to complete. All information and responses will be kept strictly confidential and will only be seen by members of the research team. Data gathered from the survey will be summarized and presented in aggregate form so that no single individual can be identified. Your privacy will be protected to the maximum extent allowable by law. If you elect to print out the survey and mail in a hard copy, please add your name and UID in order to ensure one response per participant and to match your responses to institutional data. Once data have been aggregated all identifiers will be stripped and only kept by the Advance Grant Co-PI for Research and Evaluation, Dr. KerryAnn O’Meara.

Participation in this study does not involve any known physical, financial, emotional or legal risk to you. You will not receive financial compensation for participation, but your responses will contribute to improved UM work environments and opportunities for professional growth.

You are welcome to contact Advance Grant Co-PI, Dr. KerryAnn O’Meara at any time if you have questions about the survey, at (301) 405-5579 or by email at komeara@umd.edu.

By selecting "yes" below and then proceeding with the survey you are voluntarily consenting to participate in the survey and allowing your responses to be used for research and evaluation purposes.

पYes, I voluntarily agree to participate in this survey and allow my responses to be used for research and evaluation purposes.

DNo, I do not wish to participate in this survey.

Thank you very much for taking the time to help us understand the current work environment for UM faculty.

If you choose to print the survey, please send the hard copy to: ADVANCE Program for Inclusive Excellence, 3201 Knight Hall, University of Maryland, College Park MD, 20742. 
NOTE: Several of the questions ask about your "unit." The term "unit" means department. However, if you are in a unit with no separate departments, such as a school or institute, then please take the word "unit" to mean that school or institute. Also, if you have multiple appointments in different departments, please refer to your tenure home.

Other questions inquire about the University overall, which refers to University of Maryland, College Park as a campus.

\section{Learning Opportunities}

1. Please indicate the extent to which you agree or disagree with these statements about your own "learning."

By "learning" we mean acquiring new knowledge and skills that advance one's scholarly and professional work.

\begin{tabular}{|l|c|c|c|c|c|}
\hline & $\begin{array}{c}\text { Strongly } \\
\text { Disagree }\end{array}$ & Disagree & $\begin{array}{c}\text { Neither } \\
\text { Agree } \\
\text { nor } \\
\text { Disagree }\end{array}$ & Agree & $\begin{array}{c}\text { Strongly } \\
\text { Agree }\end{array}$ \\
\hline $\begin{array}{l}\text { In the last twelve months, I have learned a } \\
\text { great deal that contributes to my research } \\
\text { and/or scholarly agenda. }\end{array}$ & 1 & 2 & 3 & 4 & 5 \\
\hline $\begin{array}{l}\text { In the last twelve months, I set aside time to } \\
\text { advance my scholarly learning. }\end{array}$ & 1 & 2 & 3 & 4 & 5 \\
\hline $\begin{array}{l}\text { In the last twelve months, I have gained } \\
\text { knowledge or skills that have made me a } \\
\text { better teacher. }\end{array}$ & 1 & 2 & 3 & 4 & 5 \\
\hline
\end{tabular}

2. Please indicate the extent to which you agree or disagree with each of the following statements about unit and campus supports for your own learning.

\begin{tabular}{|l|c|c|c|c|c|}
\hline & $\begin{array}{c}\text { Strongly } \\
\text { Disagree }\end{array}$ & Disagree & $\begin{array}{c}\text { Neither } \\
\text { Agree } \\
\text { nor } \\
\text { Disagree }\end{array}$ & Agree & $\begin{array}{c}\text { Strongly } \\
\text { Agree }\end{array}$ \\
\hline $\begin{array}{l}\text { The pressure to seek grants is a barrier to } \\
\text { my scholarly learning. }\end{array}$ & 1 & 2 & 3 & 4 & 5 \\
\hline $\begin{array}{l}\text { The pressure to publish is a barrier to my } \\
\text { scholarly learning. }\end{array}$ & 1 & 2 & 3 & 4 & 5 \\
\hline $\begin{array}{l}\text { My unit supports my learning external to } \\
\text { campus (e.g., community engagement, } \\
\text { national disciplinary associations). }\end{array}$ & 1 & 2 & 3 & 4 & 5 \\
\hline $\begin{array}{l}\text { My unit has helped me to make room } \\
\text { among my responsibilities for immersing }\end{array}$ & 1 & 2 & 3 & 4 & 5 \\
\hline
\end{tabular}




\begin{tabular}{|c|c|c|c|c|c|}
\hline $\begin{array}{l}\text { myself in my academic learning (e.g., } \\
\text { sabbaticals, course release). }\end{array}$ & & & & & \\
\hline $\begin{array}{l}\text { My unit provides an environment that } \\
\text { stimulates my academic learning. }\end{array}$ & 1 & 2 & 3 & 4 & 5 \\
\hline $\begin{array}{l}\text { The University provides an environment } \\
\text { that stimulates my academic learning. }\end{array}$ & 1 & 2 & 3 & 4 & 5 \\
\hline $\begin{array}{l}\text { My unit has financially supported my } \\
\text { learning in my field or discipline (e.g., } \\
\text { provided funds to attend conferences, buy } \\
\text { software, books or equipment for my } \\
\text { research). }\end{array}$ & 1 & 2 & 3 & 4 & 5 \\
\hline
\end{tabular}

\section{Professional Relationships, Networks, and Mentoring}

3. A core discussion network consists of the individuals you are in contact with on a regular basis who provide feedback and support for your professional work.

Please indicate your level of agreement with the following related to the individuals who compose your core discussion network:

I don't have regular contact with others about my work. [Go to Question 4]

\begin{tabular}{|l|c|c|c|c|c|}
\hline & $\begin{array}{c}\text { Strongly } \\
\text { Disagree }\end{array}$ & Disagree & $\begin{array}{c}\text { Neither } \\
\text { Agree } \\
\text { nor } \\
\text { Disagree }\end{array}$ & Agree & $\begin{array}{c}\text { Strongly } \\
\text { Agree }\end{array}$ \\
\hline They are primarily off-campus. & 1 & 2 & 3 & 4 & 5 \\
\hline They are primarily on-campus. & 1 & 2 & 3 & 4 & 5 \\
\hline They enhance my visibility in my field. & 1 & 2 & 3 & 4 & 5 \\
\hline $\begin{array}{l}\text { They let me know of professional } \\
\text { opportunities (e.g., for funding, editing } \\
\text { journals, book contracts, awards). }\end{array}$ & 1 & 2 & 3 & 4 & 5 \\
\hline $\begin{array}{l}\text { They include one or more members who } \\
\text { are influential in my field. }\end{array}$ & 1 & 2 & 3 & 4 & 5 \\
\hline $\begin{array}{l}\text { They are important sources of professional } \\
\text { advice when I have a work related } \\
\text { problem. }\end{array}$ & 1 & 2 & 3 & 4 & 5 \\
\hline $\begin{array}{l}\text { They provide helpful feedback on my } \\
\text { research. }\end{array}$ & 1 & 2 & 3 & 4 & 5 \\
\hline They are primarily in my direct field. & 1 & 2 & 3 & 4 & 5 \\
\hline They stimulate my thinking and creativity. & 1 & 2 & 3 & 4 & 5 \\
\hline They include at least one senior colleague. & 1 & 2 & 3 & 4 & 5 \\
\hline
\end{tabular}


4. Please indicate your level of agreement or disagreement with these statements about your own experiences over the last twelve months.

\begin{tabular}{|c|c|c|c|c|c|}
\hline & $\begin{array}{l}\text { Strongly } \\
\text { Disagree }\end{array}$ & Disagree & $\begin{array}{l}\text { Neither } \\
\text { Agree } \\
\text { nor } \\
\text { Disagree }\end{array}$ & Agree & $\begin{array}{l}\text { Strongly } \\
\text { Agree }\end{array}$ \\
\hline $\begin{array}{l}\text { I have found it difficult to } \\
\text { establish connections with others } \\
\text { in my field. }\end{array}$ & 1 & 2 & 3 & 4 & 5 \\
\hline $\begin{array}{l}\text { I have relationships with other } \\
\text { faculty on campus that have } \\
\text { supported my career advancement } \\
\text { (e.g., tenure, promotion, contract } \\
\text { renewal). }\end{array}$ & 1 & 2 & 3 & 4 & 5 \\
\hline $\begin{array}{l}\text { I have relationships with faculty at } \\
\text { UM that support me personally. }\end{array}$ & 1 & 2 & 3 & 4 & 5 \\
\hline $\begin{array}{l}\text { Most of the personal support I } \\
\text { receive is from colleagues off- } \\
\text { campus. }\end{array}$ & 1 & 2 & 3 & 4 & 5 \\
\hline $\begin{array}{l}\text { I have relationships with students } \\
\text { on campus that advance my } \\
\text { scholarly learning. }\end{array}$ & 1 & 2 & 3 & 4 & 5 \\
\hline $\begin{array}{l}\text { I receive useful feedback from } \\
\text { colleagues at UM that improves } \\
\text { my work. }\end{array}$ & 1 & 2 & 3 & 4 & 5 \\
\hline $\begin{array}{l}\text { Individuals at this institution have } \\
\text { made an effort to connect me with } \\
\text { important people in my field. }\end{array}$ & 1 & 2 & 3 & 4 & 5 \\
\hline $\begin{array}{l}\text { I have been effectively mentored } \\
\text { by someone in my unit. }\end{array}$ & 1 & 2 & 3 & 4 & 5 \\
\hline $\begin{array}{l}\text { I am satisfied with the amount of } \\
\text { professional interaction I have } \\
\text { with senior colleagues at the } \\
\text { University. }\end{array}$ & 1 & 2 & 3 & 4 & 5 \\
\hline $\begin{array}{l}\text { I am satisfied with the opportunity } \\
\text { I have to collaborate with other } \\
\text { UM faculty. }\end{array}$ & 1 & 2 & 3 & 4 & 5 \\
\hline $\begin{array}{l}\text { I am satisfied with the collegiality } \\
\text { in my unit. }\end{array}$ & 1 & 2 & 3 & 4 & 5 \\
\hline I feel isolated in my department. & 1 & 2 & 3 & 4 & 5 \\
\hline
\end{tabular}




\begin{tabular}{|l|l|l|l|l|l|l|}
\hline I try to support junior colleagues. & 1 & 2 & 3 & 4 & 5 & NA \\
\hline
\end{tabular}

\section{Career Advancement Opportunities at UM}

5. Please indicate the extent to which you agree or disagree with the following statements about your own experiences with career advancement over the last twelve months.

\begin{tabular}{|c|c|c|c|c|c|c|}
\hline & $\begin{array}{l}\text { Strongly } \\
\text { Disagree }\end{array}$ & Disagree & $\begin{array}{l}\text { Neither } \\
\text { Agree } \\
\text { nor } \\
\text { Disagree }\end{array}$ & Agree & $\begin{array}{c}\text { Strongly } \\
\text { Agree }\end{array}$ & \\
\hline $\begin{array}{l}\text { I have been strategic in achieving } \\
\text { my career goals. }\end{array}$ & 1 & 2 & 3 & 4 & 5 & \\
\hline $\begin{array}{l}\text { I seize opportunities when they are } \\
\text { presented to me to advance in my } \\
\text { career. }\end{array}$ & 1 & 2 & 3 & 4 & 5 & \\
\hline $\begin{array}{l}\text { I feel stuck in my ability to advance } \\
\text { in my career. }\end{array}$ & 1 & 2 & 3 & 4 & 5 & \\
\hline $\begin{array}{l}\text { I have intentionally made choices to } \\
\text { focus my career in ways that are } \\
\text { personally meaningful to me. }\end{array}$ & 1 & 2 & 3 & 4 & 5 & \\
\hline $\begin{array}{l}\text { In general, I feel that I have little } \\
\text { control over whether I advance in } \\
\text { my career. }\end{array}$ & 1 & 2 & 3 & 4 & 5 & \\
\hline $\begin{array}{l}\text { Faculty in my unit have the freedom } \\
\text { to succeed here if they work hard. }\end{array}$ & 1 & 2 & 3 & 4 & 5 & \\
\hline $\begin{array}{l}\text { I have received helpful feedback } \\
\text { from my department chair/unit head } \\
\text { in support of my career } \\
\text { advancement. }\end{array}$ & 1 & 2 & 3 & 4 & 5 & \\
\hline $\begin{array}{l}\text { In my unit, the tenure requirements } \\
\text { are clear. }\end{array}$ & 1 & 2 & 3 & 4 & 5 & $\begin{array}{l}\text { NA/Don't } \\
\text { Know }\end{array}$ \\
\hline $\begin{array}{l}\text { In my unit, the promotion } \\
\text { requirements for advancing to Full } \\
\text { Professor are clear. }\end{array}$ & 1 & 2 & 3 & 4 & 5 & $\begin{array}{l}\text { NA/Don't } \\
\text { Know }\end{array}$ \\
\hline $\begin{array}{l}\text { In my unit, the tenure process is } \\
\text { fair. }\end{array}$ & 1 & 2 & 3 & 4 & 5 & $\begin{array}{l}\text { NA/Don't } \\
\text { Know }\end{array}$ \\
\hline $\begin{array}{l}\text { In my unit, the promotion process } \\
\text { for advancing to Full Professor is } \\
\text { fair. }\end{array}$ & 1 & 2 & 3 & 4 & 5 & $\begin{array}{l}\text { NA/Don't } \\
\text { Know }\end{array}$ \\
\hline
\end{tabular}

6. Do you have any concerns about your own opportunities to advance in your career at UM? 
口 YES

$\square \mathrm{NO}$

If yes, please explain the nature of your concerns.

\section{Evaluation of Research, Scholarship, and Creative Work}

7. Please indicate the extent to which you agree or disagree with the following statements about your own experiences with evaluation of research and scholarship over the last two years (whether tenure stream or fixed term).

\begin{tabular}{|l|c|c|c|c|c|c|}
\hline & $\begin{array}{c}\text { Strongly } \\
\text { Disagree }\end{array}$ & Disagree & $\begin{array}{c}\text { Neither } \\
\text { Agree } \\
\text { nor } \\
\text { Disagree }\end{array}$ & Agree & $\begin{array}{c}\text { Strongly } \\
\text { Agree }\end{array}$ & NA \\
\hline $\begin{array}{l}\text { Interdisciplinary scholarship (i.e., } \\
\text { where perspectives from multiple } \\
\text { fields/disciplines are integrated) is } \\
\text { rewarded in my unit. }\end{array}$ & 1 & 2 & 3 & 4 & 5 & NA \\
\hline $\begin{array}{l}\text { Engaged scholarship (i.e. where } \\
\text { faculty collaborate on problems } \\
\text { aimed at the public good) is } \\
\text { rewarded in my unit. }\end{array}$ & 1 & 2 & 3 & 4 & 5 & NA \\
\hline $\begin{array}{l}\text { Collaborative research and grant } \\
\text { work where there are co-authors } \\
\text { and/or co-principal investigators is } \\
\text { encouraged in our unit's reward } \\
\text { system. }\end{array}$ & 1 & 2 & 3 & 4 & 5 & NA \\
\hline $\begin{array}{l}\text { In our unit faculty are rewarded for } \\
\text { taking risks and trying to be cutting } \\
\text { edge in their research. }\end{array}$ & 1 & 2 & 3 & 4 & 5 & NA \\
\hline
\end{tabular}

8. If there is one problem we consistently face in evaluation of research, scholarship, or creative work in our unit it is....... 


\section{Leadership Opportunities}

9. We are interested in your experiences with leadership opportunities at UM.

\begin{tabular}{|l|c|c|c|c|}
\hline $\begin{array}{l}\text { Have you ever applied for, been asked } \\
\text { to, or served in any of the following } \\
\text { positions at UM? }\end{array}$ & $\begin{array}{c}\text { I have } \\
\text { not } \\
\text { applied } \\
\text { or been } \\
\text { asked }\end{array}$ & $\begin{array}{c}\text { I applied, } \\
\text { but was } \\
\text { not } \\
\text { selected }\end{array}$ & $\begin{array}{c}\text { I was asked, } \\
\text { but did not } \\
\text { serve }\end{array}$ & $\begin{array}{c}\text { I serve now or } \\
\text { served } \\
\text { previously }\end{array}$ \\
\hline $\begin{array}{l}\text { Assistant/Associate Chair or } \\
\text { Assistant/Associate Director }\end{array}$ & & & & \\
\hline Department Chair or Director & & & & \\
\hline $\begin{array}{l}\text { Director of a Center, Institute or } \\
\text { Program }\end{array}$ & & & & \\
\hline Assistant/Associate Dean & & & & \\
\hline Dean & & & & \\
\hline
\end{tabular}

10. If you were asked to serve, but declined any of the previously stated positions, please indicate why.

11. Please indicate your level of agreement or disagreement with each of the following statements.

\begin{tabular}{|l|c|c|c|c|c|}
\hline & $\begin{array}{c}\text { Strongly } \\
\text { Disagree }\end{array}$ & Disagree & $\begin{array}{c}\text { Neither } \\
\text { Agree } \\
\text { nor } \\
\text { Disagree }\end{array}$ & Agree & $\begin{array}{c}\text { Strongly } \\
\text { Agree }\end{array}$ \\
\hline $\begin{array}{l}\text { I would like to serve in a leadership role } \\
\text { within my unit. }\end{array}$ & 1 & 2 & 3 & 4 & 5 \\
\hline $\begin{array}{l}\text { I would like to serve in a leadership role in } \\
\text { the broader UM community (college or } \\
\text { University level). }\end{array}$ & 1 & 2 & 3 & 4 & 5 \\
\hline $\begin{array}{l}\text { I have the knowledge and skills needed to } \\
\text { be an effective leader at this University. }\end{array}$ & 1 & 2 & 3 & 4 & 5 \\
\hline
\end{tabular}


12. During the past twelve months, how many times have you been encouraged, by anyone at UM, to pursue any leadership positions (Assistant/Associate Chair or Assistant/Associate Director, Department Chair or Director, Director of a Center, Institute or Program, Assistant/Associate Dean, Dean):

口Never

口Once

ㅁ2 to 3 times

口4 to 5 times

口More Than 5 times

\section{Balance of Teaching, Research and Service Responsibilities}

13. Please indicate your level of agreement or disagreement with the following statements about your own experiences over the last two years.

\begin{tabular}{|l|c|c|c|c|c|}
\hline & $\begin{array}{c}\text { Strongly } \\
\text { Disagree }\end{array}$ & Disagree & $\begin{array}{c}\text { Neither } \\
\text { Agree } \\
\text { nor } \\
\text { Disagree }\end{array}$ & Agree & $\begin{array}{c}\text { Strongly } \\
\text { Agree }\end{array}$ \\
\hline $\begin{array}{l}\text { Managing my teaching responsibilities is } \\
\text { largely under my control. }\end{array}$ & 1 & 2 & 3 & 4 & 5 \\
\hline $\begin{array}{l}\text { There is support in my department for } \\
\text { effective teaching. }\end{array}$ & 1 & 2 & 3 & 4 & 5 \\
\hline $\begin{array}{l}\text { I feel in control of my participation in } \\
\text { service activities (the amount and level of } \\
\text { participation). }\end{array}$ & 1 & 2 & 3 & 4 & 5 \\
\hline $\begin{array}{l}\text { It is possible for me to say no to additional } \\
\text { on-campus service activities without } \\
\text { negative consequences for my career. }\end{array}$ & 1 & 2 & 3 & 4 & 5 \\
\hline $\begin{array}{l}\text { I am in charge of the direction of my } \\
\text { research agenda. }\end{array}$ & 1 & 2 & 3 & 4 & 5 \\
\hline
\end{tabular}




\section{Climate and Supports for Work-life Balance}

14. Please indicate the extent to which you agree or disagree with the following statements about your own experiences with the UM environment for work-life balance over the last twelve months.

\begin{tabular}{|c|c|c|c|c|c|c|}
\hline & $\begin{array}{l}\text { Strongly } \\
\text { Disagree }\end{array}$ & Disagree & $\begin{array}{l}\text { Neither } \\
\text { Agree } \\
\text { nor } \\
\text { Disagree }\end{array}$ & Agree & $\begin{array}{l}\text { Strongly } \\
\text { Agree }\end{array}$ & \\
\hline $\begin{array}{l}\text { I have taken strategic steps toward } \\
\text { creating a satisfactory work-life } \\
\text { balance. }\end{array}$ & 1 & 2 & 3 & 4 & 5 & \\
\hline $\begin{array}{l}\text { In general, I feel I have control } \\
\text { over creating a satisfying work-life } \\
\text { balance. }\end{array}$ & 1 & 2 & 3 & 4 & 5 & \\
\hline $\begin{array}{l}\text { I am satisfied with my unit's } \\
\text { culture around work-life balance. }\end{array}$ & 1 & 2 & 3 & 4 & 5 & \\
\hline $\begin{array}{l}\text { There are role-models in my unit } \\
\text { of how to create a satisfying work- } \\
\text { life balance. }\end{array}$ & 1 & 2 & 3 & 4 & 5 & \\
\hline $\begin{array}{l}\text { The amount of work my unit } \\
\text { expects me to perform makes } \\
\text { work-life balance difficult. }\end{array}$ & 1 & 2 & 3 & 4 & 5 & \\
\hline $\begin{array}{l}\text { In my unit it is generally expected } \\
\text { that people need to make work } \\
\text { their top priority. }\end{array}$ & 1 & 2 & 3 & 4 & 5 & \\
\hline $\begin{array}{l}\text { The institution does what it can to } \\
\text { make family life and the tenure } \\
\text { track compatible. }\end{array}$ & 1 & 2 & 3 & 4 & 5 & $\begin{array}{l}\text { NA/Don't } \\
\text { know }\end{array}$ \\
\hline $\begin{array}{l}\text { My unit supports faculty } \\
\text { scheduling work commitments } \\
\text { around family schedules. }\end{array}$ & 1 & 2 & 3 & 4 & 5 & $\begin{array}{l}\text { NA/Don't } \\
\text { know }\end{array}$ \\
\hline $\begin{array}{l}\text { In my unit, faculty can be honest } \\
\text { with colleagues about family/life } \\
\text { roles and responsibilities. }\end{array}$ & 1 & 2 & 3 & 4 & 5 & $\begin{array}{l}\text { NA/Don't } \\
\text { know }\end{array}$ \\
\hline $\begin{array}{l}\text { There is NO bias against family } \\
\text { care-giving in my unit. }\end{array}$ & 1 & 2 & 3 & 4 & 5 & $\begin{array}{l}\text { NA/Don't } \\
\text { know }\end{array}$ \\
\hline
\end{tabular}


UM has implemented a number of policies and programs designed to improve the campus climate for work-life balance and to support faculty professional growth in recent years.

15. Please indicate whether you have used the program and/or would use the program in the future.

\begin{tabular}{|c|c|c|c|c|c|}
\hline & \multicolumn{2}{|c|}{$\begin{array}{l}\text { Have you ever used } \\
\text { this policy/program? }\end{array}$} & \multicolumn{2}{|c|}{$\begin{array}{c}\text { Do you anticipate } \\
\text { using this program } \\
\text { or policy in the } \\
\text { future? }\end{array}$} & \multirow[t]{2}{*}{$\begin{array}{l}\text { Have not } \\
\text { heard of it }\end{array}$} \\
\hline & Yes & No & Yes & No & \\
\hline Part-time tenure track policy & & & & & \\
\hline Campus childcare & & & & & \\
\hline Stop the tenure clock & & & & & \\
\hline Dual career support services & & & & & \\
\hline Childcare referral service & & & & & \\
\hline New faculty orientation & & & & & \\
\hline $\begin{array}{l}\text { FMLA/ family Leave without } \\
\text { pay }\end{array}$ & & & & & \\
\hline Mentoring program & & & & & \\
\hline
\end{tabular}

16. Please indicate your perception of the value of the policy/program regardless of whether you have used it.

\begin{tabular}{|l|c|c|c|c|}
\hline \multicolumn{7}{|c|}{ How valuable is this program/policy for faculty at UM? } \\
\hline & $\begin{array}{c}\text { Not at all } \\
\text { valuable }\end{array}$ & $\begin{array}{c}\text { Slightly } \\
\text { valuable }\end{array}$ & $\begin{array}{c}\text { Moderately } \\
\text { valuable }\end{array}$ & $\begin{array}{c}\text { Very } \\
\text { valuable }\end{array}$ \\
\hline $\begin{array}{l}\text { Part-time policy (permits tenure track } \\
\text { faculty to work part time) }\end{array}$ & 1 & 2 & 3 & 4 \\
\hline Campus childcare & 1 & 2 & 3 & 4 \\
\hline Tenure delay/stop the tenure clock & 1 & 2 & 3 & 4 \\
\hline Dual career support services & 1 & 2 & 3 & 4 \\
\hline Relocation assistance services & 1 & 2 & 3 & 4 \\
\hline Childcare referral service & 1 & 2 & 3 & 4 \\
\hline New faculty orientation & 1 & 2 & 3 & 4 \\
\hline $\begin{array}{l}\text { FMLA/ family Leave without } \\
\text { pay/FMLA }\end{array}$ & 1 & 2 & 3 & 4 \\
\hline $\begin{array}{l}\text { Mentoring program (i.e. assigned } \\
\text { mentor) }\end{array}$ & 1 & 2 & 3 & 4 \\
\hline
\end{tabular}


17. If you could do one thing to improve the policies and programs at UM for work-life balance, what would it be?

\section{Satisfaction with Resources and Conditions at UM}

18. Please indicate the extent to which you are satisfied or dissatisfied with the following resources or conditions at UM?

\begin{tabular}{|c|c|c|c|c|c|}
\hline & $\begin{array}{c}\text { Very } \\
\text { unsatisfied }\end{array}$ & Unsatisfied & $\begin{array}{c}\text { Neither } \\
\text { satisfied } \\
\text { nor } \\
\text { dissatisfied }\end{array}$ & Satisfied & $\begin{array}{c}\text { Very } \\
\text { Satisfied }\end{array}$ \\
\hline Assistance with finding grants & 1 & 2 & 3 & 4 & 5 \\
\hline Amount of access to TAs, RAs & 1 & 2 & 3 & 4 & 5 \\
\hline $\begin{array}{l}\text { Professional assistance for improving } \\
\text { teaching }\end{array}$ & 1 & 2 & 3 & 4 & 5 \\
\hline Expectations for committee service & 1 & 2 & 3 & 4 & 5 \\
\hline $\begin{array}{l}\text { Assistance with research } \\
\text { administration in your unit }\end{array}$ & 1 & 2 & 3 & 4 & 5 \\
\hline $\begin{array}{l}\text { My overall experience working in my } \\
\text { unit }\end{array}$ & 1 & 2 & 3 & 4 & 5 \\
\hline My overall experience working at UM & 1 & 2 & 3 & 4 & 5 \\
\hline My salary and benefits & 1 & 2 & 3 & 4 & 5 \\
\hline The University's location & 1 & 2 & 3 & 4 & 5 \\
\hline The diversity on campus & 1 & 2 & 3 & 4 & 5 \\
\hline Clerical/administrative support & 1 & 2 & 3 & 4 & 5 \\
\hline My unit's national reputation & 1 & 2 & 3 & 4 & 5 \\
\hline The University's national reputation & 1 & 2 & 3 & 4 & 5 \\
\hline The quality of the graduate students & 1 & 2 & 3 & 4 & 5 \\
\hline $\begin{array}{l}\text { The quality of the undergraduate } \\
\text { students }\end{array}$ & 1 & 2 & 3 & 4 & 5 \\
\hline $\begin{array}{l}\text { The amount of time I spend on } \\
\text { research versus teaching and service }\end{array}$ & 1 & 2 & 3 & 4 & 5 \\
\hline $\begin{array}{l}\text { The transparency of decision-making } \\
\text { within my unit }\end{array}$ & 1 & 2 & 3 & 4 & 5 \\
\hline $\begin{array}{l}\text { The amount of autonomy I have in my } \\
\text { role as a faculty member here }\end{array}$ & 1 & 2 & 3 & 4 & 5 \\
\hline The support of colleagues here & 1 & 2 & 3 & 4 & 5 \\
\hline $\begin{array}{l}\text { The sense of fit between my values } \\
\text { and those of my unit }\end{array}$ & 1 & 2 & 3 & 4 & 5 \\
\hline
\end{tabular}


19. With respect to the general diversity climate in your unit, please indicate the extent to which you agree or disagree with each of the following statements?

Note: Faculty of Color: Black/African American, Asian American/Asian, Native American, Native Hawaiian or other Pacific Islander, Hispanic/Chicano/Latino

\begin{tabular}{|l|c|c|c|c|c|}
\hline & $\begin{array}{c}\text { Strongly } \\
\text { Disagree }\end{array}$ & Disagree & $\begin{array}{c}\text { Neither } \\
\text { Agree } \\
\text { nor } \\
\text { Disagree }\end{array}$ & Agree & $\begin{array}{c}\text { Strongly } \\
\text { Agree }\end{array}$ \\
\hline $\begin{array}{l}\text { A diversified faculty is important for UM's } \\
\text { academic excellence. }\end{array}$ & 1 & 2 & 3 & 4 & 5 \\
\hline $\begin{array}{l}\text { My unit makes a conscious effort to } \\
\text { generate a diverse applicant pool for full- } \\
\text { time faculty positions. }\end{array}$ & 1 & 2 & 3 & 4 & 5 \\
\hline $\begin{array}{l}\text { The opportunities for female faculty at UM } \\
\text { are at least as good as those for male } \\
\text { faculty. }\end{array}$ & 1 & 2 & 3 & 4 & 5 \\
\hline $\begin{array}{l}\text { The opportunities for faculty of color at UM } \\
\text { are at least as good as for those for White } \\
\text { faculty. }\end{array}$ & 1 & 2 & 3 & 4 & 5 \\
\hline $\begin{array}{l}\text { I have to work harder than some of my } \\
\text { colleagues to be perceived as a legitimate } \\
\text { scholar. }\end{array}$ & 1 & 2 & 3 & 4 & 5 \\
\hline $\begin{array}{l}\text { I have experienced discrimination (either } \\
\text { overt or subtle) in my unit based on my } \\
\text { individual identities (e.g., gender, } \\
\text { race/ethnicity, religion, age, sexual } \\
\text { orientation). }\end{array}$ & 1 & 2 & 3 & 4 & 5 \\
\hline
\end{tabular}




\section{Recognition in Your Unit}

20. Please indicate the extent to which you agree or disagree with each of the following statements concerning recognition for contributions and alignment in your unit.

\begin{tabular}{|l|c|c|c|c|c|}
\hline & $\begin{array}{c}\text { Strongly } \\
\text { Disagree }\end{array}$ & Disagree & $\begin{array}{c}\text { Neither } \\
\text { Agree } \\
\text { nor } \\
\text { Disagree }\end{array}$ & Agree & $\begin{array}{c}\text { Strongly } \\
\text { Agree }\end{array}$ \\
\hline $\begin{array}{l}\text { Faculty in my unit value my teaching } \\
\text { contributions. }\end{array}$ & 1 & 2 & 3 & 4 & 5 \\
\hline $\begin{array}{l}\text { Faculty in my unit value my } \\
\text { research/scholarship. }\end{array}$ & 1 & 2 & 3 & 4 & 5 \\
\hline $\begin{array}{l}\text { Faculty in my unit are aware of the service } \\
\text { that I do for our program. }\end{array}$ & 1 & 2 & 3 & 4 & 5 \\
\hline $\begin{array}{l}\text { Faculty in my unit value my service } \\
\text { contributions. }\end{array}$ & 1 & 2 & 3 & 4 & 5 \\
\hline $\begin{array}{l}\text { Faculty in my unit care about my personal } \\
\text { well-being. }\end{array}$ & 1 & 2 & 3 & 4 & 5 \\
\hline
\end{tabular}

21. Over the last three years have you ever been nominated by someone at UM for an award?

\section{口YES}

\section{$\square \mathrm{NO}$}

If so, what kind of award?

\section{Information, Communication, and Decision-Making}

22. Please indicate the extent to which you agree or disagree with the following statements concerning information, communication and decision-making in your unit.

\begin{tabular}{|l|c|c|c|c|c|}
\hline & $\begin{array}{c}\text { Strongly } \\
\text { Disagree }\end{array}$ & Disagree & $\begin{array}{c}\text { Neither } \\
\text { Agree } \\
\text { Nor } \\
\text { Disagree }\end{array}$ & Agree & $\begin{array}{c}\text { Strongly } \\
\text { Agree }\end{array}$ \\
\hline $\begin{array}{l}\text { Major decisions in my unit are made with } \\
\text { adequate input from faculty. }\end{array}$ & 1 & 2 & 3 & 4 & 5 \\
\hline $\begin{array}{l}\text { Resource allocation in my unit (e.g., } \\
\text { space, funded research assistants) is } \\
\text { transparent. }\end{array}$ & 1 & 2 & 3 & 4 & 5 \\
\hline $\begin{array}{l}\text { Decisions regarding salary increases in } \\
\text { my unit are transparent. }\end{array}$ & 1 & 2 & 3 & 4 & 5 \\
\hline
\end{tabular}




\begin{tabular}{|l|c|c|c|c|c|}
\hline $\begin{array}{l}\text { I feel that I can voice my opinions openly } \\
\text { in my unit, even if my colleagues disagree } \\
\text { with me. }\end{array}$ & 1 & 2 & 3 & 4 & 5 \\
\hline $\begin{array}{l}\text { Information is available to understand my } \\
\text { relative standing among my peers. }\end{array}$ & 1 & 2 & 3 & 4 & 5 \\
\hline $\begin{array}{l}\text { I have a voice in decision-making that } \\
\text { affects the direction of my department. }\end{array}$ & 1 & 2 & 3 & 4 & 5 \\
\hline
\end{tabular}

\section{Organizational Commitment}

In this section, we seek to understand faculty intentions to stay or leave. As a reminder, your responses are completely confidential and will only be reported in aggregate, with no identifying information.

23. To what extent are you likely to leave the University in the next two years?

口Definitely will

口Likely

口Not likely

口Definitely will not

24. To what extent are you likely to leave the academic profession in the next two years?

口Definitely will

口Likely

पNot likely

DDefinitely will not

25. If you are likely to leave the University or the academic profession in the next two years, what would be the main reasons?

Please check up to three and/or write in a reason if it is not here.

$\square$ An offer with a higher salary

TTo be closer to family

I'm not well suited to the faculty career

口An offer from a more prestigious department or institution

$\square$ Career opportunities at another institution for my spouse/partner

DBetter policies related to child-care, parental leave

$\square$ Potential for better work-life balance in a different type of position

口Better campus climate for GLBTQ faculty at another institution

口Better campus climate for women at another institution

DBetter campus climate for faculty of color at another institution

$\square$ An offer from an institution in a more desirable geographic location

DPoor likelihood of tenure/promotion or contract renewal

口Lack of collegiality in my unit

口Retirement

$\square$ An offer for a position outside academe

口Other

26. Have you ever had an outside offer while at UM? [If no, go to question 28.] 


\section{口YES}

$\square \mathrm{NO}$

27. Did that offer result in a salary increase for you at UM?

口YES

口NO

28. Since you have been at UM, have you seen at least one colleague leave your unit in the last 3 years?

口 YES

$\square$ NO [Go to question 30]

29. Think of someone from your unit who left UM in the last three years, who you wish had remained. Please check up to three reasons you believe that she or he decided to leave:

口We have NOT had a faculty member leave that I wish had remained.

$\square$ An offer with a higher salary

$\square$ To be closer to family

$\square$ Was not well suited to the faculty career

DAn offer from a more prestigious department or institution

$\square$ Career opportunities at another institution for spouse/partner

口Better policies related to child-care, parental leave

$\square$ Potential for better work-life balance in a different type of position

口Better campus climate for GLBTQ faculty at another institution

DBetter campus climate for women at another institution

口Better campus climate for faculty of color at another institution

$\square$ An offer from an institution in a more desirable geographic location

$\square$ Poor likelihood of tenure/promotion or contract renewal

DLack of collegiality in our unit

口Retirement

$\square$ An offer for a position outside academe

口Other

\section{Faculty Professional activities}

30. What is the typical teaching load each year in your primary unit?

Number of:

Undergraduate courses:

Graduate courses:

Independent studies/directed research/readings:

31. In a typical year, on how many committees do you serve?

32. In a typical year, how many committees do you chair? 
33. In thinking briefly about your productivity, during the last 2 years, please provide approximate estimates of the following:

The number of grants you received

The total dollar amount of the grants you received

The number of publications you authored/co-authored (peer-reviewed articles, book chapters, etc.)

The number of other creative works you created (e.g., exhibitions, performances)

34. Using the criteria above, how would you rate your overall productivity compared to researchers in your field and at your rank nationwide?

$\square$ Much less productive

$\square$ Slightly less productive

口About the same

口Slightly more productive

$\square$ Much more productive

35. Using these same criteria, how do you think your unit views your level of productivity, compared to researchers in your field and at your rank nationwide?

Much Less Productive

$\square$ Slightly Less Productive

口About the Same

口Slightly More Productive

Much More Productive

\section{Demographics:}

Please be assured that all information that you provide will be kept strictly confidential. All reports will be presented in aggregate form so that no individual can be identified.

36. What is your current marital status?

口Married

口Divorced

口Life Partner

口Separated

口Widowed

$\square$ Single

37. What is your spouse's or partner's current employment status?

口Full-time at UM

DFull-time elsewhere

口Part-time at UM

口Part-time elsewhere

DNot employed, but seeking employment

$\square$ Not employed, not seeking employment 


\section{口Student}

口Retired

口Other (please specify)

38. Do you have any children or other dependents?

口 YES

$\square \mathrm{NO}$

39. Do you have any infants/toddlers age 0-2 years?

\section{口 YES}

口 NO

40. Do you have children ages 3-14?

\section{口 YES}

$\square \mathrm{NO}$

41. Is your spouse/partner an academic?

口 YES

口 NO

Thank you for participating in our research.

Please hit SUBMIT below.

\section{SUBMIT}


Appendix B. Revised Faculty Agency Framework (O’Meara, Campbell, \& Terosky, 2012)

\section{Faculty Agency in Professional Lives:}

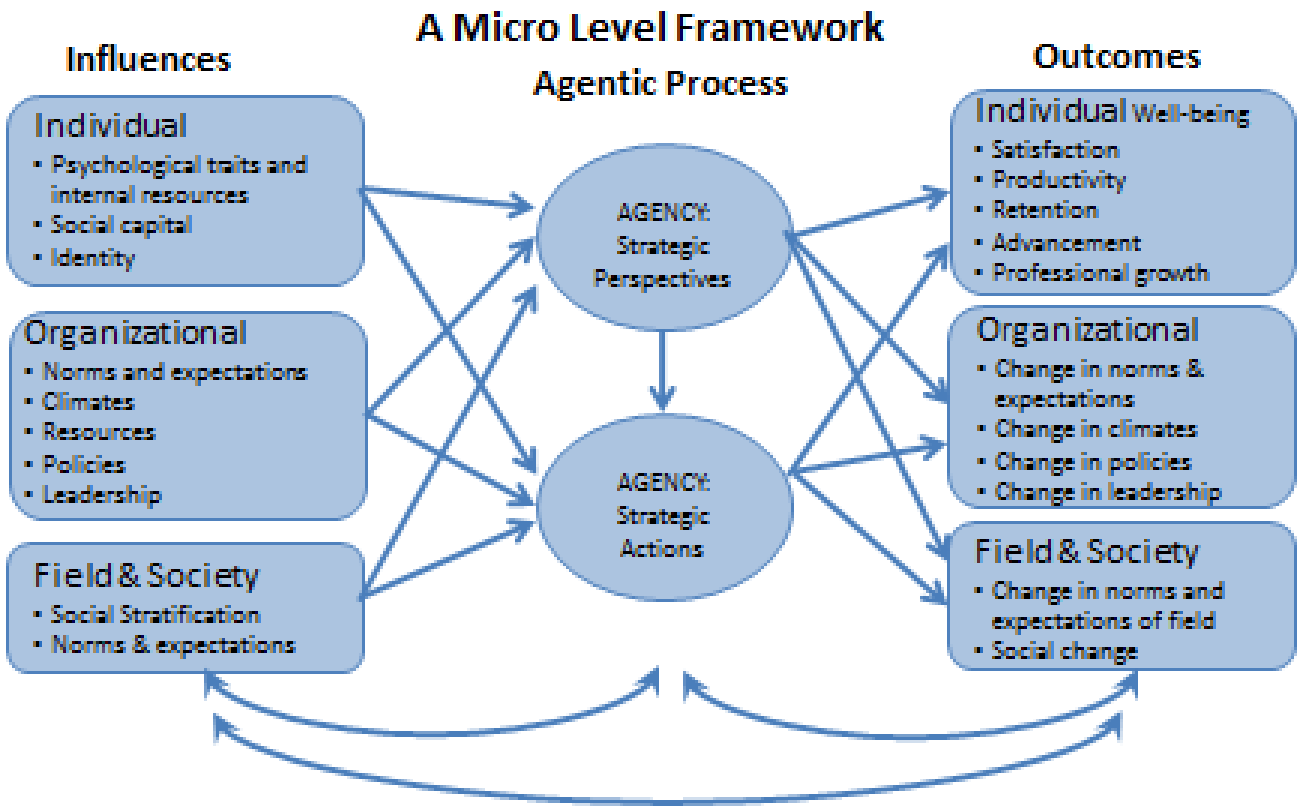

Agency defined:

Taking strategic or intentional actions or perspectives

towards goals that matter to oneself
Agency Characteristics:

- Domain specific

- As form of resistance to or in line with organizational, field, or societal norms 


\section{References}

Ackerman, S., Zuroff, D. C., \& Moskowitz, D. S. (2000). Generativity in midlife and young adults: Links to agency, communion, and subjective well-being. The International Journal of Aging and Human Development, 50, 17-41.

Alkire, S. (2005). Subjective quantitative studies of human agency. Social Indicators Research, 74, 217-260.

Alsop, R., \& Heinsohn, N. (2005). Measuring empowerment in practice: structuring analysis and framing indicators. World Bank Policy Research Working Paper No. 3510. Retrieved From http://ssrn.com/abstract=665062.

Ambrose, A.S. (2010). The influence of college selectivity and student engagement on educational outcomes and early-career earnings. Proceedings from the American Educational Research Association Annual Meeting. Denver, CO.

American Association of University Professors (AAUP; 2007). Trends in faculty status, 1975-2007. Retrieved from http://www.aaup2.org/research/TrendsinFacultyStatus2007.pdf

American Educational Research Association, American Psychological Association, \& National Council on Measurement in Education (1999). Standards for Educational and Psychological Testing. Washington, DC: American Educational Research Association.

Anderson, M. S. (2001). The complex relations between the academy and industry: Views from the literature. Journal of Higher Education, 72, 226-246.

Archer, L. (2009). The neoliberal subjects? young/er academics construction of professional identity. Journal of Educational Policy, 23(3), 265-285. 
Armenti, C. (2004). May babies and post-tenure babies. The Review of Higher Education, 27, 211-231.

Association for the Study of Higher Education. (1983). Academic workplace: New demands, heightened tensions. ASHE-ERIC higher education research report No. 10. Las Vegas, NV: Austin, A. E. \& Gamson, Z. F.

August, L., \& Waltman, J. (2004). Culture, climate, and contribution: Career satisfaction among female faculty. Research in Higher Education, 45, 177192.

Austin, A. E. (2002). Creating a bridge to the future: Preparing new faculty to face changing expectations in a shifting context. Review of Higher Education, $26,119-144$.

Babbie, E. (1990). Survey research methods. Belmont, CA: Wadsworth.

Baez, B. (2000a). Race-related service and faculty of color: Conceptualizing critical agency in academe. Higher Education, 39, 363-391.

Baez, B. (2000). Agency, structure, and power: An inquiry into racism and resistance for education. Studies in Philosophy and Education, 19, 329-348.

Bain, O., \& Cummings, W. (2000). Academe's glass ceiling: Societal, professionalorganizational, and institutional barriers to the career advancement of academic women. Comparative Education Review, 44, 493-514.

Baldwin, R. G., \& Chronister, J. L. (2001). Teaching without tenure: Policies and practices for a new era. Baltimore, MD: Johns Hopkins University Press.

Baldwin, R. G., Lunceford, C. J., \& Vanderlinden, K. E. (2005). Faculty in the middle years. The Review of Higher Education, 29, 97-118. 
Bandura, A. (1982). Self-efficacy mechanism in human agency. American Psychologist, 37, 122-147.

Bandura, A. (1989). Human agency in social cognitive theory. American Psychologist, 44, 1175-1184.

Becher, T., \& Trowler, P. R. (2001). Academic tribes and territories: intellectual enquiry and the cultures of disciplines. Philadelphia, PA: Open University Press.

Becker, G. S. (1964). Human capital: a theoretical analysis with special reference to education. New York, NY: Columbia University Press.

Bellas, M. L., \& Toutkoushian, R. K. (1999). Faculty time allocations and research productivity: Gender, race, and family effects. Review of Higher Education, 22, 367-390.

Berger, P., \& Luckmann, T. (1966). The social construction of reality. New York, NY:Doubleday.

Bess, J. L. \& Dee, J. R. (2008). Understanding college and university organization: Theories for effective policy and practice. Sterling, VA: Stylus publishing.

Bettinger, E. P., \& Long, B. T. (2005). Do faculty serve as role models? The impact of instructor gender on female students. American Economic Review, 95, 152157.

Bieber, J. P., \& Worley, L. K. (2006). Conceptualizing the academic life: Graduate students' perspectives. The Journal of Higher Education, 77, 1009-1035.

Birnbaum, R. (1988). How colleges work. The cybernetics of academic organization and leadership. San Francisco, CA: Jossey-Bass.

Blackburn, R. T., \& Lawrence, J. H. (1995). Faculty at work: Motivation, expectation, 
satisfaction. Baltimore, MD: Johns Hopkins University Press.

Blanchet-Cohen, N. (2006) Rainbow warriors: Environmental agency of early adolescents. Proceedings from the American Educational Research Association Annual Meeting. San Francisco, CA.

Bland, C. J., Center, B. A., Finstad, D. A., Risbey, K. R., \& Staples, J. (2006). The impact of appointment type on the productivity and commitment of full-time faculty in research and doctoral institutions. The Journal of Higher Education, 77, 89-123.

Bluedorn, A. C. (1982). A unified model of turnover from organizations. Human Relations, 35, 135-153.

Bolin, M. K. (2000). The collegial environment and the functional organization. Journal of Library Administration, 29(2), 49-61.

Bolman, L. G., \& Deal, T. E. (2003). Reframing organizations: Artistry, choice, and Leadership. San Francisco, CA: Jossey-Bass.

Bonewits, S., \& Soley, L. (2004). Research and the bottom line in today's university. American Academic, 1(1), 81-92.

Bowen, H. R., \& Schuster, J. H. (1986). American professors: A national resource imperiled. Fair Lawn, NJ: Oxford University Press.

Boyer, E. L. (1990). Scholarship reconsidered: Priorities of the professoriate. Lawrenceville, NJ: Princeton University Press.

Bunderson, J. S. (2001). How work ideologies shape the psychological contracts of professional employees: doctors' responses to perceived breach. Journal of Organizational Behavior, 22, 717-741. 
Byrne, B. M. (2006). Structural equation modeling with EQS: Basic concepts, applications, and programming: New York, NY: Psychology Press.

Caplan, P. J. (1993). Lifting a ton of feathers: a woman's guide for surviving in the academic world. Toronto, Canada: University of Toronto Press.

Cipriano, R. E. (2011) Facilitating a collegial department in higher education. San Francisco, CA: Jossey-Bass.

Clark, B. R. (1987). Perspectives on higher education: eight disciplinary and comparative views. Berkely, CA: University of California Press.

Clausen, J. S. (1991). Adolescent competence and the shaping of the life course. The American Journal of Sociology, 96, 805-842.

Colbeck, C. L., \& Drago, R. (2005). Accept, avoid, resist: How faculty members respond to bias against caregiving ... and how departments can help. Change Magazine, 37(6), 10-17.

Combahee River Collective (1985). A Black feminist statement: Combahee river collective statement. New York, NY: Women of Color Press.

Collins, P.H. (2000). Black feminist thought ( $2^{\text {nd }}$ ed.). New York, NY: Routledge Press.

Creswell, J. W. (2009). Research design: Qualitative, quantitative, and mixed methods approaches. Thousand Oaks, CA: Sage Publications.

Cronbach, L. J. \& Meehl, P. E. (1955). Construct validity in psychological tests. Psychological Bulletin, 52(4), 281-302.

Croninger, R. G. \& Douglas, K. M. (2005). Missing data and institutional research. In P.D. Umback (Ed.), Survey Research: Emerging issues of technology, policy, and 
analysis (pp. 33-50). San Francisco, CA: Jossey-Bass.

Daly, C. J., \& Dee, J. R. (2006). Greener pastures. The Journal of Higher Education, 77, 776-803.

Dean, D. R., Bracken, S. J., \& Allen, J. K. (2009). Women in academic leadership: professional strategies, personal choices. Sterling, VA: Stylus Publishing.

Deil-Amen, R. \& Tevis, T.L. (2010). Circumscribed agency: The relevance of standardized college entrance exams for low SES high school students. The Review of Higher Education, 33, 141-175.

DeWitz, S. J., Woolsey, M. L., \& Walsh, W. B. (2009). College student retention: An exploration of the relationship between self-efficacy beliefs and purpose in life among college students. Journal of College Student Development, 50, 19-34.

Drago, R., Scutella, R., \& Varner, A. (2002). Fertility and work/family policies, Australia and the US. Towards opportunity and prosperity. Melbourne, Australia: Melbourne Institute.

Dugan, J. P., \& Komives, S. R. (2010). Influences on college students' capacities for socially responsible leadership. Journal of College Student Development, 51, 525-549.

Eckel, P. D., \& Kezar, A. (2006). The challenges facing academic decision making: Contemporary issues and steadfast structures. In P.D. Eckel (Ed.), The Shifting Frontiers of Academic Decision Making: Responding to New Priorities, Following New Pathways (pp. 1-14). Westport, CT: Praeger Publishers.

Ehrenberg, R. G. (2006). The changing nature of the faculty and faculty employment practices. In R. Clark \& M. d'Ambrosio (Eds.), The New Balancing Act in the 
Business of Higher Education (pp. 103-117). Northampton, MA: Edward Elgar Publishing.

Elder Jr, G. H. (1994). Time, human agency, and social change: Perspectives on the life course. Social Psychology Quarterly, 57(1), 4-15.

Elder, G. H. (1997). The life course and human development. In W. Damon \& R. M. Lerner (Eds.), Handbook of child psychology (5 ${ }^{\text {th }}$ ed., pp. 939-991). New York: Wiley Publishing.

Emirbayer, M., \& Mische, A. (1998). What is agency? American Journal of Sociology, 103, 962-1023.

Finkelstein, M. J. (1984). The American academic profession: A synthesis of social scientific inquiry since World War II. Columbus, OH: Ohio State University Press.

Fowler, F. J. (2008). Survey research methods. Thousand Oaks, CA. Sage.

Fowler, F. J. (1998). Improving survey questions: Design and evaluation. Thousand Oaks, CA. Sage.

Gappa, J. M., Austin, A. E., \& Trice, A. G. (2007). Rethinking faculty work: Higher education's strategic imperative. San Francisco, CA: Jossey-Bass.

Garnes, D. (2005). Hope and self-efficacy as motivational influences in technology adoption. Retrieved from Proquest Dissertations \& Theses Database. (202605)

Glazer-Raymo, J. (2008). Unfinished agendas: New and continuing gender challenges in higher education. Baltimore, MD: Johns Hopkins University Press.

Gmelch, W. H., Lovrich, N. P., \& Wilke, P. K. (1984). Sources of stress in academe: A national perspective. Research in Higher Education, 20, 477-490. 
Gomez-Mejia, L. R., \& Balkin, D. B. (1992). Determinants of faculty pay: An agency theory perspective. Academy of Management Journal, 35, 921-955.

Gonzales, L. D. (2012) Responding to mission creep: faculty members as cosmopolitan agents. Higher Education, 61, 1-17.

Gonzales, L. D., \& Rincones, R. (2008). The role of faculty in global society. Teacher Education and Practice, 21, 382-406.

Gouldner, A. W. (1957). Cosmopolitans and locals: Toward an analysis of latent social roles. Administrative Science Quarterly, 2, 281-306.

Gregory, S. T. (2001). Black faculty women in the academy: History, status, and future. The Journal of Negro Education, 70(3), 124-138.

Groves, R. M., Fowler, F. J., Couper, M. P., Lepkowski, J. M., Singer, E., \& Tourangeau, R. (2004). Survey Methodology. Hoboken, NJ: John Wiley \& Sons.

Hagedorn, L. S. (2000). Conceptualizing faculty job satisfaction: Components, theories, and outcomes. New Directions for Institutional Research, 105, 5-20.

Hagedorn, L. S. (1994). Retirement proximity's role in the prediction of satisfaction in academe. Research in Higher Education, 35, 711-728.

Hancock, G. R., \& Mueller, R. O. (2006). Structural equation modeling: A second course. Greenwich, CT: Information Age Publishing.

Harper, E. P., Baldwin, R. G., Gansneder, B. G., \& Chronister, J. L. (2001). Full-time women faculty off the tenure track: Profile and practice. Review of Higher Education, 24, 237-257.

Hart, J. (2006). Women and feminism in higher education scholarship. The Journal of Higher Education, 77, 40-61. 
Heck, R. H., \& Thomas, S. L. (2000). An introduction to multilevel models in organizational and educational research. Mahwah, NJ: Lawrence Erlbaum.

Heinz, W. R. (1996). Status passages as micro-macro linkages in life course research. In: A. Weymann \& W. R. Heinz (Eds.), Society and biography: Interrelationships Between social structure, institutions and the life course (pp. 51-65). Weinheim: Deutscher StudienVerlag.

Heppner, M. J. (1994). An empirical investigation of the effects of a teaching practicum on prospective faculty. Journal of Counseling and Development, 72, 500-507.

Hornig, L. S. (1980). Untenured and tenuous: The status of women faculty. The Annals of the American Academy of Political and Social Science, 448(1), 115.

hooks, b. (2000). Feminist theory: From margin to center. Cambridge, MA: South End Press.

Huckaby, F. (2008). Making use of Foucault in a study of specific parrhesiastic scholars. Educational Philosophy \& Theory, 40, 770-787.

Hu, L., \& Bentler, P. M. (1999). Cutoff criteria for fit indexes in covariance structure analysis: Conventional criteria versus new alternatives. Structural Equation Modeling: A Multidisciplinary Journal, 6(1), 1-55.

Johnsrud, L. K., \& Heck, R. H. (1998). Faculty worklife: Establishing benchmarks across groups. Research in Higher Education, 39, 539-555.

Johnsrud, L. K., \& Rosser, V. J. (2002). Faculty members' morale and their intention to leave: A multilevel explanation. The Journal of Higher Education, 73, 518-542.

Johnsrud L.K. \& Sadao (2002). The common experience of "otherness:" ethnic and racial minority faculty. In C.S. Turner, A.L. Antonio, M. Garcia, B.V. Laden, 
A. Nora, \& C. Presley. (Eds.). (2002). Racial and ethnic diversity in higher Education (2 ${ }^{\text {nd }}$ ed. pp. 185-201). ASHE Reader Series. Boston, MA: Pearson Custom Publishing.

Kahana, E., \& Kahana, B. (1996). Conceptual and empirical advances in understanding aging well through proactive adaptation. In: V. L. Bengtson (Ed.), Adulthood and aging: Research on continuities and discontinuities (pp. 18-40). New York: Springer.

Kelly, M. P. (2007). Relationships of self-efficacy, exercise, social support to strain and burnout in university faculty. Retrieved from Proquest Dissertations \& Theses Database. (3261599)

Kezar, A. (2005). Redesigning for collaboration within higher education institutions: An exploration into the developmental process. Research in Higher Education, 46, 831-860.

Kezar, A. (2005). What campuses need to know about organizational learning and the learning organization. New Directions for Higher Education, 131, 7-22.

Kezar, A. J., \& Eckel, P. D. (2002). The effect of institutional culture on change strategies in higher education: Universal principles or culturally responsive concepts? The Journal of Higher Education, 73, 435-460.

Korcheck, S. A., \& Reese, M. (2002). Women as school executives: Research and reflections on educational leadership. Austin, TX: Texas Council of Women School Executives.

Kulis, S. (1997). Gender segregation among college and university employees. Sociology of Education, 70, 151-173. 
Ladson-Billings, G. (2000). For colored girls who have considered suicide when the academy’s not enough. In J. Glazer-Raymo, K. Townsend, \& B. RopersHuilman, (Eds.). Women in Higher Education: A Feminist Perspective ( $^{\text {nd }}$ Ed.). ASHE Reader Series. Boston, MA: Pearson Custom Publishing.

Lawton, M. P. (1989). Environmental proactivity and affect in older people. In: S. Spacapan \& S. Askamp (Eds), The social psychology of aging (pp. 135-163). Newbury Park: Sage.

Lease, S. H. (1999). Occupational role stressors, coping, support, and hardiness as predictors of strain in academic faculty: An emphasis on new and female faculty. Research in Higher Education, 40, 285-307.

Lee, J. J., \& Rhoads, R. A. (2004). Faculty entrepreneurialism and the challenge to undergraduate education at research universities. Research in Higher Education, 45, 739-760.

Lerner, R. M., \& Busch-Rossnagel, N. A. (1981). Individuals as producers of their development: A life-span perspective. New York, NY: Academic Press.

Lindholm, J. A. (2003). Perceived organizational fit: Nurturing the minds, hearts, and personal ambitions of university faculty. Review of Higher Education, 27, 125-149.

Lindholm, J. A. (2004). Pathways to the professoriate: The role of self, others, and environment in shaping academic career aspirations. Journal of Higher Education, 75, 603-636.

Lorde, A., \& Clarke, C. (2007). Sister outsider: Essays and speeches. Berkeley, CA: Crossing Press. 
Luthar, S. S., Cicchetti, D., \& Becker, B. (2000). The construct of resilience: A critical evaluation and guidelines for future work. Child Development, 71, 543-562.

Mabokela, R. O. (2007). From oppression to grace: Women of color and their dilemmas within the academy. [Review of the book, by Berry, T. R. \& Mirelle, N. D.]. Review of Higher Education, 30, 484-486.

Marschke, R., Laursen, S., Nielsen, J. M. C., \& Rankin, P. (2007). Demographic inertia revisited: An immodest proposal to achieve equitable gender representation among faculty in higher education. Journal of Higher Education, 78, 1-26.

Marshall, V. W. (2005). Agency, events, and structure at the end of the life course. Advances in Life Course Research, 10, 57-91.

Martinez Aleman, A. M. (2010) College women's female friendships: A longitudinal view. Journal of Higher Education, 81, 553-582.

Mason, M. A., \& Ekman, E. M. (2007). Mothers on the fast track: How a new generation can balance family and careers. New York, NY: Oxford University Press.

Mason, M. A., \& Goulden, M. (2004). Do babies matter? (Part II). Academe, 90(6), 1015.

Massy, W. F., \& Zemsky, R. (1994). Faculty discretionary time: Departments and the "academic ratchet." Journal of Higher Education, 65, 1-22.

Mayer, K. U., \& Schoepflin, U. (1989). The state and the life course. Annual Review of Sociology, 15(1), 187-209.

McAdams, D. P., de St Aubin, E., \& Logan, R. L. (1993). Generativity among young, midlife, and older adults. Psychology and Aging, 8, 221-230.

Mendoza, P. (2007). Academic capitalism and doctoral student socialization: A case 
study. The Journal of Higher Education, 78, 71-96.

Meyer, J. W., \& Jepperson, R. L. (2000). The" actors" of modern society: The cultural construction of social agency. Sociological Theory, 18(1), 100-120.

Mueller, R. O., \& Hancock, G. R. (2008). Best practices in structural equation modeling. In J.Osborne (Ed.), Best practices in quantitative methods (pp. 488-508). Thousand Oaks, CA: Sage.

National Center for Education Statistics (NCES; 2012). Statistical Standards. Processing and Editing of Data. Retrieved from http://nces.ed.gov/statprog/2002/std4_4.asp National Center for Education Statistics. (NCES; 2002). The Gender and Racial/ethnic Differences in Salary and Other Characteristics of Postsecondary Faculty: Fall 1998. Washington, DC: Bradburn, E. M., Sikora, A. C., \& Zimbler, L. J.

Nelson Laird, T. F. (2005). College students' experiences with diversity and their effects on academic self-confidence, social agency, and disposition toward critical thinking. Research in Higher Education, 46, 365-387.

Nettles, M. T., Perna, L. W., \& Bradburn, E. M. (2000). Salary, promotion, and tenure status of minority and women faculty in US colleges and universities. Education Statistics Quarterly, 2, 94-96.

Neugarten, B. L., Moore, J. W., \& Lowe, J. C. (1965). Age norms, age constraints, and adult socialization. The American Journal of Sociology, 70, 710-717.

Neumann, A. (2009). Professing to learn: Creating tenured lives and careers in the American research university. Baltimore, MD: Johns Hopkins University Press.

Neumann, A. (2006). Professing passion: Emotion in the scholarship of professors at research universities. American Educational Research Journal, 43, 381-424. 
Neumann, A. \& Terosky, A. L. (2003). Toward images of reciprocity in faculty service: Insights from a study of the earlier post-tenure career. Paper presented at the meeting of the American Educational Research Association, Chicago, IL.

Neumann, A., Terosky, A. L., \& Schell, J. (2006). Agents of learning: Strategies for assuming agency, for learning, in tenured faculty careers. In S. J. Bracken, J. K. Allen, \& D. R. Dean (Eds.), The balancing act: Gendered perspectives in faculty roles and work-lives (pp. 91-120). Sterling VA: Stylus.

Norman, M., Ambrose, S. A., \& Huston, T. A. (2006). Assessing and addressing faculty morale. Review of Higher Education, 29, 347-379.

O’Meara, K. A. (2002). Uncovering the values in faculty evaluation of service as scholarship. Review of Higher Education, 26, 57-80.

O’Meara, K. A. (2005). Encouraging multiple forms of scholarship in faculty reward systems: Does it make a difference? Research in Higher Education, 46, 479510.

O'Meara, K., Kaufman, R. R., \& Kuntz, A. M. (2003). Faculty work in challenging times: Trends, consequences, \& implications. Liberal Education, 89(4), 16-24.

O’Meara, K.A. \& Campbell, C.M. (2011). Faculty sense of agency in decisions about work and family. Review of Higher Education, 35, 447-476.

O’Meara, K. A., \& Campbell, C. M. (2011b). The work environment for tenure track faculty at the University of Maryland: Advance research and evaluation report I. College Park, MD: University of Maryland NSF ADVANCE Grant.

O’Meara, K.A., Campbell, C. M., \& Terosky, A. (2011, November). Living Agency in the Academy: A Conceptual Frameworkfor Research and Action. Paper presented at 
the annual meeting of the Association for the Study of Higher Education, Charlotte, NC.

O’Meara, K.A., Campbell, C. M., \& Terosky, A. (2012). Living Agency in the Academy: A Conceptual Framework for Research and Action. Manuscript under review for publication.

O’Meara, K., \& Bloomgarden, A. (2010). Prestige at what cost: Examining the consequences of striving for faculty work-life, reward systems, and satisfaction. Journal of the Professoriate, 4(1), 40-74.

O’Meara, K. A. (2007). Striving for what? Exploring the pursuit of prestige. In J.D. Smart (Ed), Higher Education: Handbook of Theory and Research, 22 (pp. 121179). New York, NY: Springer.

O'Meara, K. A. (2002). Uncovering the values in faculty evaluation of service as scholarship. Review of Higher Education, 26, 57-80.

O’Meara, KA, Lounder, A, \& Campbell, C.M. (2011). UM ADVANCE = Towards an Institution for Inclusive Excellence $(U M=T I 2 E)$ Project Evaluation Report: Year One. College Park, MD: University of Maryland NSF ADVANCE Grant.

O'Meara, K. A., Terosky, A. L. P., \& Neumann, A. (2008). Faculty careers and work lives: a professional growth perspective. ASHE Higher Education Report, 34 (3). San Francisco, CA: Jossey-Bass.

O'Rand, A. M. (1996). The precious and the precocious: Understanding cumulative disadvantage and cumulative advantage over the life course. The Gerontologist, $36,230-238$.

Ornstein, M., Stewart, P., \& Drakich, J. (2007). Promotion at Canadian universities: The 
intersection of gender, discipline, and institution. Canadian Journal of Higher Education, 37(3), 1-25.

Perna, L. W. (2001). Sex and race differences in faculty tenure and promotion. Research in Higher Education, 42, 541-567.

Perna, L. W. (2005). Sex differences in faculty tenure and promotion: The contribution of family ties. Research in Higher Education, 46, 277-307.

Pickering, A. (1993). The mangle of practice: Agency and emergence in the sociology of science. American Journal of Sociology, 99, 559-589.

Porter, S. R. (2011). Do college student surveys have any validity. Review of Higher Education, 35, 45-76.

Raudenbush, S. W., \& Bryk, A. S. (2002). Hierarchical linear models: Applications and data analysis methods. Thousand Oaks, CA: Sage.

Ray, J.M. (2008). Characteristics of teacher agency at a long-standing academically successful dual-language school. Proceedings from the American Educational Research Association Annual Meeting. New York, NY.

Rendon, L. I. (1994). Validating culturally diverse students: Toward a new model of learning and student development. Innovative Higher Education, 19(1), 33-51.

Rhoades, G., McCormick, R., Kiyama, J. M., \& Quiroz, M. (2007). Local cosmopolitans and cosmopolitan locals: New models of professionals in the academy. Review of Higher Education, 31, 209-235.

Rice, R. E., \& Sorcinelli, M. D. (2002). Can the tenure process be improved? In R. P. Chait (Ed.), The questions of tenure (pp.101-124). Cambridge, MA: Harvard University Press. 
Rosser, V. J. (2004). Faculty members' intentions to leave: A national study on their worklife and satisfaction. Research in Higher Education, 45, 285-309.

Rosser, V. J. (2005). Measuring the change in faculty perceptions over time: An examination of their worklife and satisfaction. Research in Higher Education, $46,81-107$.

Rusch, E. A., \& Wilbur, C. (2007). Shaping institutional environments: The process of becoming legitimate. Review of Higher Education, 30, 301-318.

Ryan, R. M., \& Deci, E. L. (2000). Self-determination theory and the facilitation of intrinsic motivation, social development, and well-being. American psychologist, 55(1), 68-78.

Safarik, L., \& Framework, T. (2003). Feminist transformation in higher education. Review of Higher Education, 26, 419-445.

Sahay, S., \& Walsham, G. (1997). Social structure and managerial agency in India. Organization Studies, 18, 415-444.

Sandler, B. R. (1986). The chilly climate revisited: Chilly for women faculty, administrators, and graduate students. Washington, DC: Association of American Colleges.

Santiago, A. M., \& Einarson, M. K. (1998). Background characteristics as predictors of academic self-confidence and academic self-efficacy among graduate science and engineering students. Research in Higher Education, 39, 163-198.

Sax, L.J., Gilmartin, S. K., \& Bryant, A. N. (2003). Assessing response rates and nonresponse bias in web and paper surveys. Research in Higher Education, 44, 409-432. 
Sax, L. J., Hagedorn, L. S., Arredondo, M., \& Dicrisi, F. A. (2002). Faculty research productivity: exploring the role of gender and family-related factors. Research in Higher Education, 43, 423-446.

Schmidt, P. (2010). Graduate-school applications spiked after economy's plunge. Chronicle of Higher Education. Retrieved from http://chronicle.com/article/Graduate-School-Application/124387/

Schuster, J. H., \& Finkelstein, M. J. (2006). The American faculty: The restructuring of academic work and careers. Baltimore, MD: The Johns Hopkins University Press.

Schutz, A. (1967). The phenomenology of the social world, translated by George Walsh and Frederick Lehnert. Evanston, IL: Northwestern University Press.

Scott, J. C. (2006). The mission of the university: Medieval to postmodern transformations. The Journal of Higher Education, 77, 1-40.

Sen, A. (1985). Well-being, agency and freedom: the Dewey lectures 1984. The Journal of Philosophy, 82(4), 169-221.

Shechtman, Z., Levy, M., \& Leichtentritt, J. (2005). Impact of life skills training on teachers' perceived environment and self-efficacy. The Journal of Educational Research, 98(3), 144-155.

Shek, Y.L. (2010). Out of anonymity into subjectivity: Asian Americans as agents in the education discourse. Proceedings from the American Educational Research Association Annual Meeting. Denver, CO.

Simone, S. Campbell, C. M. \& Newhart, D. (in press). Measuring opinion and behavior. In R. Howard, B. Knight, G. McLaughlin (Eds.). The handbook for 
institutional research. San Francisco, CA: Jossey-Bass.

Slaughter, S., \& Leslie, L. L. (1997). Academic capitalism: politics, policies, and the entrepreneurial university. Baltimore, MD: The Johns Hopkins University Press.

Slaughter, S., \& Rhoades, G. (2004). Academic capitalism and the new economy: Markets, state, and higher education. Baltimore, MD: Johns Hopkins University Press.

Smith, E., Anderson, J. L., \& Lovrich, N. P. (1995). The multiple sources of workplace stress among land-grant university faculty. Research in Higher Education, 36, 261-282.

Sørensen, A. B., Weinert, F. E., \& Sherrod, L. R. (1986). Human development and the life course: Multidisciplinary perspectives. Hillsdale, NJ: Lawrence Erlbaum.

Stack, S. (2004). Gender, children and research productivity. Research in Higher Education, 45, 891-920.

Terosky, A.L. (2005). Taking teaching seriously: A study of university professors and their undergraduates. Unpublished dissertation: Teachers College, Columbia University.

Thomas, G. D., \& Hollenshead, C. (2001). Resisting from the margins: The coping strategies of Black women and other women of color faculty members at a research university. Journal of Negro Education, 70, 166-175.

Tierney, W. G., \& Bensimon, E. M. (1996). Promotion and tenure: Community and socialization in academe. New York, NY: State University of New York Press.

Tillman, L. C. (2001). Mentoring African American faculty in predominantly White institutions. Research in Higher Education, 42, 295-325. 
Toutkoushian, R. K. (1998). Racial and marital status differences in faculty pay. Journal of Higher Education, 69, 513-541.

Toutkoushian, R. K., \& Conley, V. M. (2005). Progress for women in academe, yet inequities persist: Evidence from NSOPF: 99. Research in Higher Education, $46,1-28$.

Trower, C. A., \& Bleak, J. L. (2004a). Study of new scholars: Gender: Statistical report [Universities]. Cambridge, MA: Harvard Graduate School of Education. Retrieved February 15, 2007, from http://www.gse.harvard.edu/news/features/trower04122004.pdf

Tracz, S., Brown-Welty, S., \& Vuong, M. The effects of self-efficacy on academic success of first-generation college sophomore students. Journal of College Student Development, 51, 50-64.

Turner, C. S. V. (2002). Women of color in academe: Living with multiple marginality. Journal of Higher Education, 73, 74-93.

Turner, C.S. (2008). Women of color in academe. In Glazer-Raymo, J. (Ed.), Unfinished Agendas: New and Continuing Gender Challenges in Higher Education. Baltimore: Johns Hopkins University.

Umbach, P. D. (2006). The contribution of faculty of color to undergraduate education. Research in Higher Education, 47, 317-345.

Vroom, V. (1964). Work and motivation. New York, NY: Wiley Plublishing.

Waltman, J. \& Hollenshead, C. (2005). Creating a positive departmental climate: principles for best practices. Retrieved from: http://www.advance.rackham.umich.edu/principles.pdf 
Ward, K., \& Wolf-Wendel, L. (2004). Academic motherhood. Review of Higher Education, 27, 233-257.

West, M. S. (1995). Women faculty: frozen in time. Academe, 81(4), 26-29.

Williams, J. C., Alon, T., \& Bornstein, S. (2006). Beyond the 'chilly climate': Eliminating bias against women. Thought \& Action, 22, 79-96.

Winkler, J. A. (2000). Faculty reappointment, tenure, and promotion: Barriers for women. Professional Geographer, 52, 737-750.

Winkler, J. A., Tucker, D., \& Smith, A. K. (1996). Salaries and advancement of women faculty in atmospheric science: Some reasons for concern. Bulletin of the American Meteorological Society, 77, 473-490.

Wolfinger, N. H., Mason, M. A., \& Goulden, M. (2008). Problems in the pipeline: Gender, marriage, and fertility in the ivory tower. The Journal of Higher Education, 79, 388-405.

Wolf-Wendel, L., Ward, K., \& Twombly, S. B. (2007). Faculty life at community colleges. Community College Review, 34, 255-281.

Wolf-Wendel, L., \& Ward, K. K. A. (2003). Academic motherhood: Managing complex roles in research universities. Review of Higher Education, 27, 233-257.

Wulff, D. H., \& Austin, A. E. (2004). Paths to the professoriate: Strategies for enriching the preparation of future faculty. San Francisco, CA: Jossey-Bass.

$\mathrm{Xu}$, Y. J. (2008). Faculty turnover: Discipline-specific attention is warranted. Research in Higher Education, 49, 40-61.

Xu, Y. J. (2008). Gender disparity in STEM disciplines: A study of faculty attrition and turnover intentions. Research in Higher Education, 49, 607-624. 
Ylijoki, O. H. (2003). Entangled in academic capitalism? A case-study on changing ideals and practices of university research. Higher Education, 45, 307-335.

Zamani, E. M. (2003). African American women in higher education. New Directions for Student Services, 104, 5-18.

Zemsky, R. (2007). The Rise and fall of the Spellings Commission. Chronicle of Higher Education, 53(21).

Zhou, Y., \& Volkwein, J. F. (2004). Examining the influences on faculty departure intentions: A comparison of tenured versus nontenured faculty at research universities using NSOPF-99. Research in Higher Education, 45, 139-176. 